NBER WORKING PAPER SERIES

\title{
THE RETURNS TO MICROENTERPRISE SUPPORT AMONG THE ULTRA-POOR: A FIELD EXPERIMENT IN POST-WAR UGANDA
}

\author{
Christopher Blattman \\ Eric P. Green \\ Julian C. Jamison \\ M. Christian Lehmann \\ Jeannie Annan \\ Working Paper 21310 \\ http://www.nber.org/papers/w21310 \\ NATIONAL BUREAU OF ECONOMIC RESEARCH \\ 1050 Massachusetts Avenue \\ Cambridge, MA 02138 \\ June 2015
}

Association of Volunteers in International Service (AVSI) implemented the program and we thank Jackie Aldrette, Fabio Beltramini, Ezio Castelli, Filippo Ciantia, Francesco Frigerio, John Makoha, Francesca Oliva, Federico Riccio, Samuele Rizzo, and Massimo Zucca. For comments we thank Abhijit Banerjee, Theresa Betancourt, Gustavo Bobonis, Esther Duflo, Nathan Fiala, Don Green, Nathan Hansen, Dean Karlan, Bentley MacLeod, David McKenzie, anonymous referees, and seminar participants at GWU, Harvard, MIT, USAID, the World Bank, and Yale. A Vanguard charitable trust and the World Bank's Learning on Gender and Conflict in Africa (LOGiCA) trust fund funded the research. This article does not necessarily represent the views of the World Bank, the Consumer Financial Protection Bureau, or the U.S. government. For research assistance we thank Filder Aryemo, Natalie Carlson, Samantha DeMartino, Mathilde Emeriau, Sara Lowes, Lucy Martin, Godfrey Okot, Richard Peck, Alex Segura, Xing Xia, and Adam Xu through Innovations for Poverty Action. The views expressed herein are those of the authors and do not necessarily reflect the views of the National Bureau of Economic Research.

NBER working papers are circulated for discussion and comment purposes. They have not been peerreviewed or been subject to the review by the NBER Board of Directors that accompanies official NBER publications.

(C) 2015 by Christopher Blattman, Eric P. Green, Julian C. Jamison, M. Christian Lehmann, and Jeannie Annan. All rights reserved. Short sections of text, not to exceed two paragraphs, may be quoted without explicit permission provided that full credit, including $\mathbb{C}$ notice, is given to the source. 
The Returns to Microenterprise Support Among the Ultra-Poor: A Field Experiment in Post-War Uganda

Christopher Blattman, Eric P. Green, Julian C. Jamison, M. Christian Lehmann, and Jeannie Annan

NBER Working Paper No. 21310

June 2015

JEL No. C93,D13,J24,O12

\section{ABSTRACT}

We show that extremely poor, war-affected women in northern Uganda have high returns to a package of $\$ 150$ cash, five days of business skills training, and ongoing supervision. 16 months after grants, participants doubled their microenterprise ownership and incomes, mainly from petty trading. We also show these ultrapoor have too little social capital, but that group bonds, informal insurance, and cooperative activities could be induced and had positive returns. When the control group received cash and training 20 months later, we varied supervision, which represented half of the program costs. A year later, supervision increased business survival but not consumption.

Christopher Blattman

School of International and Public Affairs

Columbia University

420 West 118th Street

New York, NY 10027

and NBER

chrisblattman@columbia.edu

Eric P. Green

Duke Global Health Institute

Duke University

Box 90519

Durham, NC 27708

epgreen@gmail.com

Julian C. Jamison

Office of Research

Consumer Financial Protection Bureau

1700 G Street NW

Washington, DC 20552

julison@gmail.com
M. Christian Lehmann

University of Brasilia

Campus Universitário Darcy Ribeiro, Asa Norte

Brasília, Distrito Federal 70910-900, Brazil

christianlehmann0@gmail.com

Jeannie Annan

International Rescue Committee

New York, NY

jeannie.annan@gmail.com 


\section{Introduction}

The World Bank, the United Nations (UN), and the United States government have made the eradication of extreme poverty by 2030 a central development goal. ${ }^{1}$ Since the world's poor often live in economies with few firms, anti-poverty programs often try to foster selfemployment. This includes farm enterprises such as raising livestock for sale, and nonfarm enterprises such as trading or retail. But can the extreme poor be expected to start and sustain such microenterprises? And what constraints hold them back?

Two in five of the world's extreme poor are projected to live in fragile and conflict-affected states by 2030, yet rigorous evidence on what works in these settings is sparse. ${ }^{2}$ To help fill this gap, this paper studies a relatively common approach to relieving extreme poverty, transfers of human and physical capital, but to a post-war population: the most marginalized people living in small villages in northern Uganda, following a 20-year war.

A humanitarian organization, the Association of Volunteers in International Service (AVSI), identified 1800 poor people, mostly women, in 120 war-affected villages, and tried to help them start very small but sustainable retail and trading enterprises. AVSI's Women's Income Generating Support (WINGS) program provided people grants of $\$ 150$ (about $\$ 375$ in purchasing power parity, or PPP, terms), along with five days of business skills training and planning, plus ongoing supervision to help implement the plan. The grant was 30 times larger than the beneficiaries' baseline monthly earnings.

An abundance of evidence argues that the average poor person has high returns to capital and is held back in part by poor access to credit and insurance, and that capital transfers and insurance products help grow microenterprises and incomes. ${ }^{3}$ Most of this evidence, however, comes from people who already have businesses or were selected for their business aptitude. ${ }^{4}$ It's not clear if it applies to the most marginalized and "ultrapoor" - the people with the lowest incomes, no capital, and limited social networks - especially after war. ${ }^{5}$

\footnotetext{
1"Extreme poverty" refers to earning less than the $\$ 1.25$ per day international poverty line. See Burt, Hughes and Milante (2014) for a discussion of the goals.

${ }^{2}$ See Burt, Hughes and Milante (2014) for population projections. For reviews of the evidence see Blattman and Miguel (2010); Puri et al. (2014).

${ }^{3}$ For example, see Udry and Anagol (2006); de Mel, McKenzie and Woodruff (2008); Banerjee and Duflo (2011); Karlan, Knight and Udry (2012); Fafchamps et al. (2014); Blattman, Fiala and Martinez (2014).

${ }^{4}$ For example, Blattman, Fiala and Martinez (2014) see high returns to a group-based cash transfer in northern Uganda. But the program targeted young adults with much higher levels of education and existing business plans for relatively high-skill microenterprises. That program also excluded the two most conflict-affected districts, where WINGS was implemented.

${ }^{5}$ On the one hand, returns to capital or other inputs could be greater on the extensive margin than the intensive one. Indeed there is growing evidence that poor households use cash to start new enterprises and earn high returns, although little of this evidence comes from the poorest of the poor (Macours, Premand and Vakis, 2012; Gertler, Martinez and Rubio, 2012; Blattman, Fiala and Martinez, 2014; Bianchi and Bobba, 2013). Returns could also be high in a newly stable political equilibrium, as neoclassical models of growth
} 
The WINGS program has parallels to "graduation" style programs delivered to hundreds of thousands of ultrapoor households globally. Graduation programs give a bundle of temporary income support, livestock, livestock training, access to microfinance, supervision, and life-skills education. On balance, these programs have been successful: several studies show substantial shifts from casual labor to farm self-employment, and 10 to $40 \%$ increases in household consumption or earnings compared to control groups, lasting at least two to four years (Bandiera et al., 2013; Banerjee et al., 2015). The WINGS program differed from these other ultrapoor programs in several dimensions, however, including: the post-war setting; fewer program components; the focus on petty business; and providing cash rather than livestock. ${ }^{6}$ WINGS was also focused on young women.

We evaluated WINGS by assigning the targeted people to either receive the program immediately or a year-and-a-half later, randomizing at the village level. Given the extreme setting, AVSI was reluctant to have a permanent control group - a common concern in humanitarian settings, and one reason humanitarian evaluations are rare. Thus our design evaluates impacts a few months before the 60 control villages entered the program.

We also tested the role of social capital in business success: could social capital be fostered, and would it increase the returns to grants? In poor rural villages, social networks are a main source of business advice, cooperation, and informal finance. ${ }^{7}$ For instance, in microcredit, growing evidence suggests that group lending is helpful not because of joint liability, but rather because it builds social capital and promotes risk-pooling. ${ }^{8}$

To test this, in half of the treatment villages, AVSI returned a couple of months after the grants (after individual businesses had already been started) to encourage the participants to form self-help groups, and offered three additional days of training in working together. The curriculum focused on developing organizational structures, decision-making processes, leadership, and helping them form a rotating savings and credit association (ROSCA).

16 months after grants, the standard WINGS program (without group encouragement) led to large changes in occupation and incomes. 39\% of the control group had a nonfarm

predict (Blattman and Miguel, 2010). On the other hand, the ultrapoor could have low returns to capital, for instance because they lack crucial inputs such as education or business experience, or because they are vulnerable to expropriation within or outside the family.

${ }^{6}$ Many in the aid community fear cash can be seized, wasted, or cause harm. They could be right. Besides the lack of other important inputs, extreme poverty has also been associated with cognitive deficits that impede investment and raise the risk of temptation spending (e.g. Bertrand, Mullainathan and Shafir, 2004). Among the poorest women, moreover, traditional norms could pressure them to share cash, make it easy to expropriate them, or hinder their business growth (Field, Jayachandran and Pande, 2010; Duflo, 2012). This is the fundamental reason that AVSI designed WINGS to include training and supervision.

${ }^{7}$ See Fafchamps (1992); Foster and Rosenzweig (1995); Murgai et al. (2002).

${ }^{8}$ Feigenberg, Field and Pande (2013) show that encouraging social interaction via group meetings reduces default on individual loans in India. Giné and Karlan (2014) also show individual liability has little impact on default in the Philippines. 
business, and this rose to $80 \%$ among WINGS participants. Employment rose from 15 to 24 hours per week, and cash earnings rose about PPP $\$ 1$ a day. Since the average person in the control group earned less than $\$ 1$ a day, the program doubled earnings. As a result, a conservative estimate of household consumption rose by almost a third, to roughly PPP $\$ 1.25$ per day. Annualized, this impact corresponds to a PPP $\$ 465$ increase in nondurable consumption - about a quarter of the PPP $\$ 1,946$ standard program cost.

For program participants, the gains were mainly economic. There was little evidence of changes in physical health, mental health, financial autonomy, or domestic violence. Outside the household, however, the program increased self-reported social support and community participation. Participants also reported an increase in resentment and verbal abuse from some neighbors, however, perhaps due to jealousy, or because they posed competition for pre-existing traders.

The group encouragement, meanwhile, increased the frequency and intensity of group activities. We see no impact on consumption after 16 months, but program participants who received group encouragement reported double the earnings of those that did not. Interestingly, this was not because their petty trading businesses were larger, more likely to survive, or more profitable. Rather, the evidence suggests that groups spurred informal finance as well as labor-sharing and cooperative cash cropping. Group formation also seems to have mitigated the resentment and abuse from neighbors.

Ideally we could have randomly varied all program components and measured their returns. This was not possible. But, following the main evaluation, we used the entry of the control group into the program to investigate the marginal effect of the most expensive component: supervision. The supervisory visits provided substantive advice as well as pressure to implement the business plan, but were more than twice as costly as the grant. When the control group received WINGS after 20 months, we randomized them individually to receive the business training and grant plus: (i) no supervisory visits; (ii) two visits (to provide commitment to invest); or (iii) five visits for both commitment and substantive business advice.

A month after grants, but before any potential visits, expecting a visit had an ambiguous effect on business investment: those assigned to supervision increased investment by some measures and decreased by others. A year later, the effect of supervision on incomes is also ambiguous: non-durable consumption is marginally lower among those assigned to visits, earnings are marginally higher, but neither effect is statistically significant. Supervision, however, did increase business survival.

Altogether, these results come with caveats. First, the control group knew they were on the waitlist, and so anticipation of treatment could affect their behavior. Second, all 
measures are self-reported. Experimenter demand is a risk, but given the size of impacts (and the absence of non-economic impacts, where we might expect experimenter demand) the bias seems unlikely to drive our results. Third, there is mild randomization imbalance and attrition. Treatment effects, however, are robust to corrections and to missing data scenarios. Finally, these are 16-month impacts and given the fact that the control group entered the program, we cannot say whether they persist.

Nonetheless, WINGS illustrates that the poorest may be able to start and sustain small enterprises, even in very small, fairly poor communities. Moreover, the 16-month consumption impacts of WINGS are almost identical to the 1- or 2-year impacts of livestock-based ultra-poor programs, although WINGS was about half as costly. So far the livestock programs have longer term evidence in their favor, and the sustainability of cash-centric programs to the very poorest is an open question. ${ }^{9}$ Even so, studies of cash transfers to the non-extreme poor show sustained or growing impacts after 4 to 6 years (Blattman, Fiala and Martinez, 2014; de Mel, McKenzie and Woodruff, 2012a).

Cash should be much cheaper and easier to deliver than livestock or capital goods, so if it stimulates employment as well as the accumulation of income-generating assets it could affect how ultrapoor programs are designed and scaled. This warrants more investigation, especially in humanitarian settings where cash is becoming more common as it can be difficult to provide in-kind capital. Also important to investigate are cost-effective forms of supervision and training.

Finally, the results support the view that social interactions encourage cooperation, and that such social capital delivers economic returns. Most social capital is endogenously formed, and it's unusual to have experimental variation in local bonds. Echoing Feigenberg, Field and Pande (2013) on microcredit, we see that a program that simply encourages group and ROSCA formation can increase social interactions, enhance social capital, increase risk-pooling and cooperation, and perhaps even raise incomes. What's striking is that these profitable social bonds did not form in the absence of encouragement, and yet were provoked by a relatively short training. It implies the poor may be social capital constrained as well as credit constrained, and external intervention seems to help overcome barriers to collective action.

\footnotetext{
${ }^{9}$ Livestock programs sustain gains after $2-4$ years, while ultrapoor cash transfer studies have 1-2 years of evidence so far (e.g. Haushofer and Shapiro, 2013; Macours, Premand and Vakis, 2012).
} 


\section{Setting and study participants}

Uganda as a whole is a poor but stable and growing country. National income grew roughly $6.5 \%$ per year for the two decades prior to this study (Government of Uganda, 2007). A long-running, low-level insurgency in northern Uganda, however, meant that most of the north was left out.

From 1987 to 2006, small bands of rebels conscripted, abused, and stole from civilians in northern Uganda, especially Kitgum and Gulu districts. Equally devastating was the Ugandan government's decision to fight the insurgency by forcibly moving nearly the entire rural population of Kitgum and Gulu - about two million people -into dozens of displacement camps. The camps were often no more than a few miles from people's rural homes, but people generally could not access their farmland during the war. Most households lost everything - livestock, homes, savings, and household durables - as a result.

By 2006 the rebels were mostly defeated or pushed out of the country, and by 2007 the government permitted displaced people to return home and rebuild. The north's economy began growing quickly, aided by an increase in demand from a newly peaceful Sudan. The government started a number of large-scale development programs to help the north catch up to the rest of the country. Even so, northern Uganda had some of the lowest standards of living in the world. By 2007, two-thirds of households were unable to meet basic needs and lived mainly on food aid (Government of Uganda, 2007).

By 2009, when this study begins, most people had rebuilt their homes and had begun farming again. Food distribution and other emergency relief had ended. Most rural villagers, however, were still desperately impoverished.

\section{A Study sites and participants}

AVSI identified 120 villages in the two most war-affected districts, Kitgum and Gulu. Most villages ranged in size from 350 to 1000 people, with an average population of 699 (about 100 households). The study villages represented about a quarter of the population of the six rural subcounties where AVSI worked. ${ }^{10}$

AVSI held community meetings to describe the program and asked communities to nominate 20 marginalized villagers, asking that three-quarters be women aged 14 to 30 . AVSI staff

\footnotetext{
${ }^{10}$ AVSI actively worked in six subcounties - Odek, Lakwana and Lalogi in Gulu and Omiya Anyima, Namokora and Orom in Kitgum. These have 252 total villages: 84 in Gulu; 168 in Kitgum. AVSI excluded from the sample villages with fewer than 80 households. AVSI then chose program villages proportional to parish population. whereby more populous parishes would have a higher number of program villages (A parish is an administrative unit within the subcountry with five to ten villages). Official population figures did not exist and estimates were based on 2008 data from AVSI and the UN. We estimate participant households in treatment villages were less than $2 \%$ of households in the subcounty.
} 
interviewed all nominees and selected 10 to 17 participants per village, excluding relatives of leaders and the least poor.

Table 1 describes the 120 villages and all 1800 study participants, based on a baseline survey of participants and each community leader. $26 \%$ of villages had a weekly market, and while on average there were three shops or kiosks selling goods, the median village had none. Most goods were imported from the district capital and retailed by a handful of shop owners.

Outside of traditional occupations (e.g. subsistence agriculture and some casual labor), main work opportunities came from petty trade and retail, cottage production (e.g. bricks, charcoal), livestock rearing, and cash crops. These farm and nonfarm microenterprises required few new skills or education, but they were capital-intensive and had fixed costs of entry.

The average participant in the program was female, 27 years old, and had 2.8 years of education. Half were married or partnered. They reported an average of 15 hours of work a week in the past month, mainly in their own agriculture. Just $3 \%$ did any petty trade or business.

In general they were poor with no access to finance. Average cash earnings in the month before the survey were UGX 8,940 (\$4.47 at 2009 market exchange rates). Formal insurance was unknown, and almost no formal lenders were present in the north at the outset of this study in 2008. Only $9 \%$ of the sample were members of a village savings and loans group. On average they had UGX 4,860 (\$2.42) in cash savings and a nearly equal amount in debts, usually from family and friends. Just $4 \%$ said they could get a loan of $\$ 50$, which is unsurprising because of high transaction costs and the near absence of informal or formal lending institutions. Formal loan terms seldom extended beyond three months, moreover, with annual interest rates of 100 to $200 \%$. Because of high fees, real interest rates on savings were typically negative. Given the startup costs of microenterprise, this absence of credit and insurance was a major barrier to entry.

\section{Effects of the war}

The war affected and displaced everyone in the study sample, impoverishing all. Until about a year before the program, everyone in the village had lived in a nearby displacement camp for at least three years, with no access to farmland, during which their lands became overgrown and their houses destroyed. At the time of the WINGS program, households were reestablishing agriculture for the first time since at least 2003.

One in five people in our sample were abducted into the armed group at some point, usually only for a few days to carry looted goods. Long stays with the armed group were less 
Table 1: Descriptive statistics and randomization balance for select covariates

\begin{tabular}{|c|c|c|c|c|}
\hline \multirow{3}{*}{ Variable } & \multicolumn{2}{|c|}{ Means, Full sample } & \multicolumn{2}{|c|}{ Balance test } \\
\hline & $\begin{array}{c}\text { Treatment } \\
(\mathrm{n}=896)\end{array}$ & $\begin{array}{l}\text { Control } \\
(\mathrm{n}=904)\end{array}$ & Difference & p-value \\
\hline & (1) & $(2)$ & $(3)$ & $(4)$ \\
\hline \multicolumn{5}{|l|}{ Demographics: } \\
\hline Age & 27.02 & 27.63 & -0.62 & 0.17 \\
\hline Female & 0.86 & 0.86 & -0.01 & 0.72 \\
\hline Married or living with partner & 0.46 & 0.50 & -0.05 & 0.26 \\
\hline Single-headed household & 0.51 & 0.47 & 0.04 & 0.17 \\
\hline Highest grade reached at school & 2.82 & 2.75 & 0.07 & 0.70 \\
\hline Forcibly recruited into rebel group & 0.20 & 0.25 & -0.05 & 0.03 \\
\hline Carried gun within rebel group & 0.03 & 0.04 & -0.01 & 0.45 \\
\hline Forcibly married within rebel group & 0.03 & 0.03 & -0.00 & 0.63 \\
\hline \multicolumn{5}{|l|}{ Lagged outcomes: } \\
\hline Any non-farm self-employment & 0.03 & 0.04 & -0.01 & 0.17 \\
\hline Average work hours per week & 14.57 & 16.19 & -1.62 & 0.12 \\
\hline Agricultural & 11.27 & 13.36 & -2.09 & 0.02 \\
\hline Nonagricultural & 3.29 & 2.83 & 0.46 & 0.25 \\
\hline Average hours of chores per week & 34.88 & 34.25 & 0.63 & 0.68 \\
\hline No employment hours in past month & 0.23 & 0.18 & 0.05 & 0.07 \\
\hline Monthly cash earnings, 000s UGX & 8.54 & 9.32 & -0.78 & 0.26 \\
\hline Durable assets (consumption), z-score & -0.67 & -0.59 & -0.07 & 0.05 \\
\hline Durable assets (production), z-score & -0.53 & -0.50 & -0.02 & 0.48 \\
\hline \# of community groups & 0.48 & 0.58 & -0.10 & 0.04 \\
\hline Member of a savings group & 0.08 & 0.11 & -0.03 & 0.07 \\
\hline Total savings, 000s UGX & 4.24 & 5.47 & -1.23 & 0.20 \\
\hline Total debts, 000s UGX & 4.24 & 4.08 & 0.15 & 0.82 \\
\hline Activities of daily life, z-score & -0.06 & -0.04 & -0.02 & 0.75 \\
\hline Symptoms of distress, z-score & 0.09 & -0.09 & 0.18 & 0.02 \\
\hline Quality of family relationships, z-score & -0.09 & 0.09 & -0.19 & 0.00 \\
\hline Any community maltreatment, past year & 0.19 & 0.16 & 0.03 & 0.11 \\
\hline \multicolumn{5}{|l|}{ Village-level covariates $(N=120)$ : } \\
\hline Village population & 749.62 & 649.05 & 100.58 & 0.34 \\
\hline Inverse distance to all villages & 0.51 & 0.58 & -0.07 & 0.34 \\
\hline Inverse distance to treatment villages & 0.56 & 0.47 & 0.09 & 0.43 \\
\hline Distance to capital (km) & 46.21 & 44.72 & 1.48 & 0.58 \\
\hline Accessible by bus & 0.98 & 0.91 & 0.08 & 0.05 \\
\hline Village has a market & 0.18 & 0.34 & -0.16 & 0.05 \\
\hline Number of shops in village & 1.23 & 1.75 & -0.52 & 0.30 \\
\hline Total NGOs in village & 7.13 & 7.42 & -0.29 & 0.68 \\
\hline
\end{tabular}

Notes: All variables denominated in UGX and hours were top-censored at the 99th percentile to contain outliers. The durable asset indexes (z-scores) are calculated so that they have mean zero and unit standard deviation for the full sample over all survey waves, and hence the sign is negative at baseline. The differences in Columns 3 and 4 come from OLS regression of baseline covariates on an indicator for treatment plus a district fixed effect, with robust standard errors clustered by village. 
Table 2: Participants versus non-participants (Control villages at Phase 1 endline)

\begin{tabular}{|c|c|c|c|c|}
\hline \multirow[b]{2}{*}{ Covariate } & \multirow[b]{2}{*}{$\begin{array}{c}\text { Participants } \\
\text { (1) }\end{array}$} & \multicolumn{3}{|c|}{ Non-participants ages $17-40$, control villages } \\
\hline & & $\begin{array}{c}\text { Traders } \\
(2)\end{array}$ & $\begin{array}{c}\text { Nontraders } \\
\text { (3) }\end{array}$ & $\begin{array}{l}\text { All } \\
(4)\end{array}$ \\
\hline Age & 28.10 & 29.35 & 28.55 & 28.71 \\
\hline Years of education & 2.81 & 5.58 & 4.48 & 4.70 \\
\hline Average weekly work hours & 15.02 & 31.08 & 21.93 & 23.78 \\
\hline Agricultural weekly hours & 9.68 & 21.11 & 16.80 & 17.67 \\
\hline Non-agricultural weekly hours & 5.47 & 9.98 & 5.13 & 6.11 \\
\hline Reports any hours in petty business & 0.16 & 0.26 & 0.07 & 0.11 \\
\hline Monthly cash earnings, 000s of UGX & 15.76 & 23.45 & 10.14 & 12.82 \\
\hline Monthly household consumption, 000s of UGX & 108.38 & 175.05 & 134.04 & 142.30 \\
\hline Durable assets (consumption), z-score & -0.45 & 0.64 & 0.06 & 0.18 \\
\hline Metal roof & 0.00 & 0.03 & 0.00 & 0.01 \\
\hline Number of goats & 0.97 & 1.62 & 1.22 & 1.30 \\
\hline Number of bicycles & 0.39 & 0.77 & 0.60 & 0.63 \\
\hline Number of mobile phones & 0.14 & 0.58 & 0.35 & 0.39 \\
\hline Durable assets (production), z-score & -0.21 & 0.30 & -0.07 & 0.01 \\
\hline Observations & 917 & 360 & 1,427 & 1,787 \\
\hline
\end{tabular}

Notes: For work hours and income, we report household averages in non-participant households, restricting data to adults aged 17-40. A household is coded as a trading household if at least one household respondent says he or she regularly sold an item a year ago, and did not obtain that item from his or her own production, for any items in a list of 35 . Individual-level covariates come from a self-reported survey of all respondents. All variables denominated in UGX and hours were top-censored at the 99 th percentile to contain outliers.

common, and only $5 \%$ of the sample became fighters or forced to marry a rebel commander. Abduction and conscription, however, were not necessarily a source of relative poverty. Annan et al. (2011) used exogenous variation in conscription to identify the long term effects. Social acceptance of former conscripts was high, and most people were psychologically resilient. ${ }^{11}$ These findings hold even for the longest-serving females and those who were forcibly married or bore children. Conscription also had little effect on women's schooling and labor market outcomes. Women's options outside the armed group were not much better than inside the armed group, since most would not have been schooled or accumulated capital. Conscripted men, however, were well behind their peers after the war, because they missed out on opportunities to accumulate physical and human capital.

In short, the war was so destructive that few young people emerged with any assets or schooling. At the time of the WINGS program, they were rebuilding their livelihoods from almost nothing.

\footnotetext{
${ }^{11}$ Psychological distress is commonplace, but serious symptoms are concentrated in the minority exposed to the most violence and with the least social support.
} 


\section{B Comparison to non-participating villagers}

In general, the program successfully targeted the villages poorest, but it's worth noting that almost all villagers are very poor by any measure. We do not have data on nonparticipants at baseline. Twenty months after the start of the program, however, we surveyed 2,836 non-participant households in treatment and control villages (about 25 from each village), and sought to interview two working age adults per household, in order to measure spillovers. ${ }^{12}$ Table 2 reports summary statistics for participants and non-participants in the control villages only, in order to compare people in the absence of direct treatment effects. We distinguish between households that were and were not traders at baseline.

If we look at similar-aged adults in "non-participant" households, participants have similar cash earnings, but $23 \%$ lower consumption, .63 standard deviations fewer durable consumption assets (e.g. house quality, furniture and household items), and .22 standard deviations fewer production assets (e.g. livestock or farm tools). Participants also have about half the education and $61 \%$ of non-participants' work hours. About a third of non-participant households have at least one adult engaged in trading at baseline, and these tend to be wealthier than average.

\section{Intervention, experimental design, and data}

The WINGS program had four components:

Basic skills training Participants received five days of business skills training, ending with the preparation of a simple business plan. Training was designed for the illiterate and focused on business planning, sales, marketing, record-keeping, and budgeting (see Appendix A for the curriculum). Trainers reviewed plans with the participants and returned unsatisfactory plans for revision. They encouraged participants to consider high cash flow activities that would diversify their income sources, especially petty trading and retailing.

Cash Once a plan was approved, the participant received a grant of 300,000 Ugandan shillings (UGX) or $\$ 150$ at 2009 market exchange rates. The grant was framed as funds to implement the business plan. AVSI delivered cash in two equal installments about 2 and 6 weeks after training.

\footnotetext{
${ }^{12}$ Shortly before Phase 2 disbursement we created village household lists, randomly sampled 25 nonparticipant households from each village (excluding the roughly 15 participant households), and sought to interview two working age adults per household on their economic activities, plus household data on assets and expenditures. We also collected village prices on a variety of goods. Non-response to the survey was only $5.5 \%$.
} 
Supervision AVSI trainers traveled four to five times to the villages in the six months after the grant to provide one-on-one advising and supervision.

Group formation About two months after grants were disbursed, AVSI also offered a three-day "group dynamics training" that encouraged participants in the village to form selfhelp groups that would exchange ideas for improving their petty business and agriculture, organize savings and credit, and (to a lesser extent) collaborate or cooperate in activities such as marketing their produce or buying inputs.

The vast majority of the three days focused on providing information and skills related to working effectively as a group, including: leader selection, group decision-making, communication and listening skills, and conflict resolution methods. It applied these skills to the same topics that were the focus of the five-day business skills training: business planning, saving, and record-keeping. The difference is that the group dynamics training mostly focused on how they could adapt these skills when working as a group. The final day focused on how to organize a savings group, including best practices and record-keeping. Other forms of business cooperation, such as joint purchasing and collaborative marketing, were mentioned in passing as advantages of working in groups, but these production economies of scale received very little attention. Indeed, AVSI deliberately did not encourage participants to form firms or cooperatives. This is one reason AVSI offered the group training some weeks after the individual business plans, grants, and initial investment decisions.

Groups decided on their own aims and organization, however, and at the end of the training AVSI helped groups write a "constitution" that formalized the aims, leadership, and decision-making structure of the group. Appendix A describes the curriculum.

On average, WINGS cost $\$ 860$ per person at market exchange rates: $\$ 150$ for grants; $\$ 125$ for targeting and disbursement; $\$ 124$ for business training; $\$ 82$ for group dynamics training; $\$ 348$ for five supervisory visits; and $\$ 31$ in other costs. This is equivalent to PPP $\$ 2,150$.

\section{A Phase 1 research design}

In Phase 1, we randomized 60 of the 120 villages to receive the WINGS program. The other 60 were randomized to a "waitlist" group (Phase 2) to be treated at least 18 months later. The participants in the waitlist villages were aware of this treatment status.

Within these 60 treatment villages in Phase 1, we randomized 30 to receive the group dynamics training and 30 to no group encouragement. Participants in the 60 control villages 
were told they would receive the intervention in about 18 to 24 months, called Phase 2. Figure 1 illustrates the sample, design, and timing.

We randomized by public draw, to ensure village buy-in and transparency. ${ }^{13}$ The draw resulted in a slight imbalance in baseline covariates, reported in Table $1 .{ }^{14}$ Treatment participants were slightly worse off, with lower durable assets, employment, literacy, savings group memberships, participation in armed groups, and family and community support. The villages they lived in were also less likely to have a market. A test of joint significance of all covariates has a p-value of <.001. If anything, this may lead us to understate treatment effects. To account for possible bias, we will control for these covariates in all treatment effects estimates and show robustness to difference in difference measures.

To evaluate Phase 1, we attempted to survey all 1800 participants 20 months after baseline, 16 months after the first grant (at the median). Attrition was minimal; we tracked migrants to their current location and found $96.3 \%$ (not including three who died). Attrition is generally not significantly correlated with treatment or baseline covariates (see Appendix B). ${ }^{15}$

\section{B Phase 2 research design}

In Phase 2, participants in the 60 control villages received the WINGS program. ${ }^{16}$ We used this as an opportunity to evaluate the marginal impact of the highest-cost component, supervision. ${ }^{17}$ The first supervisory visit or two was mainly to hold grantees accountable for implementing their business plan. The later visits were primarily to provide advice. Of the 904 people in Phase 2, we randomly assigned individuals to receive the cash and basic training with one of three treatments: (1) no supervisory visits; (2) one to two supervisory visits, focused principally on commitment to invest; or (3) all five supervisory visits, to provide commitment but also substantive advice on business management and household

\footnotetext{
${ }^{13}$ We gathered village leaders in each district. They drew village names without replacement to be assigned to Phase 1 or 2 . The authors were present for the draw to ensure its validity. We randomized group dynamics training via computer.

${ }^{14}$ See Appendix B for all 76 covariates, as well as balance tests for the group dynamics randomization. In total, $24 \%$ of the (non-independent) covariates have $\mathrm{p}<.10$.In general, the group dynamics randomization was balanced.

${ }^{15}$ In addition to these survey data, we collected formal qualitative data to better understand program experiences, constraints, and mechanisms. Two Ugandan research assistants interviewed 32 randomly selected participants in eight villages three times during and after the program. They followed semi-scripted questionnaires and recorded, transcribed, and translated all interviews and notes.

${ }^{16}$ Program changes were minor. AVSI increased grants to 360,000 UGX to account for inflation, and disbursed grants in a single tranche for efficiency.

${ }^{17} 30$ of the 60 villages were also randomized to have spouses included in the training, and present at the grant disbursement, described in a companion paper (Green et al., 2015a).
} 
Figure 1: Description of the study sample and experimental design

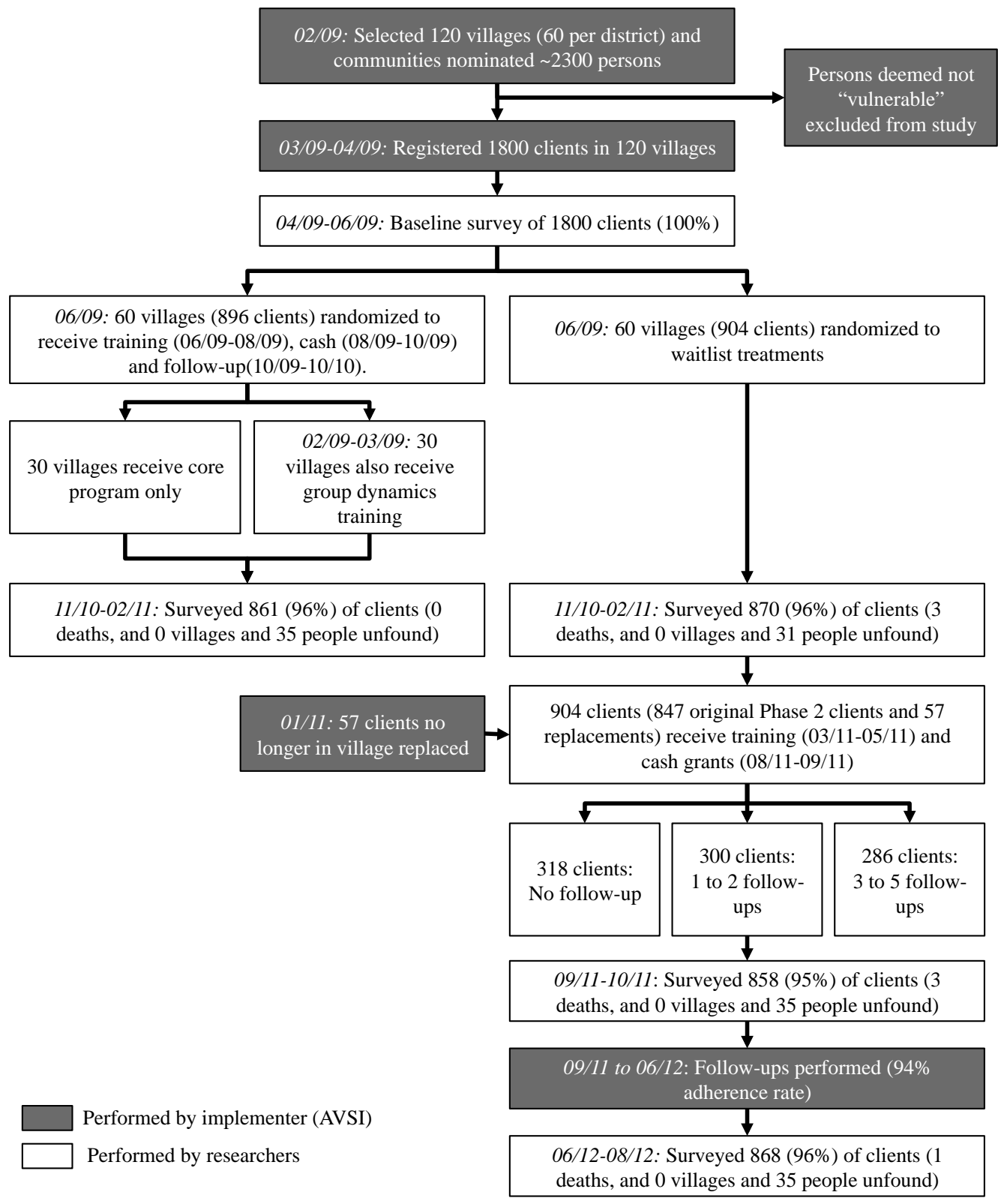


bargaining. ${ }^{18}$

To evaluate impacts, we first surveyed Phase 2 participants about a month after the grant, shortly before the first follow-up. We intended this short-run survey to assess how participants' actions and investments varied with expectations of any supervision. We surveyed them again about a year after the grants to study the impacts of actual supervision. Again, attrition was low; we found $95 \%$ at the 1-month survey and $96 \%$ at the 1-year survey.

\section{Empirical strategy}

We estimate intent-to-treat (ITT) effects via the OLS regression:

$$
Y_{i j}=\theta T_{j}+\delta_{T} D_{j}^{T}+\delta_{\bar{T}} D_{j}^{A}+X_{i j} \beta+\varepsilon_{i j}
$$

where $Y$ is an outcome for participant $i$ in village $j, T$ is an indicator for treatment (e.g. assignment to Phase 1 versus Phase 2), $X$ is a vector of controls that includes a district fixed effect and all baseline covariates, including lagged outcomes. ${ }^{19}$ Robust standard errors are clustered by village.

The terms $D_{j}^{T}$ and $D_{j}^{A}$ are weighted measures of distance from the village to other treatment villages and all other evaluation villages. We include them to account for and estimate potential spillovers from participants in treatment villages to those in wait-list villages, which could otherwise bias treatment effects. The average wait-list village has at least five treatment villages within $10 \mathrm{~km}$, and many villages share markets. We can identify and control for cross-village externalities using exogenous variation in the local density of treatment villages generated by the randomization, conditional on the density of all evaluation villages in the sample (Miguel and Kremer, 2004). ${ }^{20}$

There are two other threats to identification. One is anticipation of treatment. If participants delayed investments by one to two years in expectation of a grant, this would lead us to overstate treatment effects. Alternatively, the expectation of a future grant could

\footnotetext{
${ }^{18}$ We randomized via computer at the individual level, blocking by village. The groups are relatively balanced, with balance tests reported in Appendix B. Before Phase 2 began, 57 of the 904 participants assigned to Phase 2 had died or left the village and were no longer eligible. In February 2011, AVSI replaced these participants with others from the same village following the same nomination and screening procedures described above.

${ }^{19}$ See Appendix B for all baseline covariates. Also, note that baseline and endline variables denominated in UGX or hours can have a long upper tail. Extreme values will be influential in any treatment effect, and we therefore top-code them at the 99th percentile.

${ }^{20}$ That is, $D_{j}^{T}$ is a random variable conditional on $D_{j}^{A}$. Previous papers estimate distance measures as the number of villages within a fixed radius. We use a slightly less dichotomous measure, described in Appendix $\mathrm{D}$, using road network distances. In practice these spillovers appear to be negligible and so they do not materially change our conclusions (Appendix D).
} 
act as a form of insurance and increase investment, leading us to understate impacts. For instance, Bianchi and Bobba (2013) show that expectation of conditional cash transfers in Mexico increase microenterprise investment by relaxing an insurance rather than a liquidity constraint. Our design does not allow us to say what these anticipation effects might be.

A second threat is that, since outcomes are self-reported, we will overestimate the impact if experimenter demand leads treated subjects to overreport well-being, or if the controls under-report outcomes in the (mistaken) belief that they could be dropped from eligibility. We feel these biases are unlikely to drive our results for a few reasons. Most of all, as we will see below, we observe no impact on variables such as empowerment or health, meaning that incentives to misreport would have to be confined to economic outcomes alone. Related to this, misreporting would have to be highly systematic within economic outcomes: income and employment was collected through more than 100 questions across 25 activities, and assets and expenditures were calculated from 150 questions.

\section{Results}

\section{A Impacts of the full intervention}

95\% of the treated made initial business plans for the buying and selling of goods, and the remainder made plans for butchery, livestock, or other business. ${ }^{21}$ As we will see, however, over time their investments diversified into more non-farm businesses and also livestock.

While the capital was seen as crucial to starting their enterprises, most participants also reported that the training, business planning, and supervision were valuable. 16 months after the grants, $98 \%$ said that AVSI staff were important in planning their business, $77 \%$ of people said the supervisory visits made them somewhat anxious, and $94 \%$ would recommend the supervisory visits. Yet this advising was not too constricting: $95 \%$ said they felt free to spend the grant as they saw fit.

Table 3 reports impacts 16 months after grants. ${ }^{22}$ We start by focusing on the program without group dynamics training.

At baseline, only $3 \%$ of the sample reported any non-farm business, a category that includes mainly petty trading and cottage production, but excludes agricultural enterprise and livestock-related work (Table 1). These non-farm businesses grew substantially in the

\footnotetext{
${ }^{21} 96 \%$ of people assigned to treatment received the training and grant in Phase 1. The main reasons for not receiving a grant were death or migration, in which case someone outside the study sample received the program instead.

${ }^{22}$ We focus on occupational choice, employment levels, and incomes. This focus is in line with the model in Appendix C.
} 


\section{Table 3: Economic impacts of WINGS program and group formation}

\begin{tabular}{|c|c|c|c|c|}
\hline \multirow[b]{2}{*}{ Outcome } & \multirow[b]{2}{*}{$\begin{array}{c}\text { Control } \\
\text { mean } \\
(1)\end{array}$} & \multicolumn{3}{|c|}{ ITT estimates, 16 mo. after grants $(\mathrm{n}=1,734)$} \\
\hline & & $\begin{array}{c}\text { No group } \\
\text { training } \\
(2)\end{array}$ & $\begin{array}{c}\text { Group } \\
\text { training } \\
(3)\end{array}$ & $\begin{array}{c}\text { Difference } \\
(4)\end{array}$ \\
\hline \multicolumn{5}{|l|}{ Occupational choice: } \\
\hline Any non-farm self-employment & 0.39 & $\begin{array}{c}0.401 \\
{[.030]^{* * *}}\end{array}$ & $\begin{array}{c}0.409 \\
{[.033]^{* * *}}\end{array}$ & $\begin{array}{l}0.008 \\
{[.034]}\end{array}$ \\
\hline Started enterprise since baseline & 0.50 & $\begin{array}{c}0.487 \\
{[.025]^{* * *}}\end{array}$ & $\begin{array}{c}0.485 \\
{[.025]^{* * *}}\end{array}$ & $\begin{array}{r}-0.002 \\
{[.018]}\end{array}$ \\
\hline Average work hours per week & 14.98 & $\begin{array}{c}9.391 \\
{[1.608]^{* * *}}\end{array}$ & $\begin{array}{c}9.877 \\
{[1.794]^{* * *}}\end{array}$ & $\begin{array}{c}0.486 \\
{[2.029]}\end{array}$ \\
\hline Agricultural & 9.52 & $\begin{array}{c}3.496 \\
{[1.389]^{* *}}\end{array}$ & $\begin{array}{c}4.002 \\
{[1.300]^{* * *}}\end{array}$ & $\begin{array}{c}0.506 \\
{[1.524]}\end{array}$ \\
\hline Non-agricultural & 5.342 & $\begin{array}{c}5.895 \\
{[.893]^{* * *}}\end{array}$ & $\begin{array}{c}5.875 \\
{[.916]^{* * *}}\end{array}$ & $\begin{array}{l}-0.020 \\
{[1.217]}\end{array}$ \\
\hline Average hours of chores per week & 39.75 & $\begin{array}{c}0.305 \\
{[1.013]}\end{array}$ & $\begin{array}{c}1.416 \\
{[1.203]}\end{array}$ & $\begin{array}{c}1.111 \\
{[1.301]}\end{array}$ \\
\hline Income and food security: & & & & \\
\hline Index of income measures, z-score & -0.22 & $\begin{array}{c}0.464 \\
{[.068]^{* * *}}\end{array}$ & $\begin{array}{c}0.616 \\
{[.080]^{* * *}}\end{array}$ & $\begin{array}{c}0.151 \\
{[.087]^{*}}\end{array}$ \\
\hline Monthly cash earnings, 000s UGX & 15.53 & $\begin{array}{c}10.372 \\
{[3.443]^{* * *}}\end{array}$ & $\begin{array}{c}23.390 \\
{[4.607]^{* * *}}\end{array}$ & $\begin{array}{c}13.018 \\
{[5.512]^{* *}}\end{array}$ \\
\hline Durable assets (consumption), z-score & 0.12 & $\begin{array}{c}0.327 \\
{[.067]^{* * *}}\end{array}$ & $\begin{array}{c}0.384 \\
{[.068]^{* * *}}\end{array}$ & $\begin{array}{l}0.056 \\
{[.073]}\end{array}$ \\
\hline Monthly non-durable consumption, 000s UGX & 107.74 & $\begin{array}{c}31.031 \\
{[5.010]^{* * *}}\end{array}$ & $\begin{array}{c}33.439 \\
{[5.227]^{* * *}}\end{array}$ & $\begin{array}{c}2.408 \\
{[6.049]}\end{array}$ \\
\hline Durable assets (production), z-score & -0.02 & $\begin{array}{c}0.402 \\
{[.064]^{* * *}}\end{array}$ & $\begin{array}{c}0.397 \\
{[.058]^{* * *}}\end{array}$ & $\begin{array}{c}-0.005 \\
{[.064]}\end{array}$ \\
\hline Times went hungry, past week & 0.19 & $\begin{array}{c}-0.098 \\
{[.039]^{* *}}\end{array}$ & $\begin{array}{c}-0.084 \\
{[.036]^{* *}}\end{array}$ & $\begin{array}{l}0.013 \\
{[.043]}\end{array}$ \\
\hline Usual \# meals per day & 1.76 & $\begin{array}{c}0.057 \\
{[.028]^{* *}} \\
\end{array}$ & $\begin{array}{c}0.078 \\
{[.031]^{* *}} \\
\end{array}$ & $\begin{array}{l}0.021 \\
{[.031]}\end{array}$ \\
\hline
\end{tabular}

Notes: All variables denominated in UGX and hours were top-censored at the 99th percentile to contain outliers. Columns 2 and 3 report the coefficients and standard errors on indicator for assignment to Phase 1 without and with the group dynamics component in an OLS regression of each outcome on treatment indicators, a Gulu district (strata) fixed effect, and baseline covariates. Column 4 reports the difference between the two treatment groups. Standard errors are robust and clustered at the village level. ${ }^{* * *} \mathrm{p}<0.01,{ }^{* *} \mathrm{p}<0.05,{ }^{*} \mathrm{p}<0.1$ 
20 months after the baseline survey. In control villages, half of the participants eligible for the program say they attempted to start some nonfarm business since baseline, and $39 \%$ have some form of non-farm business at the endline survey - an increase of 36 percentage points. This investment could be an anticipation effect of the future grant (since they will enter Phase 2 a few months after the endline, reducing the risk of investments) in which case treatment effects understate the effect of the WINGS program. Alternatively, the investment and enterprise start-up could reflect the rise in business we would expect as people recover from an adverse shock. In principle, the control group could delay some investment in anticipation of the grant, though this would mean delaying for nearly two years. If so, we overestimate the effect of the WINGS program.

Nonetheless, there are even greater changes in treatment villages. Nearly every participant tried to start a nonfarm enterprise, and $79 \%$ have one at endline - a doubling compared to the control group. We see a large shift in occupation choice towards nonfarm enterprise, mainly wholesale and retail trade, kiosks, and shops, but also including some services.

As a result, nonfarm hours of work in the treatment group double compared to controls, rising from about 5 to 11 per week. But there is no crowding out of other activities, as the participants were generally underemployed beforehand. Farm hours actually rise compared to controls, from about 9.5 hours per week in the control group to about 13 with treatment. Most of this increase comes from increased hours caring for livestock, as ownership of cattle, sheep, goats and pigs more than doubles.

We have three measures of income. The first is cash earnings in the past month, in 2009 UGX. Cash earnings are noisy, subject to seasonality, and will understate income by omitting home production. Thus we also emphasize two measures of permanent income. One is an index of 33 durable assets for consumption purposes (including housing quality, furniture, and household items), standardized to have mean zero across all survey rounds, and hence measures asset changes over time. This is commonly used as a proxy for consumption (Filmer and Scott, 2008). Unfortunately we do not have asset values.

The other measure is estimated total household consumption of 57 goods in the past month, including food, small household items, communications, transport, and so forth. ${ }^{23}$ This is a partial list of goods, and may understate true consumption, especially because we do not have durable asset prices and cannot impute consumption of durables. Of course it is possible that the consumption measure overstates the value of home-produced items because of quality differences. We also consider a family index of all three measures.

\footnotetext{
${ }^{23}$ This abbreviated approach follows Beegle et al. (2012). Some items (such as food) are asked with a three-day recall period, some items (such as communications are transport are asked with a one or two week period, and larger non-durable spending (such as festivals, etc) are asked with a recall of several months. All items are then adjusted to monthly totals and added.
} 
The baseline was run at a time of intensive planting and weeding, shortly before the lean season began. The Phase 1 endline was run at a time of planting and harvesting at the outset of a dry season, during which dry season crops are produced and nonfarm activities such as brick-making are common. Major activities include the sale of crops and animals for festivals and payment of school tuition fees. We see incomes rise from baseline to endline partly because of this seasonality, but also because the 20 months from baseline to endline were a time of increasing incomes and productivity.

Durable assets in control villages rose .75 standard deviations since baseline. Their cash earnings rose by two thirds, from UGX 8,940 per month (about \$4.50 at 2009 market exchange rates) to UGX 15,530 (\$7.72), while hours of work stayed steady. We do not have non-durable consumption data at baseline.

The WINGS program leads to large increases in all three income measures, by .46 standard deviations overall. This includes a $66 \%$ increase in monthly cash earnings relative to the control group, though this is just UGX 10,315 (\$5.16) in absolute terms. Durable consumption assets rise by .32 standard deviations. Non-durable consumption rises $29 \%$ relative to the control group, UGX 31,019 per month, or about $\$ 15.50$ at market exchange rates. ${ }^{24}$ Note this is a total household level measure of consumption, and there are 6.9 members in the average household.

This consumption treatment effect is three times the earnings treatment effect, which could either reflect a number of factors besides measurement error: low seasonal earnings; earnings that are reinvested in other household members' enterprises or home-produced forms of consumption (e.g. products from livestock); or the consumption of some of the saved grant.

Because no income measure is perfect, this introduces uncertainty into the true effect on poverty. But if we use $\$ 5.16$ per month as a lower bound and $\$ 15.50$ as an upper one (about $\$ 13$ and $\$ 39$ in PPP terms) this is indisputably a large impact on income in absolute and relative terms.

We also have an index of 19 production-related durables, mainly livestock, farm equipment, and vocational tools (e.g. sewing machines). These are not included in the consumption durables. These investments rise .4 standard deviations, primarily from livestock purchases - .27 more cattle, 2 more fowl, and 2 more other animals such as goats, sheep, or pigs (Appendix D). Hence profits are being reinvested in productive assets.

Food security improves slightly as a result of this increase in incomes and enterprise. Times going hungry in the past week fall from .2 to .1, and the number of meals per day rises from 1.76 to 1.82. Since the endline was not run in the lean season, the effects may be

\footnotetext{
${ }^{24}$ We cannot reject equality of treatment effects by gender (not shown).
} 
muted. The bulk of earnings seems to go into assets, savings, and non-food consumption. For instance, savings more than tripled, increasing UGX 107,344 (\$54).

Two concerns are bias arising from baseline imbalance and systematic attrition. The results, however, are robust to exclusions of the baseline covariates, a differences-in-differences ITT estimate controlling for other baseline covariates, and also relatively extreme attrition bounds (see Appendix D).

\section{Comparison to non-participants}

We can also see how WINGS affects the position of program participants in the community by comparing them to non-participants in control villages. Figure 2 depicts the distribution of the standardized income index for (i) participants in treatment villages, (ii) participants in control villages (i.e. those nominated for the program), and (iii) adults from non-participant households in the control villages, divided into households that did and did not engage in petty trading at baseline. Comparing distributions, we see that treatment brings the ultrapoor nearly past the income levels of non-trading households, but not past the income levels of traders. In control villages, means are -.36 among participants, -.06 among nontrading non-participants, and .59 among trading non-participants. Participants in treatment villages have a mean of .02.

\section{Within-village spillovers}

About $10 \%$ of village households received WINGS, meaning WINGS provided a large cash influx into the village. Most participants entered petty trading, and so we might wonder about the effect of new entrants on prices or pre-existing traders in treatment villages (especially given that the median village has no shops). ${ }^{25}$ Comparing treatment and control villages, prices of imported and produced/exported goods both fell a slight amount (.05 and

\footnotetext{
${ }^{25}$ If the local retail market is not perfectly competitive (e.g. due to liquidity constraints serving as entry barrier), a program that promotes petty trading should drive down the price of imported goods by increasing competition. Cunha, De Giorgi and Jayachandran (2011) find some evidence that imperfect competition partly explains the price effects of transfers in rural Mexico. This would benefit consumers, but potentially decrease the profits of existing retail sellers, leading them to shift occupations and potentially lose income. Also, as in Buera, Kaboski and Shin (2012), new entrepreneurs could supply less labor to the market, more labor to their own business, and may even demand labor from the market instead. This will push up market wages. Given that most people in northern Ugandan villages are not fully employed, most enterprises are owner-operated, and there is a limited market for casual labor, we did not expect to see a significant change in wages. At the same time, to the extent that higher earnings increases participants' consumption, it could create a countervailing effect on prices, diminishing any decline. Studies of Mexican conditional cash transfer programs find that the transfers increase consumption of both cash recipients and program-ineligible households (Hoddinott and Skoufias, 2004; Angelucci and De Giorgi, 2009). Higher demand can increase prices as a result, especially in more remote locales (Cunha, De Giorgi and Jayachandran, 2011).
} 
Figure 2: Income index density, working-age adult participants and non-participants

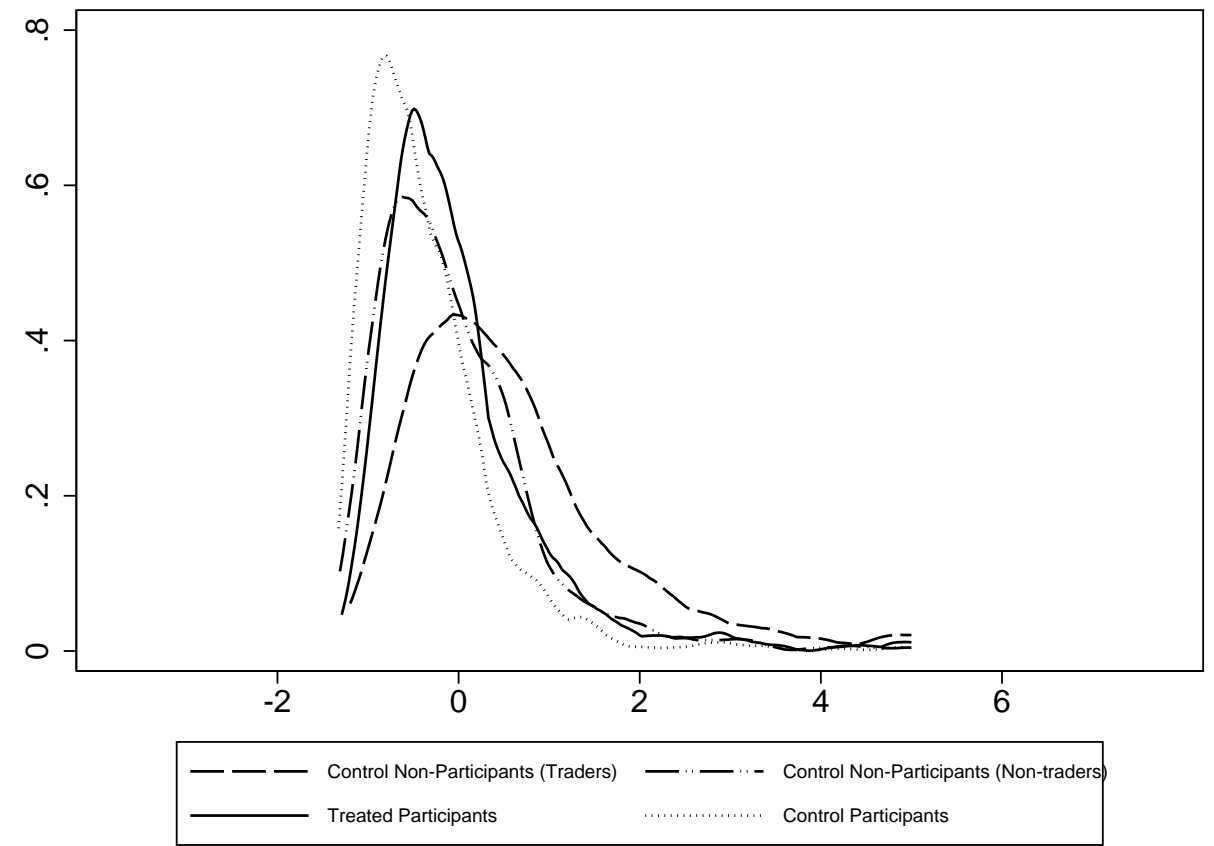

Notes: The income index is scaled to have zero mean and unit standard deviation across all participants and non-participants. We restrict the sample to 17 to 40 year olds. 
.09 standard deviations, not statistically significant), potentially because increased trade decreased the market power of existing traders and brought prices closer to the competitive equilibrium. We present these results in detail in Appendix 5.

We can also compare non-participants in treatment villages to non-participants in control villages (with the caveat that within villages participants were not randomly selected). Overall, despite the size of the program, there are limited spillovers to markets or non-participant households. We see no effect on the incomes or occupational choice of non-participant households, although if we look only at pre-existing traders we see a slight shift from petty trading to casual and agricultural work, with incomes holding more or less steady.

\section{B Impacts of group formation}

Columns 3 and 4 of Table 3 report the impacts of receiving the group encouragement. There is no evidence of an impact on business start-up, occupational choice, and levels of work. By one measure, though, group formation increased incomes. With group formation and training, the earnings treatment effect is more than double the size of the WINGS program without the group intervention. Durable assets and non-durable consumption, however, are not much higher. Overall, because of the earnings impact, The income index is .15 standard deviations greater, but significant only at the $10 \%$ level.

We thus treat the earnings effect with caution. The magnitude is large enough, however, that it's worth exploring potential reasons. The evidence suggests that informal insurance and cooperative activities (especially farming) play a role.

Table 4 reports ITT estimates for various group interactions. Two thirds of the control group are members in a community group of some kind, from water and school committees to savings and farming groups. Being in a treatment village without group encouragement increases group membership by 12.8 percentage points, and the group formation treatment nearly doubles this effect. The people in group formation villages go from being in 1.7 groups to 2.9 .

Treatment without group encouragement increases the frequency of meeting with a group. People in control villages meet with their "most important group" (not necessarily the WINGS-identified group) 1.4 times a month. This rises to about 1.8 times a month with the standard WINGS program, and to 2.4 times with the group dynamics training. Meetings are principally for savings-related activities or communal farming, and seldom for petty business-related activities.

The group is more likely to save together and lend to one another - in effect providing a form of informal insurance. The group dynamics training leads to an increase in loans to 
Table 4: Participatory and financial impacts of group formation

\begin{tabular}{|c|c|c|c|c|}
\hline \multirow[b]{2}{*}{ Outcome } & \multirow[b]{2}{*}{$\begin{array}{l}\text { Control } \\
\text { mean } \\
(1)\end{array}$} & \multicolumn{3}{|c|}{ ITT estimates, 16 mo. after grants $(\mathrm{n}=1,734)$} \\
\hline & & $\begin{array}{l}\text { No group } \\
\text { training } \\
(2)\end{array}$ & $\begin{array}{c}\text { Group } \\
\text { training } \\
(3)\end{array}$ & Difference \\
\hline \multicolumn{5}{|l|}{ Group engagement: } \\
\hline Member of any community group & 0.668 & $\begin{array}{c}0.129 \\
{[.028]^{* * *}}\end{array}$ & $\begin{array}{c}0.245 \\
{[.026]^{* * *}}\end{array}$ & $\begin{array}{c}0.117 \\
{[.025]^{* * *}}\end{array}$ \\
\hline \# of community groups & 1.721 & $\begin{array}{c}0.444 \\
{[.137]^{* * *}}\end{array}$ & $\begin{array}{c}1.163 \\
{[.155]^{* * *}}\end{array}$ & $\begin{array}{c}0.719 \\
{[.173]^{* * *}}\end{array}$ \\
\hline \multicolumn{5}{|l|}{ Of your "most important" group: } \\
\hline Times you meet per month & 1.409 & $\begin{array}{c}0.362 \\
{[.155]^{* *}}\end{array}$ & $\begin{array}{c}0.954 \\
{[.147]^{* * *}}\end{array}$ & $\begin{array}{c}0.592 \\
{[.176]^{* * *}}\end{array}$ \\
\hline For communal farming & 1.297 & $\begin{array}{l}0.415 \\
{[.326]}\end{array}$ & $\begin{array}{c}0.843 \\
{[.292]^{* * *}}\end{array}$ & $\begin{array}{l}0.428 \\
{[.375]}\end{array}$ \\
\hline For savings & 1.037 & $\begin{array}{c}0.767 \\
{[.196]^{* * *}}\end{array}$ & $\begin{array}{c}1.555 \\
{[.149]^{* * *}}\end{array}$ & $\begin{array}{c}0.788 \\
{[.217]^{* * *}}\end{array}$ \\
\hline For social support & 0.117 & $\begin{array}{l}0.051 \\
{[.032]}\end{array}$ & $\begin{array}{c}0.201 \\
{[.040]^{* * *}}\end{array}$ & $\begin{array}{c}0.150 \\
{[.044]^{* * *}}\end{array}$ \\
\hline For business & 0.142 & $\begin{array}{l}0.089 \\
{[.104]}\end{array}$ & $\begin{array}{c}0.142 \\
{[.062]^{* *}}\end{array}$ & $\begin{array}{l}0.053 \\
{[.116]}\end{array}$ \\
\hline \multicolumn{5}{|l|}{ Financial access and inter-HH transfers: } \\
\hline Transfers to other HH, 000s UGX & 8.495 & $\begin{array}{c}7.269 \\
{[2.219]^{* * *}}\end{array}$ & $\begin{array}{c}9.126 \\
{[1.960]^{* * *}}\end{array}$ & $\begin{array}{c}1.857 \\
{[2.797]}\end{array}$ \\
\hline Transfers from other HH, 000s UGX & 19.809 & $\begin{array}{c}44.663 \\
{[6.920]^{* * *}}\end{array}$ & $\begin{array}{c}40.858 \\
{[7.028]^{* * *}}\end{array}$ & $\begin{array}{l}-3.805 \\
{[9.644]}\end{array}$ \\
\hline Loans to other HH, 000s UGX & 6.317 & $\begin{array}{c}4.487 \\
{[1.872]^{* *}}\end{array}$ & $\begin{array}{c}10.457 \\
{[1.992]^{* * *}}\end{array}$ & $\begin{array}{c}5.970 \\
{[2.437]^{* *}}\end{array}$ \\
\hline Loans from other HH, 000s UGX & 9.215 & $\begin{array}{c}1.408 \\
{[1.614]}\end{array}$ & $\begin{array}{c}6.578 \\
{[2.320]^{* * *}}\end{array}$ & $\begin{array}{c}5.170 \\
{[2.487]^{* *}}\end{array}$ \\
\hline Member of a savings group & 0.272 & $\begin{array}{c}0.271 \\
{[.048]^{* * *}}\end{array}$ & $\begin{array}{c}0.517 \\
{[.039]^{* * *}}\end{array}$ & $\begin{array}{c}0.246 \\
{[.052]^{* * *}}\end{array}$ \\
\hline Total savings, 000s UGX & 37.374 & $\begin{array}{c}107.607 \\
{[12.330]^{* * *}}\end{array}$ & $\begin{array}{c}115.467 \\
{[12.545]^{* * *}}\end{array}$ & $\begin{array}{c}7.860 \\
{[16.937]}\end{array}$ \\
\hline Total debts, 000s UGX & 5.232 & $\begin{array}{l}0.974 \\
{[.994]}\end{array}$ & $\begin{array}{c}4.141 \\
{[1.254]^{* * *}}\end{array}$ & $\begin{array}{c}3.167 \\
{[1.489]^{* *}}\end{array}$ \\
\hline \multicolumn{5}{|l|}{ Other outcomes: } \\
\hline Access to business advice in village, $\mathrm{z}$-score & -0.081 & $\begin{array}{c}0.145 \\
{[.062]^{* *}}\end{array}$ & $\begin{array}{c}0.213 \\
{[.064]^{* * *}}\end{array}$ & $\begin{array}{l}0.068 \\
{[.064]}\end{array}$ \\
\hline Earnings in last harvest, 000s UGX & 152.768 & $\begin{array}{c}-33.211 \\
{[14.795]^{* *}}\end{array}$ & $\begin{array}{c}2.204 \\
{[13.914]}\end{array}$ & $\begin{array}{c}35.415 \\
{[16.377]^{* *}}\end{array}$ \\
\hline
\end{tabular}

Notes: See notes to Table 3.

*** $\mathrm{p}<0.01,{ }^{* *} \mathrm{p}<0.05,{ }^{*} \mathrm{p}<0.1$ 
and from other households, but no significant change in transfers (which do not have to be repaid). Total debts rise as a result of group dynamics to almost double the control level of debts.

Communal farming is one of the most commonplace forms of economic cooperationpeople pool their labor and either assist each other on one another's plots, or farm a new plot collectively for cash or own consumption. Control villagers meet 1.3 times a month for farming, and this rises by almost two thirds with WINGS and group dynamics training. We do not have a measure of total cooperative farming hours, but note that with WINGS alone, earnings from the last harvest falls by UGX 33,294 (about \$18) compared to the control group, perhaps because petty trading crowds out these activities. But there is no decrease in the group dynamics trained villages.

\section{Health, social relations, and empowerment}

Health Table 5 reports non-economic program impacts. There is little change in an index of physical health measures. ${ }^{26}$ But of the three people who died between baseline and endline, all were control group members. This translates to a $.5 \%$ decrease in mortality, significant at the $10 \%$ level. $^{27}$

Social and community participation and status Increased income and employment is associated with greater social support, community participation, but also community hostility, according to several index measures. ${ }^{28}$ We see little change in an index of three questions on the quality of family relationships, but we see a .2 standard deviation increase in seven forms of social support received in the past month (such as someone comforting you when you are feeling sad); and a .16 standard deviation increase in five forms of community participation (such as speaking out at community meetings or being a community leader).

But program participants (at least those who did not receive the group dynamics training) were more likely to report disputes with neighbors or verbal abuse from others. Our qualitative interviews, however, suggest they were targets of jealously or resentment from a small number of other households in the village, rather than the village at large. Group formation and training may have insulated marginalized women from such abuse.

\footnotetext{
${ }^{26}$ It is a standardized index of days ill, a subjective "overall" health question, and three activities of daily living (walking a distance, carrying a heavy load, and working on a farm). See Appendix D for component treatment effects.

${ }^{27}$ Also, as shown by Green et al. (2015b), there is also no change in mental health, as measured by an index of 35 symptoms of depression and distress.

${ }^{28}$ Means and treatment effects for individual components are available in Appendix D.
} 
Table 5: Impacts of WINGS on health, social relations, and empowerment

\begin{tabular}{|c|c|c|c|c|}
\hline \multirow[b]{2}{*}{ Outcome } & \multirow[b]{2}{*}{$\begin{array}{l}\text { Control } \\
\text { mean } \\
(1)\end{array}$} & \multicolumn{3}{|c|}{ ITT estimates, 16 months after grants } \\
\hline & & $\begin{array}{l}\text { No group } \\
\text { training } \\
(2)\end{array}$ & $\begin{array}{c}\text { Group } \\
\text { training } \\
(3)\end{array}$ & Difference \\
\hline \multicolumn{5}{|l|}{ Health: } \\
\hline Physical health index, z-score & 0.002 & $\begin{array}{l}0.020 \\
{[.070]}\end{array}$ & $\begin{array}{c}-0.013 \\
{[.069]}\end{array}$ & $\begin{array}{c}-0.033 \\
{[.085]}\end{array}$ \\
\hline Died since baseline & 0.003 & $\begin{array}{l}-0.005 \\
{[.002]^{*}}\end{array}$ & $\begin{array}{l}-0.005 \\
{[.002]^{*}}\end{array}$ & $\begin{array}{l}0.000 \\
{[.002]}\end{array}$ \\
\hline \multicolumn{5}{|l|}{ Social relationships: } \\
\hline Quality of family relationships, z-score & 0.018 & $\begin{array}{l}0.034 \\
{[.057]}\end{array}$ & $\begin{array}{l}0.011 \\
{[.053]}\end{array}$ & $\begin{array}{c}-0.023 \\
{[.067]}\end{array}$ \\
\hline Social support received, z-score & -0.084 & $\begin{array}{c}0.195 \\
{[.069]^{* * *}}\end{array}$ & $\begin{array}{c}0.159 \\
{[.063]^{* *}}\end{array}$ & $\begin{array}{c}-0.037 \\
{[.081]}\end{array}$ \\
\hline Community participation, z-score & -0.086 & $\begin{array}{c}0.159 \\
{[.055]^{* * *}}\end{array}$ & $\begin{array}{c}0.345 \\
{[.063]^{* * *}}\end{array}$ & $\begin{array}{c}0.187 \\
{[.070]^{* * *}}\end{array}$ \\
\hline Community hostility index, z-score & -0.070 & $\begin{array}{c}0.164 \\
{[.074]^{* *}}\end{array}$ & $\begin{array}{l}-0.018 \\
{[.049]}\end{array}$ & $\begin{array}{c}-0.182 \\
{[.077]^{* *}}\end{array}$ \\
\hline \multicolumn{5}{|l|}{ Empowerment: } \\
\hline Autonomy in purchases, z-score & -0.026 & $\begin{array}{l}0.082 \\
{[.059]}\end{array}$ & $\begin{array}{l}0.089 \\
{[.062]}\end{array}$ & $\begin{array}{l}0.007 \\
{[.074]}\end{array}$ \\
\hline Physical and emotional abuse, z-score ${ }^{\dagger}$ & -0.030 & $\begin{array}{l}0.066 \\
{[.088]}\end{array}$ & $\begin{array}{c}-0.046 \\
{[.098]}\end{array}$ & $\begin{array}{c}-0.113 \\
{[.092]}\end{array}$ \\
\hline Degree of partner control, z-score ${ }^{\dagger}$ & -0.110 & $\begin{array}{l}0.170 \\
{[.038]}\end{array}$ & $\begin{array}{c}0.129 \\
{[.031]^{*}}\end{array}$ & $\begin{array}{r}-0.041 \\
{[.037]}\end{array}$ \\
\hline Partner relationship quality, z-score ${ }^{\dagger}$ & -0.086 & $\begin{array}{c}0.180 \\
{[.095]^{*}}\end{array}$ & $\begin{array}{l}0.201 \\
{[.106]}\end{array}$ & $\begin{array}{l}0.021 \\
{[.115]}\end{array}$ \\
\hline Female and lives with partner at endline & 0.536 & $\begin{array}{c}0.046 \\
{[.020]^{* *}}\end{array}$ & $\begin{array}{c}0.072 \\
{[.021]^{* * *}}\end{array}$ & $\begin{array}{l}0.026 \\
{[.024]}\end{array}$ \\
\hline
\end{tabular}

Notes: See notes to Table 3. Means and ITTs for index components are in Appendix D. ${ }^{* * *} \mathrm{p}<0.01,{ }^{* *} \mathrm{p}<0.05,{ }^{*}$

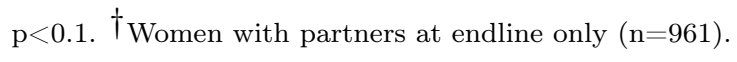


Empowerment Finally, we see little evidence that enhanced business activity and incomes increased reports of empowerment. We ask all subjects about their autonomy in household financial decisions, such as whether they can decide how to spend their pocket money, use their earnings to buy clothes without permission, or have a say in the purchase of large assets in the household. ${ }^{29}$ This autonomy measure increases by .08 standard deviations (not statistically significant). ${ }^{30}$ We also asked women with a partner at endline about aspects of their relationship. ${ }^{31}$ There is almost no change in self-reported physical and emotional abuse by the partner. ${ }^{32}$ And, if anything, women actually report an increase in the degree of control their spouse asserts over their finances and freedoms of movement and association. The husband increased tendencies to control contact outside the home and also demands or seizes some of the women's newfound earnings (see Appendix D). At the same time, women report a .18 standard deviation increase in the quality of the relationship, feeling more free to express their opinions and reporting a healthier relationship. Overall, these results paint a picture of husbands who encourage but then control their wife's business earnings, in return for weak increases in purchasing autonomy.

\section{Impacts of supervision}

In Phase 2, when control villages received the program, we surveyed participants about grant use and future expectations a month after they received it (a few weeks before the first followup visits), and again a year later. Table 6 reports 1-month treatment effects of expecting any follow-up, and Table 7 reports 12-month treatment effects of 2 visits (supervision without advice) and 5 visits (supervision with extended advice).

One-month impacts People appear to have believed their treatment assignment: only $10 \%$ of the "no follow up" group said they expected a visit whereas $98 \%$ of those assigned to

\footnotetext{
${ }^{29}$ We adapted empowerment questions from the Uganda Demographic and Health Survey.

${ }^{30}$ For women alone the result is significant at the $10 \%$ level.

${ }^{31}$ Treated women were more likely to answer these questions because they were slightly more likely to be married at endline, principally because of new marriages rather than any change in divorce rates. This could introduce positive or negative selection from "marginal marriages". We are interested in spousal abuse and relations as an outcome, and so the current results including selection are relevant. Alternatively, we could confine our analysis to the subset of women reporting partners at baseline. These results are not shown, but in general abuse and marital control are lower (though not significantly so) implying the marginal marriages are slightly better quality on average than baseline ones.

${ }^{32}$ See Green et al. (2015a) for a more detailed study of intimate partner violence in this setting. Note, however, that abuse is reported by fewer than a quarter of women, and so is probably under-reported. Even so, the effect of treatment is close to zero and so even significant underreporting is unlikely to affect the basic conclusion, so long as it is not significantly correlated with treatment.
} 
Table 6: Impacts of expecting supervision, 1 month after grant

\begin{tabular}{lccc}
\hline & & \multicolumn{2}{c}{ ITT estimates, } \\
& Mean, no & Any supervision $(\mathrm{n}=858)$ \\
\cline { 3 - 5 } Outcome & supervision & Coeff. & Std. Err. \\
& $(1)$ & $(2)$ & $(3)$ \\
\hline Expects AVSI staff to visit them in future & 0.097 & 0.878 & {$[.021]^{* * *}$} \\
Autonomy in grant planning \& spending, z-score & 0.082 & -0.170 & {$[.072]^{* *}$} \\
Grant money diverted to others, 000s UGX & 1.290 & 0.281 & {$[1.293]$} \\
Proportion of grant spent on: & & & \\
$\quad$ Business investments and expenditures & 0.269 & 0.050 & {$[.022]^{* *}$} \\
Large assets or home improvements & 0.119 & -0.038 & {$[.018]^{* *}$} \\
Food, clothing, personal items & 0.018 & -0.007 & {$[.002]^{* * *}$} \\
Gifts, contributions, or celebrations & 0.002 & 0.000 & {$[.001]$} \\
Health or education & 0.035 & -0.007 & {$[.005]$} \\
Saved or unspent & 0.537 & 0.002 & {$[.022]$} \\
Expenditure data (000s $U G X)$ : & & & \\
Non-durable consumption & & & {$[2.211]$} \\
Total business investments since grant & 47.821 & -0.509 & {$[3.539]$} \\
\hline
\end{tabular}

Notes: Columns 2 and 3 report the coefficients and standard errors on assignment to either 2 or 5 visits from an OLS regression of each outcome on this treatment indicator, a stratum fixed effect, and baseline covariates. Standard errors are robust and clustered by village. ${ }^{* * *} \mathrm{p}<0.01,{ }^{* *} \mathrm{p}<0.05, * \mathrm{p}<0.1$

any follow-ups did. ${ }^{33}$ As in Phase 1, participants also expressed independence and control over the funds. For instance, $94 \%$ of the no supervision group said they felt free to spend the grant how they wished, and $80 \%$ said they could deviate from the business plan. An index of 7 such measures of autonomy fell by .17 standard deviations with supervision. With or without supervision, however, there is little evidence of diversion of the grant or social pressure to share it. ${ }^{34}$

Expecting supervision has a modest impact on investment, at least by some measures. First, we asked participants to categorize how they spent the grant. Second, we sum all investment-related expenses in the last month from an expenditure module. Using the grant allocation measure, people have saved or not spent $54 \%$ of the grant and reported almost no spending on celebrations and gifts, whether they expected supervision or not. But those expecting a visit increased their share of the grant spent on business investment by 5 percentage points, reducing the share spent on durables (e.g. homes or livestock).

\footnotetext{
${ }^{33}$ AVSI followed through on this assignment: none of the "no follow-up" people were visited, and $91 \%$ of those assigned to two or five follow ups reported receiving the correct amount.

${ }^{34}$ We asked participants how much of the grant they had to give to household members and other community members. In total this was typically less than $1 \%$ of the grant, and expecting follow-up had little impact on the amount.
} 
By the expenditure survey, however, follow-up has little effect on the amount reported spent on business items. One reason could be that money is fungible, and while expenditures in the days following the grant might have fallen more heavily on durables the participants may have made up the investment shortfall by spending other earned income on the relevant materials for their business.

One-year impacts Table 7 reports the impacts of supervision a year after grants. We conducted the survey during a time of wet season planting and the beginning of the main harvest, at the closing of a lean season.

Two supervisory visits increase the likelihood someone is operating a business by 11 percentage points (19\%), and hours of nonfarm work per week by 2.2 hours (43\%). The three further visits lead to slight, not statistically significant increases.

Incomes are .024 standard deviations higher as a result of the two visits, and .037 standard deviations higher from five visits. Neither result is statistically significant. ${ }^{35}$ Compared to those with no visits, those with two visits have nearly a quarter higher cash earnings. Overall, cash earnings are low because of the season. This is one reason we focus on measures of permanent income, including durable assets and non-durable consumption, where we see no significant increase with supervision.

We also tested whether supervision has greater impact on the most present-biased or least autonomous individuals. We measured future orientation using incentivized games and selfreported survey questions. We also use a composite measure of three self-reported financial autonomy questions. We interact these baseline measures with treatment in Appendix D. The future orientation level and interaction have the expected sign (i.e. more investment and earnings) though the autonomy measure does not. None are statistically significant, but the coefficients on treatment-which represents the effect of treatment on the present-biased and less autonomous-are larger and more statistically significant than in Table 7.

\section{E Rate of return on the program}

We lack the long term data to do a full cost-effectiveness analysis, but in Table 8 we imagine the simple case where the increase in income is permanent, and calculate a simple internal rate of return (IRR) given program costs. Our preferred measure is our estimate of nondurable consumption. We also report IRR calculations for the lower earnings treatment effect, although earnings probably understate returns because it ignores other household

\footnotetext{
${ }^{35}$ Given sample size, we estimated we would require income increases of .15 or greater to have $80 \%$ statistical power.
} 
Table 7: Economic impacts of supervision, 12 months after grants

\begin{tabular}{|c|c|c|c|c|}
\hline \multirow[b]{2}{*}{ Outcome } & \multirow{2}{*}{$\begin{array}{c}\text { Mean, No } \\
\text { supervision } \\
\text { (1) }\end{array}$} & \multicolumn{3}{|c|}{ ITT estimates, $(\mathrm{n}=868)$} \\
\hline & & $\begin{array}{c}2 \text { visits } \\
(2)\end{array}$ & $\begin{array}{c}5 \text { visits } \\
(3)\end{array}$ & $\begin{array}{c}\text { Difference } \\
(4)\end{array}$ \\
\hline \multicolumn{5}{|l|}{ Occupational choice: } \\
\hline Any non-farm self-employment & 0.58 & $\begin{array}{c}0.110 \\
{[.039]^{* * *}}\end{array}$ & $\begin{array}{c}0.152 \\
{[.044]^{* * *}}\end{array}$ & $\begin{array}{l}0.042 \\
{[.037]}\end{array}$ \\
\hline Started enterprise since baseline & 0.92 & $\begin{array}{c}0.045 \\
{[.019]^{* *}}\end{array}$ & $\begin{array}{c}0.061 \\
{[.018]^{* * *}}\end{array}$ & $\begin{array}{l}0.016 \\
{[.014]}\end{array}$ \\
\hline Average work hours per week & 31.49 & $\begin{array}{c}1.105 \\
{[2.229]}\end{array}$ & $\begin{array}{c}4.764 \\
{[2.187]^{* *}}\end{array}$ & $\begin{array}{c}3.659 \\
{[2.453]}\end{array}$ \\
\hline Agricultural & 26.28 & $\begin{array}{l}-1.168 \\
{[2.213]}\end{array}$ & $\begin{array}{c}1.588 \\
{[2.168]}\end{array}$ & $\begin{array}{c}2.757 \\
{[2.230]}\end{array}$ \\
\hline Non-agricultural & 5.206 & $\begin{array}{c}2.274 \\
{[.907]^{* *}}\end{array}$ & $\begin{array}{c}3.176 \\
{[.892]^{* * *}}\end{array}$ & $\begin{array}{c}0.902 \\
{[1.137]}\end{array}$ \\
\hline Average hours of chores per week & 33.42 & $\begin{array}{c}1.698 \\
{[1.718]}\end{array}$ & $\begin{array}{c}1.797 \\
{[1.481]}\end{array}$ & $\begin{array}{c}0.099 \\
{[1.570]}\end{array}$ \\
\hline Income and food security: & & & & \\
\hline Index of income measures, z-score & -0.06 & $\begin{array}{l}0.021 \\
{[.082]}\end{array}$ & $\begin{array}{l}0.036 \\
{[.068]}\end{array}$ & $\begin{array}{l}0.015 \\
{[.073]}\end{array}$ \\
\hline Monthly cash earnings, 000s UGX & 13.06 & $\begin{array}{c}3.308 \\
{[2.523]}\end{array}$ & $\begin{array}{c}2.170 \\
{[2.010]}\end{array}$ & $\begin{array}{l}-1.138 \\
{[2.637]}\end{array}$ \\
\hline Durable assets, z-score & 0.81 & $\begin{array}{l}-0.065 \\
{[.089]}\end{array}$ & $\begin{array}{l}0.052 \\
{[.088]}\end{array}$ & $\begin{array}{l}0.117 \\
{[.082]}\end{array}$ \\
\hline Non-durable consumption, 000s UGX & 132.57 & $\begin{array}{l}-1.008 \\
{[4.968]}\end{array}$ & $\begin{array}{l}-3.022 \\
{[5.464]}\end{array}$ & $\begin{array}{l}-2.014 \\
{[4.781]}\end{array}$ \\
\hline Times went hungry, past week & 0.16 & $\begin{array}{l}-0.019 \\
{[.043]}\end{array}$ & $\begin{array}{c}-0.077 \\
{[.030]^{* *}}\end{array}$ & $\begin{array}{c}-0.058 \\
{[.036]}\end{array}$ \\
\hline Usual \# meals per day & 1.73 & $\begin{array}{l}0.029 \\
{[.041]}\end{array}$ & $\begin{array}{l}0.043 \\
{[.038]}\end{array}$ & $\begin{array}{l}0.014 \\
{[.037]}\end{array}$ \\
\hline
\end{tabular}

Notes: All variables denominated in UGX and hours were top-coded at the 99th percentile to contain outliers. Standard errors are robust and clustered at the village level. ${ }^{* * *} \mathrm{p}<0.01,{ }^{* *} \mathrm{p}<0.05,{ }^{*} \mathrm{p}<0.1$ 
members, non-cash earnings, and the proportion of the grant that went into savings or durable assets.

The full WINGS program has an internal rate of return of roughly $24 \%$ using total household non-durable consumption. Since we used an abbreviated consumption measure, this is probably an underestimate of the true effect. This consumption-based return is similar with or without group encouragement, since the impact and cost rise more or less proportionally. ${ }^{36}$ If we use the social discount rate of $5 \%$ commonly used by the World Bank and IMF, the present value of the consumption treatment effect is nearly five times the cost of the program.

By way of comparison, the six livestock-based graduation programs evaluated by Banerjee et al. (2015) had IRRs ranging from $2 \%$ to $24 \%$ two years after the program, with an average IRR of $8 \%$. Total consumption benefits were about 2.3 times as great as total costs of that program. The graduation programs have an additional year of data, however, and so we can be more confident in the sustainability of its gains.

Finally, despite the fact that supervisory visits represent about half of program costs, we cannot reject a negative or zero return. The sign of the IRR for supervisory visits is ambiguous, however, because the treatment effects of supervision on earnings and consumption run in different directions, and were in neither case statistically significant. The IRR is negative for the preferred consumption measure. It's possible, however, that supervision pays off in the longer term since business survival rates are higher.

\section{Discussion and conclusions}

These results show that a package of $\$ 150$ cash ( $\$ 375$ in PPP terms), five days of business training, and ongoing supervision led to a doubling of new non-farm enterprises and a significant rise in incomes among extremely poor and conflict-affected villagers, most of whom were women who had never operated such an enterprise before.

Second, the results show that simply encouraging people to form self-help groupscentered around communal savings, lending, and work - was enough to boost incomes. By some measures (such as consumption) this benefit was proportional to the cost. By other measures (monthly earnings) the benefit was more than proportional. Either way, it suggests that the poorest were not simply constrained by a lack of capital, credit, and insurance. Social interactions among the marginalized were simple to encourage and this stimulated valuable labor- and risk-sharing.

\footnotetext{
${ }^{36}$ If we use the earnings treatment effects, the IRRs are lower but still large and positive: $8 \%$ without group encouragement and 16\% with it.
} 


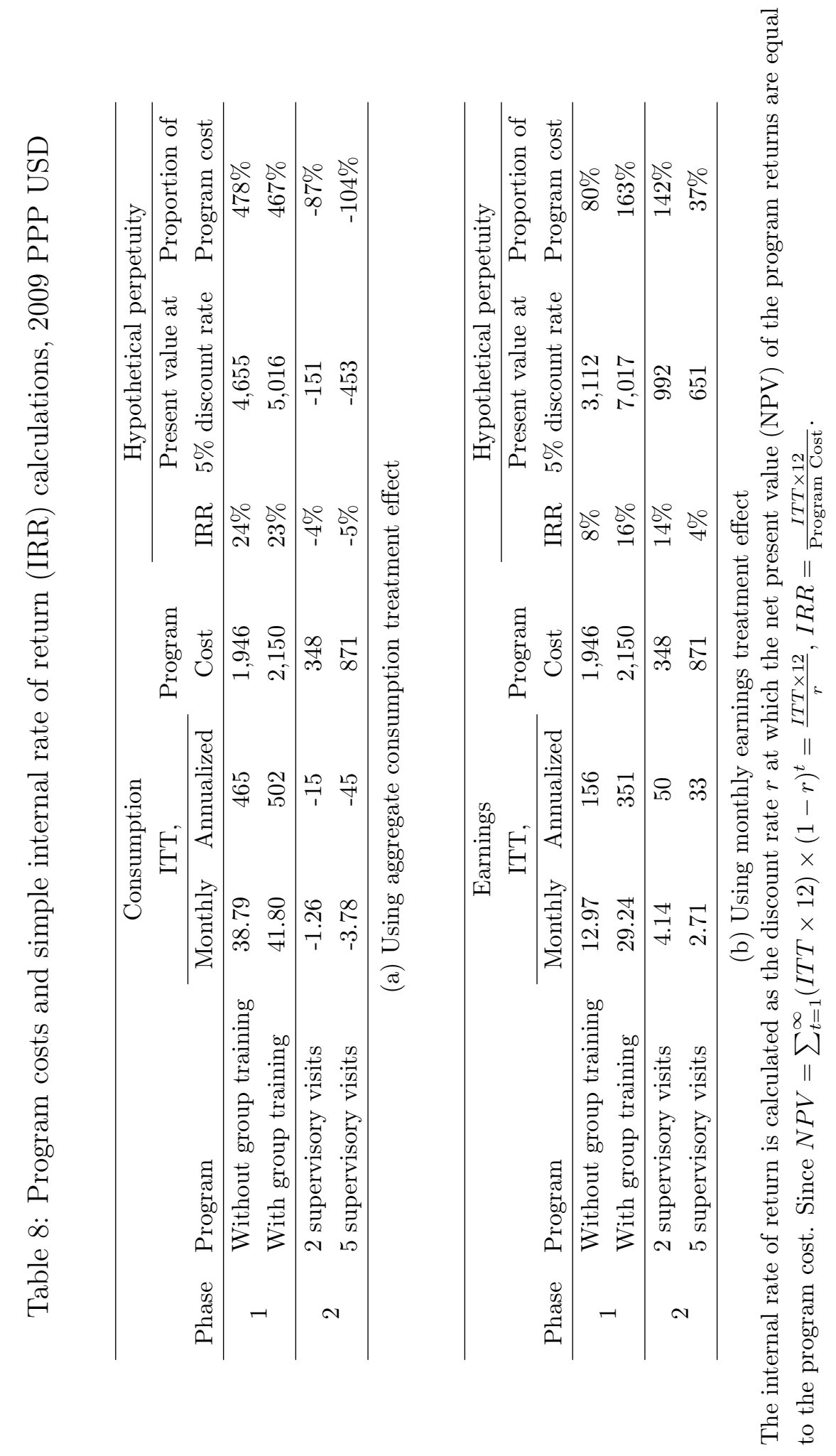


Finally, by some measures, supervising how participants spent the grant strengthened their incentives and commitment to invest. We see no evidence that supervision increased long-run performance, however, since the impact on income by some measures (such as consumption) was negative, and by other measures (earnings) was positive, but in neither case was it statistically significant after one year. We were not able to test the effects of a grant with or without supervision against a pure control group in Phase 1 of the study, which is an unfortunate limitation. We also only have one-year data on the impacts of supervision. Nonetheless, given that supervision costs 2-3 times as much as the grant itself, the impacts are surprisingly ambiguous.

The returns to streamlining programs such as WINGS are potentially large, potentially allowing more marginalized people to benefit for the same level of aid spending. For instance, targeting and disbursement were nearly as costly as the grant itself, yet participants were not much different than non-participants in the village who were not already traders. Moreover, mobile banking technologies are cheaper and becoming available in the region. Finally, the last three to five visits cost more than the grant itself, but the returns to additional supervision appear to be diminishing at best.

Reducing these costs could have high returns. For instance, a hypothetical program that delivered similar impacts for half to two-thirds the cost could have a 35-55\% internal rate of return. ${ }^{37}$ It's impossible to say what would happen to program impacts from such cost-cutting, but given the estimates in Table 8 it is difficult to imagine that impacts would fall proportionately to costs. Given the growing amount of cash-based programming in humanitarian and development settings, this proposition demands testing.

\section{A Comparisons to other ultrapoor programs}

It's difficult to compare this program to the alternatives without randomized, head-to-head comparisons, but the impacts of WINGS compare favorably to evidence on transfers of livestock and unconditional cash, at least within the timeframe we can evaluate with our design.

"Graduated" ultra-poor programs provide in-kind capital, such as livestock, along with training and other services, such as temporary income support. The fact that the WINGS participants invested much of their microenterprise profits in livestock suggests that animals are important investments and stores of value. Yet the fact that the poorest chose to make

\footnotetext{
${ }^{37}$ For instance, if targeting and disbursement costs could be limited to $10 \%$ of the cost of grants (a cost reached in the Kenya GiveDirectly experiment, as discussed by Haushofer and Shapiro (2013)) and if there were merely 1-2 supervisory visits, the average program cost would be half of the current amount.
} 
these investments on their own, plus the relatively high returns to petty business, also suggest that the ultrapoor can make forward-looking, profitable investment choices with some basic assistance.

Graduated programs have more and longer-term evidence in their favor than cash-based programs, however, with studies showing 10 to $40 \%$ increases in consumption or earnings over two to four years (Banerjee et al., 2010; Bandiera et al., 2013; Banerjee et al., 2015). The 16-month impacts of WINGS are comparable to the upper end of this range using an abbreviated consumption measure. We cannot say if the WINGS impacts persist, but several cash transfer studies with non-extreme poor demonstrate steady or increasing 4 to 6 year impacts (Blattman, Fiala and Martinez, 2014; de Mel, McKenzie and Woodruff, 2012a). ${ }^{38}$

Unconditional cash transfers lie at the other extreme. This is the approach taken by GiveDirectly in Kenya. Results from a randomized control trial of grants of one-time transfers of $\$ 400$ and $\$ 1500$ (in PPP terms) show high returns to investment in household durables after an average of about seven months, and large short-term increases in consumption (Haushofer and Shapiro, 2013). It remains to be seen if these returns persisted, as there is some indication they decline over the seven months.

\section{B Mechanism}

Why might WINGS have had such large impacts on income? To generate investment and high returns, programs such as WINGS must help overcome some constraint. Otherwise the ultrapoor in our sample would already be operating at their efficient scale, and a cash influx would not be invested in such a way as to generate high returns. ${ }^{39}$ Four of the most common constraints in the literature are: lack of credit, imperfect insurance, low business knowledge (or skill) levels, and present bias. Most anti-poverty interventions implicitly or explicitly target one or more of these.

While all these constraints undoubtedly play a role, the circumstantial evidence points to the importance of cash and group encouragement relieving a credit constraint. First, credit constraints in northern Uganda were extreme. As we noted in Section II, participants' ability to borrow before the program was almost non-existent. Just $4 \%$ of our sample said they could get a loan of $\$ 50$, and those loans were short term and typically carried interest rates in excess of the business returns we observe. The cash relieved this constraint directly,

\footnotetext{
${ }^{38}$ Note that, like WINGS, none of these cases are truly unconditional cash transfers, as most cash transfers are labelled or involve some selection, such as preparation of a business plan.

${ }^{39}$ See Appendix $\mathrm{C}$ for a formal model of occupational choice under various constraints, and a proof of the efficient scale argument.
} 
obviously, but group formation also had significant effects on the formation of ROSCAs and the incidence of borrowing. Group formation may also have increased informal insurance (though since the main effect of group formation was on inter-household loans rather than transfers, insurance is difficult to separate from increased access to credit). ${ }^{40}$

The success of the group encouragement program component is intriguing. The impacts on income are ambiguous but the effects on behavior are not. It illustrates that social capital of various forms was important and may not always form without third-party encouragement. Our design probably understates the importance of group encouragement, moreover, since some of the success of the core intervention, without formal group encouragement, was surely due in part to the group encouragement implicit in the group-based training and other elements of the program design. There are close parallels to findings by Feigenberg, Field and Pande (2013), who show that encouraging social interaction via group meetings reduced default on individual loans in India. It seems that encouraging group and ROSCA formation can increase social interactions, enhance social capital, increase risk-pooling and cooperation, and raise incomes.

Finally, the training and follow-up provided business advice and information. Most of the people in our sample had little experience in microenterprises in general or petty trading in particular. Moreover, the positive effect of two initial supervisory visits (by some measures, at least) is consistent with the hypothesis that at least a subset of people are time-inconsistent. Thus skills training and supervision cannot be separated from the effects of credit constraints and low social capital. Even so, the training and supervision cost four times as much to deliver as the grant, and six times as much as the group dynamics training. Also, a review of more than a dozen evaluations of business skills training fails to find that it passes a cost benefit test, at least on its own (McKenzie and Woodruff, 2012). Given the prevalence of training and supervision components in other programs, and their obvious cost, a clear experimental test of their efficacy with cash (or other capital transfers) is important.

\footnotetext{
${ }^{40}$ It's unlikely that a single cash transfer relieved the insurance constraint. Bianchi and Bobba (2013) show that knowledge of future cash transfers can increase current entrepreneurship because future transfers insure against risky enterprise income. In the program they study, however, households knew they would receive regular transfers over several years, whereas in our case people receive a grant only once and in the very near future. Furthermore, relieving an insurance constraint is only consistent with high returns to capital if the petty business is significantly more risky than traditional occupations. We asked respondents about expected variance in incomes, and found that even though treated people expect more volatile incomes in the future, their lowest expected income after the program is twice as high as in the control group. We asked people to estimate their highest, median, and lowest incomes in the coming year. The difference between highest and lowest expectation increases by two thirds but their lower bound doubles (Appendix Table D.2). Qualitatively, our interviews also suggested that subsistence farming is perceived to be as or more risky than petty trade, if only because petty trade has higher cash flow and plentiful local markets.
} 


\section{Generalizability}

How generalizable are these results? The post-conflict context in which WINGS was implemented could mean that returns to capital are higher than elsewhere: low levels of initial competition, scarce capital, and low financial development, all within a national economy that is growing as it adjusts to a politically stable equilibrium. ${ }^{41}$ On the other hand, we observe similar impacts in non-conflicted regions, whether from the graduation program evaluations mentioned above, or microenterprise programs elsewhere in Uganda. ${ }^{42}$

In the event that post-conflict arenas do offer higher returns, however, there is unfortunately no shortage of refugees, displaced persons, disaster victims, and conflict-affected populations. Our results suggest that cash-centric ultrapoor programs could reduce extreme poverty in such settings, in addition to the stable contexts where they are more familiar. This is useful to know, since with logistical and funding challenges, the UN and other donors are turning to cash as a main form of support for complex emergencies and humanitarian settings, such as cash support to the millions of Syrian refugees across the Middle East.

The matter is unsettled. Given the potential scalability and cost-effectiveness of cash, and the huge number of extreme poor, what is needed most is a multi-country trial, ideally one that evaluates the returns to additional components (such as training) and pits cash transfers head-to-head with other asset transfer strategies.

\section{References}

Angelucci, Manuela, and Giacomo De Giorgi. 2009. "Indirect Effects of an Aid Program: How Do Cash Transfers Affect Ineligibles' Consumption?" American Economic Review, 99(1): 486-508.

Annan, Jeannie, Christopher Blattman, Dyan Mazurana, and Khristopher Carlson. 2011. "Civil War, Reintegration, and Gender in Northern Uganda." Journal of Conflict Resolution, 55(6): 875-906.

Bandiera, Oriana, Niklas Buehren, Robin Burgess, Markus Goldstein, Selim Gulesci, Imran Rasul, and Munshi Sulaiman. 2012. "Empowering Adolescent Girls: Evidence from a Randomized Control Trial in Uganda." Working paper.

Bandiera, Oriana, Robin Burgess, Narayan Das, Selim Gulesci, Imran Rasul, and Munshi Sulaiman. 2013. "Can entrepreneurship programs transform the economic lives of the poor?" Working paper.

\footnotetext{
${ }^{41}$ A study in post-tsunami Sri Lanka finds a slow return of firms to pre-disaster capital, that firms receiving grants recovered sooner, that returns to capital doubled in damaged areas, and that capital had the largest impacts on retail firms (de Mel, McKenzie and Woodruff, 2012b).

${ }^{42}$ See Bandiera et al. (2012); Blattman, Fiala and Martinez (2014).
} 
Banerjee, Abhijit V., and Esther Duflo. 2011. Poor economics: A radical rethinking of the way to fight global poverty. New York:Public Affairs.

Banerjee, Abhijit V., Esther Duflo, Nathanael Goldberg, Dean Karlan, Robert Osei, William Parienté, Jeremy Shapiro, Bram Thuysbaert, and Christopher Udry. 2015. "A Multi-faceted Program Causes Lasting Progress for the Very Poor: Evidence from Six Countries." Science.

Banerjee, Abhijit V., Esther Duflo, Raghabendra Chattopadhyay, and Jeremy Shapiro. 2010. "Targeting the Hard-Core Poor: An Impact Assessment." Working paper.

Beegle, Kathleen, Joachim De Weerdt, Jed Friedman, and John Gibson. 2012. "Methods of household consumption measurement through surveys: Experimental results from Tanzania." Journal of Development Economics, 98: 3-18. 1.

Bertrand, Marianne, Sendhil Mullainathan, and Eldar Shafir. 2004. "A BehavioralEconomics View of Poverty." American Economic Review, 94: 419-423. 2.

Bianchi, Milo, and Matteo Bobba. 2013. "Liquidity, Risk, and Occupational Choices." Review of Economic Studies, 80(2): 491-511.

Blattman, Christopher, and Edward Miguel. 2010. "Civil War." Journal of Economic Literature, 48: 3-57. 1.

Blattman, Christopher, Nathan Fiala, and Sebastian Martinez. 2014. "Generating skilled employment in developing countries: Experimental evidence from Uganda." Quarterly Journal of Economics, 129(2): 697-752.

Buera, Francisco J., Joseph P. Kaboski, and Yongseok Shin. 2012. "The macroeconomics of microfinance." NBER Working Paper, 17905.

Burt, Alison, Barry Hughes, and Gary Milante. 2014. "Eradicating Poverty in Fragile States: Prospects of Reaching the "High-Hanging" Fruit by 2030." World Bank Policy Research Working Paper, 7002.

Cunha, Jesse M., Giacomo De Giorgi, and Seema Jayachandran. 2011. "The price effects of cash versus in-kind transfers." Unpublished working paper.

de Mel, Suresh, David J. McKenzie, and Christopher Woodruff. 2008. "Returns to Capital in Microenterprises: Evidence from a Field Experiment." Quarterly Journal of Economics, 123(4): 1329-1372.

de Mel, Suresh, David J. McKenzie, and Christopher Woodruff. $2012 a$. "One-Time Transfers of Cash or Capital Have Long-Lasting Effects on Microenterprises in Sri Lanka." Science, 335(6071): 962-966.

de Mel, Suresh, David McKenzie, and Christopher Woodruff. 2012b. "Enterprise Recovery Following Natural Disasters." The Economic Journal, 122(559): 64-91. 
Duflo, Esther. 2012. "Women Empowerment and Economic Development." Journal of Economic Literature, 50(4): 1051-1079.

Fafchamps, Marcel. 1992. "Solidarity Networks in Preindustrial Societies: Rational Peasants with a Moral Economy." Economic Development and Cultural Change, 41(1): 147-174.

Fafchamps, Marcel, David J. McKenzie, Simon Quinn, and Christopher Woodruff. 2014. "When is capital enough to get female microenterprises growing? Evidence from a randomized experiment in Ghana." Journal of Development Economics, 106(1): 211-226.

Feigenberg, Benjamin, Erica Field, and Rohini Pande. 2013. "The economic returns to social interaction: Experimental evidence from microfinance." The Review of Economic Studies, 80(4): 1459-1483.

Field, Erica, Seema Jayachandran, and Rohini Pande. 2010. "Do Traditional Institutions Constrain Female Entrepreneurship? A Field Experiment on Business Training in India." American Economic Review, 100(1): 125-129.

Filmer, Deon, and Kinnon Scott. 2008. "Assessing asset indices." World Bank Policy Research Working Paper Series, 4605.

Foster, Andrew D., and Mark R. Rosenzweig. 1995. "Learning by doing and learning from others: Human capital and technical change in agriculture." Journal of political Economy, 103(6): 1176-1209.

Gertler, Paul, Sebastian Martinez, and Marta Rubio. 2012. "Investing Cash Transfers to Raise Long Term Living Standards." American Economic Journal: Applied Economics, 4(1): 164-192.

Giné, Xavier, and Dean S. Karlan. 2014. "Group versus individual liability: Short and long term evidence from Philippine microcredit lending groups." Journal of Development Economics, 107: 65-83.

Government of Uganda. 2007. "National Peace, Recovery and Development Plan for Northern Uganda: 2006-2009." Government of Uganda, Kampala.

Green, Eric P., Jeannie Annan, Julian Jamison, and Christopher Blattman. 2015a. "Women's entrepreneurship and intimate partner violence: A cluster randomized trial of microenterprise assistance and partner participation in post-conflict Uganda." Social Science \& Medicine, 133: 177-188.

Green, Eric P., Julian Jamison, Christopher Blattman, and Jeannie Annan. 2015b. "Does poverty alleviation decrease depression symptoms in post-conflict settings? A cluster-randomized trial of microenterprise assistance in northern Uganda." Working paper.

Haushofer, Johannes, and Jeremy Shapiro. 2013. "Welfare Effects of Unconditional Cash Transfers: Evidence from a Randomized Controlled Trial in Kenya." Working paper. 
Hoddinott, John, and Emmanuel Skoufias. 2004. "The Impact of PROGRESA on Food Consumption." Economic Development and Cultural Change, 53(1): 37-61.

Kaboski, Joseph P., and Robert M. Townsend. 2011. "A Structural Evaluation of a Large-Scale Quasi-Experimental Microfinance Initiative.” Econometrica, 79(5): 1357-1406.

Karlan, Dean, Ryan Knight, and Christopher Udry. 2012. "Hoping to win, expected to lose: Theory and lessons on micro enterprise development." NBER Working Paper, 18325.

Macours, Karen, Patrick Premand, and Renos Vakis. 2012. "Transfers, Diversification and Household Risk Strategies: Experimental evidence with lessons for climate change adaptation." World Bank Policy Research Working Paper, , (6053).

McKenzie, David J., and Christopher Woodruff. 2012. "What are we learning from business training and entrepreneurship evaluations around the developing world?" Working paper.

Miguel, Edward, and Michael Kremer. 2004. "Worms: identifying impacts on education and health in the presence of treatment externalities." Econometrica, 72(1): 159-217.

Murgai, Rinku, Paul Winters, Elisabeth Sadoulet, and Alain de Janvry. 2002. "Localized and incomplete mutual insurance." Journal of Development Economics, 67(2): 245274.

Puri, Jyotsna, Anastasia Aladysheva, Vegard Iversen, Yashodhan Ghorpade, and Tilman Brück. 2014. "What methods may be used in impact evaluations of humanitarian assistance?" 3ie Working Paper 22.

Udry, Christopher. 2010. "The Economics of Agriculture in Africa: Notes on a Research Program." African Journal of Agricultural and Resource Economics, 5(1): 284-299.

Udry, Christopher, and Santosh Anagol. 2006. "The return to capital in Ghana." American Economic Review, 96(2): 388-393. 


\section{Appendix}

\section{A Training programs: Aims and curricula}

\section{A.1 Business skills training}

The stated objectives of the business skills training were to increase basic knowledge and skills of business management, to develop confidence in enterprise initiation and management, to help participants assess their own capabilities and motivation in entrepreneurial careers, and to strengthen and develop business skills. The training was adapted from the CAREUganda Ecodev projects training manual which is based on CARE Bangladesh's Small Economic Activity Development Sector and Rural Maintenance Program. The program manual is available at http://chrisblattman.com/documents/policy/WINGS. Business.Skills.Training.Manual.pdf.

Training and subsequent follow-up visits were led by AVSI resident field officers (RFOs), full time professional staff of the NGO. RFOs typically had tertiary education in social work, the slight majority were men, and most had at least a few years of experience on similar interventions. AVSI trained them in providing business support as well as psychological and social support. They were based in field offices at the sub-county level. Prior to administering the training, each RFO had participated in a two-week course led by an external facilitator. RFOs were trained using the Participatory Rural Approach Manual and the Community Resilience and Dialogue (CRD) Manual, aimed for literate and non-literate persons, respectively. Training time was divided equally between each training manual.

During this business skills training, participants were asked to address five key questions: a) Can I operate this IGA? b) Will people buy my products? c) Is the IGA profitable? d) How much money do I need to start and operate the IGA? e) Will the income from the IGA when added to other family income, be enough to pay household incomes? These key questions were practically presented to participants through lectures, small group discussion, group games, storytelling, dramatizations and role-playing by participants, large group sharing of experiences, and drawings. Participants were also constantly asked to recite the five key questions that they have to ask themselves as they think about starting their businesses. After the training, participants were given two weeks to develop a business plan, at which point AVSI staff would return to review plans individually.

The curriculum outline was as follows:

1. Business identification strategy and start-up process

(a) Business identification games 
(b) Characteristics of an entrepreneur or good business person

(c) Steps to become a businessperson

(d) Business experience sharing

2. Business management

(a) Constraints on business growth and performance

(b) Advantages and disadvantages of being in business

(c) Importance of monitoring activities and progress, avoiding delays and taking timely corrective actions

(d) Sales and sales promotion

(e) Choosing location and prices

3. Whether to sell on cash or credit

(a) What are credit sales?

(b) Advantages and disadvantages of credit

4. Financial management

(a) Separation of home and business finances

(b) Simple record keeping

(c) Simple income and expenditure tracking

(d) Costing of products and services

(e) Simple budgeting

5. Developing a business plan

(a) Definition and purpose of a business plan

(b) How to prepare a simple business plan

6. Basic management of a group savings and credit fund

(a) Reasons for saving

(b) Structure of a group savings system

(c) Reasons for a credit system 
(d) Structure of a group credit system

A copy of the training manual is available from AVSI USA on request (http://www . avsi-usa.org/).

\section{A.2 Group dynamics training}

AVSI did not typically encourage women to form support groups. Prior to the study, however, our qualitative work suggested that receiving training and grants could strengthen bonds among the beneficiaries in a village and induce them to cooperate, share ideas, and informally save together or insure one another.

The group dynamics training took place over three days, several weeks or months after grant disbursement. The program manual is available at http://chrisblattman.com/ documents/policy/WINGS.Group. Dynamic.Training.Manual.pdf.

AVSI intended for group members to exchange business ideas (including in agriculture), to organize savings and credit, and to collaborate or cooperate in economic activities such as marketing their produce or buying their inputs. The stated importance of groups, for instance, emphasized on the first day of training, included the following:

- Farmers learn from each other

- Farmers can market their produce and buy inputs together

- Groups ease organizing demonstrations

- Groups help to organize saving and credit for farmers

- Groups simplify interpersonal communication among members

- Groups are powerful in changing behaviors, attitude and values

- Groups can be used for decision making, negotiation and bargaining

- Groups are a door for new innovation

The stated goals of the training present AVSI's mechanism to do so:

- To enable members acquire basic skills in leadership and management of a group

- To instill the spirit of good communication habit essential for building cooperation, unity and trust in a group

- To enable members value and respect decision made collectively 
- To enable members to understand the importance of record keeping and identify types of record to keep in a group.

The curriculum had several key components and messages:

1. Introduction to the Advantages and importance of groups. As outlined above.

2. LEADERShip STYles. Different types of leadership were illustrated to the members in order to make them understand the importance of an inclusive approach to group decision-making. For example, participants were asked to role play the parts of a dictator, passive and democratic.

3. Communication And Listening. AVSI field workers stressed the importance of clear, open, and inclusive communication with regard to group activities. For example, participants were asked to take parts in dramatizations that illustrate bad and good communication skills and present their observations. They also practice listening skills.

4. Decision making Process. The objective of this topic was to help the member to choose how decisions relevant for the group would be taken to then be reflected in a group Constitution. Again, the training underlined the importance of group inclusion. Here participants were asked to identify any topic of interest, discuss as a group and arrive at a conclusion and present results. They also learn mechanisms to resolve interpersonal conflicts.

5. Roles And Responsibilities. Group members participated in activities designed to demonstrate the different roles that group members can take on, their responsibilities and unhelpful behavior in groups. For example, this was done through animal codes where facilitators presented pictures of 19 different animals such as elephant, monkeys, owl, tortoise etc. Each of these animals were attached to a given behavioral pattern and participants were expected to discuss the reality of such behavior in a group. The training stressed the importance of saving and suggested that groups collectively maintain a group savings account to make investments.

6. RECORD KEEPING. Basic record keeping techniques were illustrated to the participants as well as the importance of maintaining some level of record keeping. For example the facilitators illustrated the use of a ledger book for keeping records of monthly income and expenditure. Facilitators also presented different types of books that can be used in business such as a cash book, bank book and a purchase book, sales day book, the 
suppliers account record book, the customer account record book, a receipt book and an expense account book.

7. Constitution. Field workers also facilitated the creation of a group constitution in which participants agreed to a set their expectations for group activities and adopted rules governing how members interacted and supported one another. The purpose of the constitution was to reinforce the group goals and expectations agreed upon on the initial three-day training course. After the course, a copy of the constitution remained in the village with the group members.

AVSI also provided stationery packages to the group members for purposes of record keeping. After the course, AVSI staff members administered follow-up meetings every two months to monitor group formation and progress. The purpose of these follow-ups was for AVSI staff to track group formation progress as well as for the staff to interact with the groups and offer advice and guidance.

\section{B Survey summary statistics, attrition, and randomiza- tion balance}

\section{B.1 Villages}

Figure B.1 displays the location of treatment and control villages. Only villages eligible for the study and intervention are displayed (roughly $40 \%$ of all villages in the six highlighted sub-counties). Thick and thin lines indicate district and sub-county boundaries. Villages assigned to initial treatment (Phase 1) are represented by black circles. Villages assigned to delayed treatment (Phase 2) are hollow circles. 
Figure B.1: Villages in the study sample

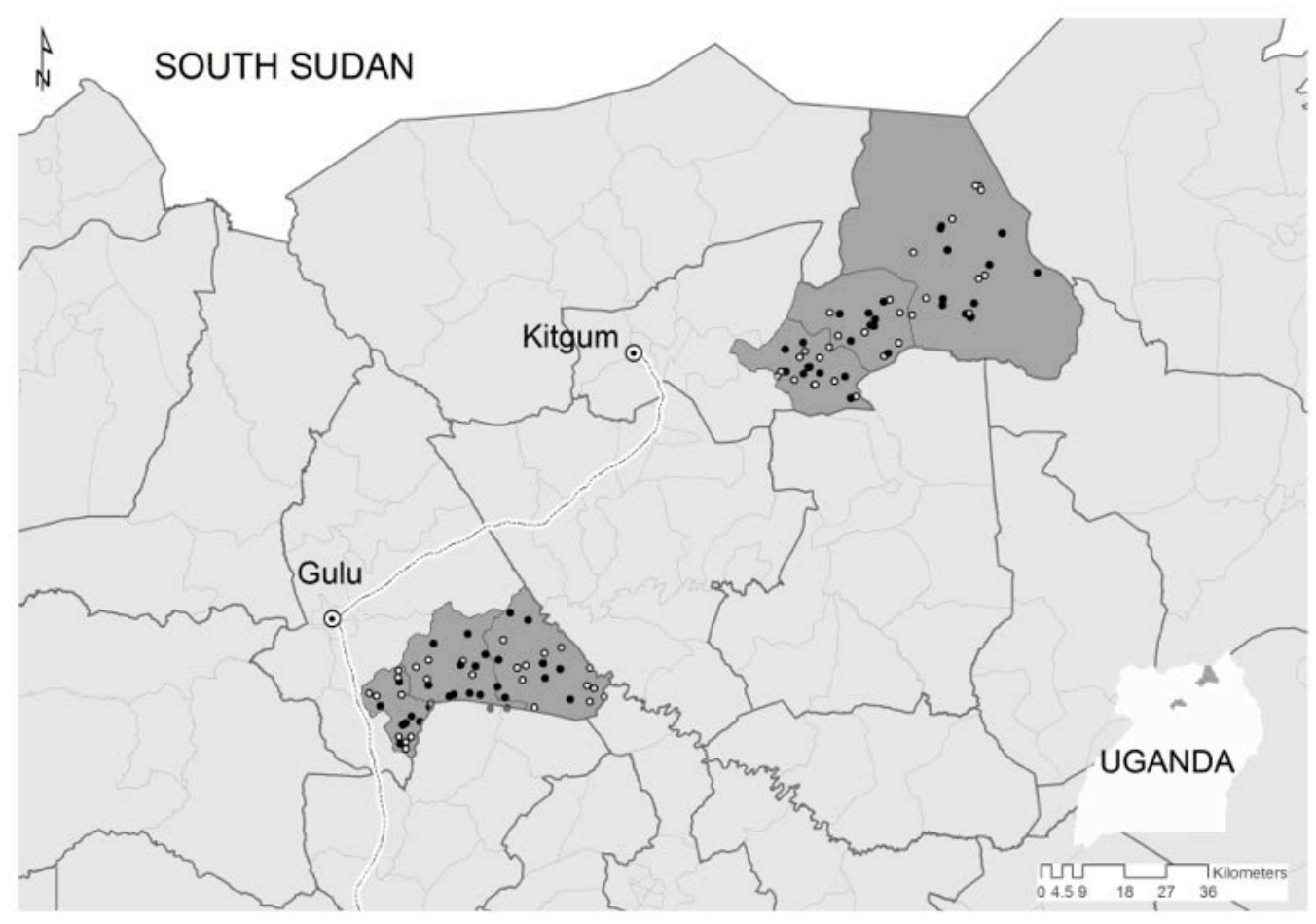

\section{B.2 Baseline summary statistics and balance}

Table B.1 reports summary statistics and balance tests for all baseline covariates. 
Table B.1: Summary statistics and balance tests

\begin{tabular}{|c|c|c|c|c|c|c|}
\hline \multirow[b]{2}{*}{ Covariate } & \multirow[b]{2}{*}{$\begin{array}{l}\text { Sample } \\
\text { mean, } \\
\text { baseline } \\
(1)\end{array}$} & \multirow[b]{2}{*}{$\begin{array}{c}\text { Phase } 1 \\
\text {-Phase } 2 \\
\text { difference } \\
\text { (2) }\end{array}$} & \multicolumn{4}{|c|}{ Balance test, p-values } \\
\hline & & & $\begin{array}{c}\text { Assigned } \\
\text { to Phase } \\
1 \\
(\mathrm{n}=1800) \\
(3)\end{array}$ & $\begin{array}{c}\text { Assigned } \\
\text { to Phase } \\
1, \text { post- } \\
\text { attrition } \\
(\mathrm{n}=1,734) \\
(4)\end{array}$ & $\begin{array}{l}\text { Assigned } \\
\text { to group } \\
\text { formation } \\
(\mathrm{n}=896) \\
(4)\end{array}$ & $\begin{array}{c}\text { Assigned } \\
\text { to any } \\
\text { follow-up } \\
(\mathrm{n}=904) \\
(5)\end{array}$ \\
\hline Age & 27.33 & -0.62 & 0.17 & 0.13 & 0.39 & 0.31 \\
\hline Female & 0.86 & -0.01 & 0.72 & 0.67 & 0.24 & 0.73 \\
\hline Household size & 6.90 & -0.26 & 0.06 & 0.04 & 0.62 & 0.71 \\
\hline Married or living with partner & 0.48 & -0.05 & 0.26 & 0.24 & 0.07 & 0.10 \\
\hline Single headed household & 0.49 & 0.04 & 0.17 & 0.22 & 0.47 & 0.01 \\
\hline Biological children alive & 3.34 & -0.24 & 0.08 & 0.07 & 0.53 & 0.10 \\
\hline Non-Acholi ethnic group & 0.15 & 0.02 & 0.63 & 0.65 & 0.35 & 0.20 \\
\hline Currently in school & 0.07 & -0.01 & 0.49 & 0.53 & 0.20 & 0.40 \\
\hline Highest grade reached at school & 2.79 & 0.07 & 0.70 & 0.69 & 0.69 & 0.02 \\
\hline Able to read and write minimally & 0.26 & -0.05 & 0.04 & 0.02 & 0.53 & 0.47 \\
\hline Able to speak some English & 0.09 & -0.01 & 0.37 & 0.30 & 0.37 & 0.09 \\
\hline Months of non-formal training & 0.44 & -0.25 & 0.06 & 0.17 & 0.69 & 0.39 \\
\hline Digit recall test score & 0.00 & -0.02 & 0.89 & 0.89 & 0.76 & 0.07 \\
\hline Any nonfarm self-employment & 0.03 & -0.01 & 0.17 & 0.20 & 0.59 & 0.47 \\
\hline Average work hours per week & 15.38 & -1.62 & 0.12 & 0.12 & 0.50 & 0.17 \\
\hline Agricultural & 12.32 & -2.09 & 0.02 & 0.02 & 0.17 & 0.09 \\
\hline Own farm and animals & 8.36 & -1.33 & 0.08 & 0.08 & 0.23 & 0.08 \\
\hline Agricultural wage labor & 3.96 & -0.75 & 0.08 & 0.09 & 0.47 & 0.75 \\
\hline Casual non-agricultural labor & 1.62 & 0.04 & 0.86 & 0.93 & 0.53 & 0.92 \\
\hline Nonagricultural & 3.06 & 0.46 & 0.25 & 0.28 & 0.31 & 0.64 \\
\hline Brewing alcohol/beer & 0.52 & 0.05 & 0.58 & 0.52 & 0.97 & 0.17 \\
\hline Petty trading & 0.40 & 0.07 & 0.70 & 0.69 & 0.52 & 0.55 \\
\hline Other work & 0.53 & 0.30 & 0.11 & 0.13 & 0.44 & 0.33 \\
\hline Average hours of chores per week & 34.56 & 0.63 & 0.68 & 0.82 & 0.80 & 0.01 \\
\hline Zero employment hours in past month & 0.20 & 0.05 & 0.07 & 0.08 & 0.15 & 0.31 \\
\hline Consumption durables (z-score) & -0.63 & -0.07 & 0.05 & 0.04 & 0.59 & 0.42 \\
\hline Production durables (z-score) & -0.51 & -0.02 & 0.48 & 0.40 & 0.20 & 0.32 \\
\hline Monthly cash earnings (000s UGX) & 8.93 & -0.78 & 0.26 & 0.22 & 0.50 & 0.66 \\
\hline \multicolumn{7}{|l|}{ Monthly cash earnings of other } \\
\hline household earner & 850.59 & -127.93 & 0.20 & 0.14 & 0.74 & 0.00 \\
\hline Member of a savings group & 0.09 & -0.03 & 0.07 & 0.06 & 0.42 & 0.52 \\
\hline Total savings, 000s UGX & 4.86 & -1.23 & 0.20 & 0.17 & 0.54 & 0.82 \\
\hline Total debts, 000s UGX & 4.16 & 0.15 & 0.82 & 0.77 & 0.99 & 0.98 \\
\hline Can obtain 15,000 UGX (\$7.50) loan & 0.24 & -0.01 & 0.53 & 0.39 & 0.76 & 0.59 \\
\hline Can obtain 100,000 UGX (\$50) loan & 0.04 & 0.01 & 0.34 & 0.28 & 0.86 & 0.25 \\
\hline Quality of family relationships, z-score & -0.00 & -0.19 & 0.00 & 0.00 & 0.63 & 0.90 \\
\hline
\end{tabular}




\begin{tabular}{|c|c|c|c|c|c|c|}
\hline \multirow[b]{2}{*}{ Covariate } & \multirow[b]{2}{*}{$\begin{array}{l}\text { Sample } \\
\text { mean, } \\
\text { baseline } \\
(1)\end{array}$} & \multirow[b]{2}{*}{$\begin{array}{c}\text { Phase } 1 \\
\text {-Phase } 2 \\
\text { difference } \\
\text { (2) }\end{array}$} & \multicolumn{4}{|c|}{ Balance test, p-values } \\
\hline & & & $\begin{array}{c}\text { Assigned } \\
\text { to Phase } \\
1 \\
(\mathrm{n}=1800) \\
(3)\end{array}$ & $\begin{array}{c}\text { Assigned } \\
\text { to Phase } \\
1, \text { post- } \\
\text { attrition } \\
(\mathrm{n}=1,734) \\
(4)\end{array}$ & $\begin{array}{l}\text { Assigned } \\
\text { to group } \\
\text { formation } \\
(\mathrm{n}=896) \\
(4)\end{array}$ & $\begin{array}{c}\text { Assigned } \\
\text { to any } \\
\text { follow-up } \\
(\mathrm{n}=904) \\
(5)\end{array}$ \\
\hline Community participation, z-score & 0.00 & -0.11 & 0.05 & 0.04 & 0.40 & 0.15 \\
\hline Neighbor relations, z-score & 0.00 & -0.03 & 0.62 & 0.55 & 0.27 & 0.94 \\
\hline \# of community groups & 0.53 & -0.10 & 0.04 & 0.04 & 0.02 & 0.23 \\
\hline Community maltreatment, past year & 0.18 & 0.03 & 0.11 & 0.09 & 0.06 & 0.48 \\
\hline Physical and emotional abuse, z-score & 0.07 & -0.04 & 0.54 & 0.69 & 0.25 & 0.60 \\
\hline Economic autonomy, z-score & 0.00 & 0.07 & 0.20 & 0.20 & 0.62 & 0.67 \\
\hline Attitudes to women's rights, z-score & -0.00 & 0.04 & 0.51 & 0.51 & 0.46 & 0.54 \\
\hline Related to a traditional chief or $\mathrm{LC} 1$ & 0.28 & -0.06 & 0.02 & 0.03 & 0.64 & 0.86 \\
\hline Physical health index, z-score & -0.05 & -0.02 & 0.75 & 0.89 & 0.83 & 0.60 \\
\hline Reports having HIV or AIDS & 0.06 & -0.01 & 0.59 & 0.48 & 0.26 & 0.20 \\
\hline Symptoms of distress, z-score & -0.00 & 0.18 & 0.02 & 0.01 & 0.65 & 0.82 \\
\hline War violence experienced, z-score & -0.01 & -0.08 & 0.19 & 0.28 & 0.64 & 0.65 \\
\hline Forcibly recruited into rebel group & 0.23 & -0.05 & 0.03 & 0.02 & 0.39 & 0.43 \\
\hline Carried gun within rebel group & 0.03 & -0.01 & 0.45 & 0.66 & 0.85 & 0.58 \\
\hline Forcibly married within rebel group & 0.03 & -0.00 & 0.63 & 0.73 & 0.83 & 0.96 \\
\hline Bore a child in forced marriage & 0.01 & -0.00 & 0.70 & 0.70 & 0.99 & 0.75 \\
\hline Self-reported risk aversion, z-score & 0.00 & 0.03 & 0.55 & 0.60 & 0.39 & 0.63 \\
\hline Self-reported patience, z-score & 0.00 & -0.03 & 0.57 & 0.64 & 0.42 & 0.07 \\
\hline \multicolumn{7}{|l|}{ Village-level covariates $(\mathrm{N}=120)$} \\
\hline Village population & 699.11 & 100.58 & 0.34 & 0.34 & 0.09 & 0.24 \\
\hline Average education of village & 4.38 & -0.25 & 0.16 & 0.14 & 0.48 & 0.16 \\
\hline Weighted distance to all villages & 0.55 & -0.07 & 0.34 & 0.35 & 0.61 & 0.16 \\
\hline \multicolumn{7}{|l|}{ Weighted distance to treatment } \\
\hline villages & 0.52 & 0.09 & 0.43 & 0.43 & 0.68 & 0.10 \\
\hline Distance to capital $(\mathrm{km})$ & 45.46 & 1.48 & 0.58 & 0.57 & 0.62 & 0.04 \\
\hline Sample members in the village & 15.16 & -0.18 & 0.50 & 0.48 & 0.95 & 0.13 \\
\hline Remoteness index, z-score & -0.01 & 0.12 & 0.49 & 0.46 & 0.31 & 0.01 \\
\hline Accessible by bus & 0.95 & 0.08 & 0.05 & 0.05 & 0.31 & 0.06 \\
\hline Minutes walk to primary school & 54.48 & 6.66 & 0.49 & 0.45 & 0.77 & 0.44 \\
\hline No mobile coverage & 0.04 & 0.02 & 0.61 & 0.60 & 0.58 & 0.16 \\
\hline Minutes walk to pay phone & 99.19 & 9.38 & 0.49 & 0.49 & 0.85 & 0.76 \\
\hline Minutes walk to health center & 274.81 & -10.49 & 0.73 & 0.76 & 0.16 & 0.10 \\
\hline Village has a market & 0.26 & -0.16 & 0.05 & 0.05 & 0.83 & 0.07 \\
\hline Minutes walk to market & 110.73 & 12.11 & 0.36 & 0.35 & 0.51 & 0.44 \\
\hline Price index, z-score & 0.01 & -0.32 & 0.05 & 0.05 & 0.14 & 0.64 \\
\hline Cost of renting one unit land (UGX) & 104.12 & 0.33 & 0.97 & 0.98 & 0.18 & 0.98 \\
\hline Village was a camp & 0.06 & -0.05 & 0.25 & 0.26 & 0.96 & 0.35 \\
\hline Number of NGOs active in village & 7.27 & -0.29 & 0.68 & 0.66 & 0.21 & 0.40 \\
\hline
\end{tabular}




\begin{tabular}{|c|c|c|c|c|c|c|}
\hline \multirow{7}{*}{ Covariate } & \multirow{7}{*}{$\begin{array}{l}\text { Sample } \\
\text { mean, } \\
\text { baseline } \\
\text { (1) }\end{array}$} & \multirow{7}{*}{$\begin{array}{c}\text { Phase } 1 \\
\text {-Phase } 2 \\
\text { difference } \\
\text { (2) }\end{array}$} & \multicolumn{4}{|c|}{ Balance test, $\mathrm{p}$-values } \\
\hline & & & & Assigned & & \\
\hline & & & Assigned & to Phase & Assigned & Assigned \\
\hline & & & to Phase & 1 , post- & to group & to any \\
\hline & & & 1 & attrition & formation & follow-up \\
\hline & & & $(\mathrm{n}=1800)$ & $(\mathrm{n}=1,734)$ & $(\mathrm{n}=896)$ & $(\mathrm{n}=904)$ \\
\hline & & & $(3)$ & $(4)$ & $(4)$ & $(5)$ \\
\hline Number of vendors in village & 3.20 & -1.56 & 0.17 & 0.16 & 0.21 & 0.79 \\
\hline Number of kiosks in village & 1.62 & 0.45 & 0.40 & 0.39 & 0.95 & 0.80 \\
\hline Number of shops in village & 1.49 & -0.52 & 0.30 & 0.30 & 0.97 & 0.24 \\
\hline Number of tailors in village & 1.47 & 0.36 & 0.66 & 0.63 & 0.50 & 0.35 \\
\hline Number of restaurants in village & 0.42 & 0.18 & 0.42 & 0.40 & 0.96 & 0.28 \\
\hline People buy goods from here & 0.27 & 0.04 & 0.59 & 0.64 & 0.52 & 0.44 \\
\hline Observations & & & 1,800 & 1,734 & 896 & 890 \\
\hline p-value (join significance) & & & 0.00 & 0.00 & 0.00 & 0.00 \\
\hline
\end{tabular}

Notes: All variables denominated in UGX and hours were top-censored at the 99th percentile to contain outliers. The p-values (and associated treatment group differences, not shown) in Columns 3-5 come from an OLS regression of each baseline characteristics on an indicator for treatment assignment plus a strata (district) fixed effect, with robust standard errors clustered at the village level.

\section{B.3 Response rates and attrition}

Table B.2: Survey response rates

\begin{tabular}{|c|c|c|c|c|c|c|c|c|}
\hline \multirow[b]{2}{*}{ Survey round } & \multirow[b]{2}{*}{$\begin{array}{l}\text { Median date } \\
\text { (1) }\end{array}$} & \multicolumn{2}{|c|}{ Observations } & \multicolumn{5}{|c|}{ Response rates } \\
\hline & & $\begin{array}{c}\text { Sought } \\
(2)\end{array}$ & $\begin{array}{c}\text { Surveyed } \\
(3)\end{array}$ & $\begin{array}{l}\text { All } \\
(4)\end{array}$ & $\begin{array}{c}\text { Control } \\
\text { (5) }\end{array}$ & $\begin{array}{c}\text { Treatment } \\
\text { (6) }\end{array}$ & $\begin{array}{c}\text { Difference } \\
\quad(7)\end{array}$ & $\begin{array}{c}\text { p-value } \\
(8)\end{array}$ \\
\hline \multicolumn{9}{|l|}{ Phase 1: } \\
\hline Baseline & $5 / 09$ & 1,800 & 1,800 & $100.0 \%$ & $100.0 \%$ & $100.0 \%$ & $0.0 \%$ & \\
\hline Endline & $12 / 10$ & 1,800 & 1,734 & $96.3 \%$ & $96.6 \%$ & $96.1 \%$ & $-0.5 \%$ & 0.62 \\
\hline \multicolumn{9}{|l|}{ Phase 2: } \\
\hline Baseline & $12 / 10$ & 904 & 882 & $97.6 \%$ & $97.8 \%$ & $97.4 \%$ & $-0.4 \%$ & 0.72 \\
\hline Endline (1 mo.) & $9 / 11$ & 904 & 858 & $94.9 \%$ & $93.1 \%$ & $95.9 \%$ & $2.8 \%$ & 0.13 \\
\hline Endline (1 yr.) & $7 / 12$ & 904 & 868 & $96.0 \%$ & $95.0 \%$ & $96.6 \%$ & $1.6 \%$ & 0.29 \\
\hline
\end{tabular}

Notes: Columns 7 and 8 report the treatment-control difference in response rates, calculated via OLS regression controlling for baseline district, using robust standard errors clustered by village. There were 1800 study subjects in Phase 1. Baseline data in Phase 2 includes the 847 original sample members from 2009, plus 2011 data on the 57 new respondents who replaced those who died or left the village.

Table B.2 reports response rates by survey and round. Missing data and attrition are low. For instance: 
- All 1800 participants completed the baseline survey. A very small number of respondents did not answer some questions. For the purpose of treatment effects analysis, we impute missing baseline data with the sample median in order to avoid losing the observation.

- Attrition at the Phase 1 endline was low (3.7\%) and uncorrelated with assignment to treatment.

- The Phase 2 baseline represents a baseline of the 57 replacements (for the Phase 2 subjects who died or migrated away since the Phase 1 baseline) and the data collected at Phase 1 endline for all those assigned to Phase 2 who were interviewed and not replaced. We are missing $2.4 \%$ of this Phase 2 baseline data because 7 of the 57 replacements could not be surveyed, and because a small number of people were not found at the Phase 2 endline but were still eligible for the program. We impute missing Phase 2 baseline data with the Phase 1 baseline value if available and the sample median if not.

- Attrition at the Phase 2 1-month endline is $5.1 \%$ and at the 1-year endline is $4 \%$. There is no significant correlation with treatment (assignment to any follow-ups).

Table B.3 reports the correlates of attrition in Phases 1 and 2, regressing an indicator for being found on selected baseline covariates. We pool Phases 1 and 2, clustering standard errors at the individual level, because: (a) the determinants of attrition are likely to be similar in each round, and (b) there are so few attritors (less than 40 per round) that there are almost as many plausible independent variables as unfound members of the sample. From Columns 1 and 2 illustrate that there is no significant correlation with treatment assignment. There is some correlation with covariates, namely age, schooling, and current enrollment. All covariates are jointly significant in explaining attrition, but all covariates explains just 3 percent of the variation. 
Table B.3: Correlates of attrition, all phases pooled

\begin{tabular}{lcc}
\hline & \multirow{2}{*}{ Dependent variable: Not found } \\
\cline { 2 - 3 } Covariate & Coeff. & Std. Err. \\
\hline Assigned to treatment at P1 & 0.0119 & {$[.012]$} \\
Assigned to group dynamics & -0.0172 & {$[.013]$} \\
Assigned to 2 follow-ups & -0.0217 & {$[.016]$} \\
Assigned to 5 follow-ups & 0.0105 & {$[.015]$} \\
Phase 2 dummy & 0.0177 & {$[.013]$} \\
Gulu district & -0.0264 & {$[.008]^{* * *}$} \\
Age & -0.0028 & {$[.001]^{* * *}$} \\
Female & -0.0185 & {$[.013]$} \\
Married or living with partner & -0.0135 & {$[.008]^{*}$} \\
Highest grade reached at school & -0.0032 & {$[.001]^{* * *}$} \\
Currently in school & 0.0532 & {$[.021]^{* *}$} \\
Average farm work hours per week & -0.0001 & {$[0000]$} \\
Average nonfarm work hours per week & -0.0003 & {$[0000]$} \\
Durable assets, z-score & 0.0065 & {$[.009]$} \\
Monthly cash earnings, 000s UGX & -0.0002 & {$[0000]$} \\
Activities of daily life, z-score & -0.0061 & {$[.005]$} \\
Symptoms of distress, z-score & 0.0003 & {$[.007]$} \\
Village population & 0.0000 & {$[0000]$} \\
Village remoteness, z-score & -0.0025 & {$[.004]$} \\
\hline Observations & 2704 & \\
R-squared & 0.0283 & \\
P(baseline covariates are jointly insignificant) & $<0.001$ & \\
P(treatment assignments are jointly insignificant) & 0.4508 & \\
\hline & & \\
\hline
\end{tabular}

\section{Ramsey model of occupational choice and investment with heterogeneous agents}

Our central questions are under what conditions, and why, do we expect the poorest to start new, profitable enterprises as a result of business training and a grant, with or without supervision and advice?

To interpret the interventions and understand potential mechanisms, we consider a model where people choose how many (if any) hours to work in each of two occupational sectors: traditional labor-intensive work (e.g. subsistence agriculture and casual labor) and capitalintensive small enterprise (both farm and non-farm). ${ }^{1}$

\footnotetext{
${ }^{1}$ The model is rooted in models of investment and occupation choice by Udry (2010); Fafchamps et al. (2014); Blattman et al. (2014), and has parallels to models by Kaboski and Townsend (2011). We thank Xing Xia for research assistance in developing this model.
} 
The model is rooted in the basic idea that, to expect investment and high returns, programs such as WINGS must help overcome some constraint. We see four main candidates: lack of credit, imperfect insurance, low business knowledge (skill) levels, and timeinconsistency (present bias). In order to make predictions, we match these possible constraints with the various components of the WINGS program.

The cash windfall in WINGS was mainly designed to alleviate credit constraints, which according to the model could have a first-order effect on outcomes in the sense of producing sustained high returns. Cash could also alleviate an insurance constraint, though we discussed in the main paper why this is unlikely in this context.

Both the business skills training and the extended supervision could relax knowledge constraints. Given our cross-cutting design, we cannot disentangle the effect of cash on credit constraints from the effect of business skills training on knowledge, or the disciplining effects of supervision.

The initial accountability element of the follow-ups (i.e. belief that one would be monitored) could help to address time-inconsistency (along with other potential rivers of poor decision-making, such as attention). However, as the model below shows, using a commitment device to address present bias alone cannot produce high returns. There must also be another constraint such as imperfect credit markets. If we see an effect of the initial supervisory visits on business size and profitability, then this implies that time-consistency likely exists in this population and that it affects consumption and saving levels, but not that it affects occupational choice and investment returns.

Finally, the group formation intervention was designed to impact social capital more generally. In the model this potentially corresponds to both credit constraints (via semiformal savings \& loan groups) and knowledge constraints (via diffusion of ideas).

\section{C.1 Setup}

Consider an individual who can spend time working in one of two sectors: enterprise or traditional labor. Production functions for enterprise and traditional labor are $f^{E}\left(k, l^{E}, \theta\right)$ and $f^{T}\left(l^{T}, \omega\right)$, where $k$ is accumulated physical and human capital used in enterprise, $l^{E}$ is hours spent on enterprise, $l^{T}$ is hours on traditional labor, and $\theta$ is individual specific talent in enterprise, and $\omega$ is individual specific talent in traditional labor. Working in enterprise requires a minimum capital stock $\underline{k} \geq 0$, while traditional labor has no capital requirement. We assume positive but diminishing marginal returns to inputs, $f_{k}^{E}>0>f_{k k}^{E}, f_{l}^{E}>0>f_{l l}^{E}$; inputs are complements, $f_{k l}^{E}>0$; and the returns to inputs are increasing in ability, $f_{k \theta}^{E}>0$, 
$f_{l \theta}^{E}>0$ and $f_{l \omega}^{T}>0 .^{2}$ Also, note that $l_{t}=l_{t}^{E}+l_{t}^{T} \in[0,1]$.

The individual thus faces the problem:

$$
\begin{aligned}
\max _{c_{t}>0, l_{t} \geq 0, k_{t+1} \geq 0, a_{t+1}} & \sum_{t=0} \delta^{t} u\left(c_{t}, l_{t}\right) \\
\text { s.t. } c_{t}+a_{t+1}+k_{t+1}= & \left(1+r_{t}\right) a_{t}+k_{t}+f^{E}\left(k_{t}, l_{t}^{E}, \theta\right)+f^{T}\left(l_{t}^{T}, \omega\right) \\
l_{t}= & l_{t}^{E}+l_{t}^{T} \leq 1 \\
k_{0}= & 0 \\
a_{0} & \text { given }
\end{aligned}
$$

where $a_{t}$ is any financial assets other than capital invested in enterprise and $r_{t}$ is the returns to these alternative financial assets at time $t$. Without loss of generality, we assume $k_{0}=0$ and all initial wealth is in the financial asset, $a_{0}$. To make analysis simple, we fix $r_{t}=$ $r>0$. Finally, to fully characterize the equilibrium we add a transversality condition: $\lim _{t \rightarrow \infty} \delta^{t} u_{c}^{\prime}\left(c_{t}, l_{t}\right) a_{t}=0$.

This benchmark case considers perfect financial markets and consistent time preferences. In this case, individuals will allocate assets between the enterprise and savings until the returns of capital are equal, and will allocate their time across sectors until the marginal disutility is equal. The solution to the problem is characterized as time-paths of quantities $\left\{c_{t}, l_{t}^{E}, l_{t}^{T}, k_{t+1}, a_{t+1}\right\}_{t=0}^{\infty}$ that satisfy the following set of conditions given $k_{0}=0$ and $a_{0}>0$ :

$$
\begin{aligned}
\frac{u_{c}^{\prime}\left(c_{t}, l_{t}\right)}{u_{c}^{\prime}\left(c_{t+1}, l_{t+1}\right)} & =\delta(1+r) \\
-\frac{u_{l}^{\prime}\left(c_{t}, l_{t}\right)}{u_{c}^{\prime}\left(c_{t}, l_{t}\right)} & =f_{l}^{E^{\prime}}\left(k_{t}, l_{t}^{E}, \theta\right) \quad \text { if } l_{t}^{E}>0 \\
-\frac{u_{l}^{\prime}\left(c_{t}, l_{t}\right)}{u_{c}^{\prime}\left(c_{t}, l_{t}\right)} & =f_{l}^{T^{\prime}}\left(l_{t}^{T}, \omega\right) \quad \text { if } l_{t}^{T}>0 \\
\frac{u_{c}^{\prime}\left(c_{t}, l_{t}\right)}{u_{c}^{\prime}\left(c_{t+1}, l_{t+1}\right)} & =\delta\left(1+f_{k}^{E^{\prime}}\left(k_{t+1}, l_{t+1}^{E}, \theta\right)\right) \quad \text { if } k_{t+1}>0 \\
c_{t}+a_{t+1}+k_{t+1} & =(1+r) a_{t}+k_{t}+f^{E}\left(k_{t}, l_{t}^{E}, \theta\right)+f^{T}\left(l_{t}^{T}, \omega\right) \\
\lim _{t \rightarrow \infty} \delta^{t} u_{c}^{\prime}\left(c_{t}, l_{t}\right) a_{t} & =0
\end{aligned}
$$

\footnotetext{
${ }^{2}$ We also assume the minimum capital requirement means that $f^{E}\left(k, l^{E}, \theta\right) \equiv 0$ as long as $k<\underline{k}$, and that for any ability level, at very low levels of $k$, marginal product of the first unit of labor is always higher in traditional labor than in enterprise, while at higher levels of $k$ it is the opposite, $\lim _{k \downarrow 0} \frac{f_{l}^{E}(k, 0, \theta)}{f_{l}^{T}(0, \omega)}=0$ and $\lim _{k \uparrow+\infty} \frac{f_{l}^{E}(k, 0, \theta)}{f_{l}^{T}(0, \omega)}=+\infty$. For simplicity, we assume $f^{E}\left(k, l^{E}, \theta\right)$ is homogeneous of degree 1 in $\left(k, l^{E}\right)$.
} 
Conditions 1 and 4 imply that whenever investment in enterprise is positive the individual always produces at efficient scale, i.e. $f_{k}^{E^{\prime}}\left(k_{t+1}, l_{t+1}^{E}, \theta\right)=r$. For simplicity, we focus on interior solutions only throughout.

Who runs an enterprise? For $\underline{k}>0$, there will be low $\theta$ types who cannot reach efficient scale because their returns to capital are lower than $r$. We can define a minimum ability before enterprise is feasible, $\underline{\theta}=\underline{\theta}(r, \underline{k})$ for $f_{k}^{E^{\prime}}(\underline{k}, 1, \underline{\theta})=r{ }^{3}$ Note that $\underline{\theta}$ does not depend on $a_{0}$.

As $\theta$ rises above $\underline{\theta}$, the returns to capital and labor increase in enterprise, and enterprise becomes a better alternative than saving all assets in $a_{t}$. This does not guarantee that the individual will invest, since time could be allocated instead to traditional labor. Not surprisingly, those with high values of $\omega$ and low values of $\theta$ will only engage in traditional labor. Specifically, there will be a second threshold, $\tilde{\theta}$, above which individuals will invest in enterprise if $\theta>\underline{\theta}$ is also satisfied. $\tilde{\theta}$ is a function of the relative marginal products of labor. The marginal product of labor in enterprise, $M P L^{E}(r, \theta)$, is decreasing in $r$ and increasing in $\theta .^{4}$ In the traditional sector, $M P L^{T}\left(\omega, a_{0}, r\right)$ is determined by the equilibrium level of $l^{T}$, and is increasing in $\omega, a_{o}$ and $r .^{5}$ For high enough $\omega, M P L^{T}\left(\omega, a_{0}, r\right) \geq M P L^{E}(r, \theta)$, and these individuals will engage only in traditional labor and save all their assets in $a_{t}$. $M P L^{T}\left(\omega, a_{0}, r\right)=M P L^{E}(r, \theta)$ defines a threshold level of $\tilde{\theta}=\tilde{\theta}\left(\omega, r, a_{o}\right)$ where $\theta>\tilde{\theta}$ if and only if $M P L^{T}\left(\omega, a_{0}, r\right)<M P L^{E}(r, \theta)$. $\tilde{\theta}\left(\omega, r, a_{0}\right)$ is increasing in all three arguments $r, \omega$ and $a_{o}$. However, the effect of $a_{o}$ on $\tilde{\theta}$ will be negligible and so we simplify to $\tilde{\theta}(\omega, r)$.

Finally, in the steady state ${ }^{6}$, occupational choice is determined by the threshold $\theta^{*}=$

\footnotetext{
${ }^{3}$ Since hours working in the enterprise are upward bounded by 1 while capital invested in skilled trade must be higher than $\underline{k}$, for any individual that invests in the enterprise, $\frac{k}{l^{E}}$ must be higher than $\underline{k}$. Then for any $\theta<\underline{\theta}, k \geq \underline{k}$, and $l^{s}<1, f_{k}^{E^{\prime}}\left(k, l^{E}, \theta\right)<f_{k}^{E^{\prime}}(\underline{k}, 1, \underline{\theta})=r$. The inequality arises because $f_{k}^{E^{\prime}}$ is decreasing in $k$ but increasing in $l^{E}$ and $\theta$. Therefore, for individuals with $\theta<\underline{\theta}$, their returns to capital in enterprise is below $r$ regardless of the level of $l^{E}$ and $k$. Note that $\underline{\theta}$ is an increasing function of $\underline{k}, r$ and other parameters in the production function $f^{E}$.

${ }^{4}$ If there is positive investment in enterprise, condition $f_{k}^{E^{\prime}}\left(k, l^{E}, \theta\right)=r$ pins down the level of $\frac{k}{l^{E}}$ (this is because we assumed $f^{E}$ is homogenous of degree one in $\left.\left(k, l^{E}\right)\right)$. $\frac{k}{l^{E}}$ then pins down the marginal product of labor on the right hand side of condition $3:-\frac{u_{l}^{\prime}\left(c_{t}, l_{t}\right)}{u_{c}^{\prime}\left(c_{t}, l_{t}\right)}=f_{l}^{E^{\prime}}\left(k_{t}, l_{t}, \theta\right)$.

${ }^{5}$ If an individual does not invest in enterprise and only engages in traditional labor, conditions $1,3,5$ and 6 will pin down a level of $l^{T}$.

${ }^{6}$ Note that we cannot have growth on the steady state because total hours available to the individual is 1 , and we assume there is no exogenous growth in productivity or individual ability. Therefore, we characterize a steady state where $c_{t}, k_{t}, l_{t}$ and $a_{t}$ are all constant. From optimal condition 1 , we can see that, without any restraints on savings or borrowing, the existence of a steady state requires $\delta(1+r)=1$, otherwise we cannot keep consumption constant. Notice that this is because we assumed there is free lending and free borrowing, both at the same rate $r$. Patient individuals whose $\delta>\frac{1}{1+r}$ would over save and accumulate infinite wealth when $t \rightarrow \infty$; impatient individuals whose $\delta<\frac{1}{1+r}$ would borrow too much today and their
} 
$\theta^{*}(r, \underline{k}, \omega)=\max \{\underline{\theta}(r, \underline{k}), \tilde{\theta}(\omega, r)\}$. Low ability individuals whose $\theta<\theta^{*}(r, \underline{k}, \omega)$ will set $k=0$ and $l^{E}=0$. $c$ and $l^{T}$ will be determined by $a_{o}, r$ and $w$. High ability individuals whose $\theta \geq \theta^{*}$ will invest in enterprise and set $k^{*}>0$ and $l^{E *}>0$ such that $f_{k}^{E^{\prime}}\left(k^{*}, l^{E *}, \theta\right)=r$ and $-\frac{u_{l}^{\prime}\left(c^{*}, l^{*}\right)}{u_{c}^{\prime}\left(c^{*}, l^{*}\right)}=f_{l}^{E^{\prime}}\left(k^{*}, l^{E *}, \theta\right)=f_{l}^{T^{\prime}}\left(l^{T *}, \omega\right)$. Their returns to capital will be $r$ regardless of their level of wealth. The ratio $\frac{k^{*}}{l^{E *}}$ will be determined by $\theta$ and $r$, while hours in traditional labor $l^{T *}$ will be determined by $w$ and $r$. Initial wealth $a_{o}$ will have a small effect on the level of $k^{*}, l^{E *}, c$ and $a$. Without any constraints, all individuals will immediately jump to these efficient steady state levels of production and consumption at time $t=1$.

In our comparative statics below we focus mainly on the cash component of our crosscutting research design. But the model is also informative about the other components (training, group formation, and supervision). The simplest way to think of basic business skills training is in increasing $\theta$, perhaps most of all among low types. This will raise the number of people above the minimum ability threshold, and potentially raise the returns to capital for people already above that threshold. Thus if people received training alone, we would expect to see increased entry into enterprise and greater enterprise earnings. This is the case with or without a windfall. Group formation may increase productivity $(\theta)$ either through shared ideas or possibly through some forms of cooperation (e.g. economies of scale in sourcing wholesale goods or selling in the same place), bring down the costs of borrowing $r$ (e.g. by forming loans\&savings groups, which usually provide cheaper finance than conventional money lenders), or reduce credit constraints $(a)$ and uncertainty (e.g. about own ability, $\delta_{\theta}$, introduced in section C.2 below) as the group pools resources and idiosyncratic risk. The accountability portion of the supervision component (designed to provide commitment to invest) is supposed to affect discount factor $\delta$, whereas the additional supervisory visits (provision of substantive advice) enhance productivity $(\theta)$.

Impact of a windfall. With perfect financial markets, an unrestricted windfall will have no effect on entry into enterprise and little effect on earnings because it does not change $\theta$, $\omega$ or $r$. The individual will immediately jump to a new steady state with higher level of savings $a$ and consumption $c$, and will slightly reduce investment $k$ and hours in enterprise $l^{E}$ because of greater wealth.

Suppose instead the windfall is granted in the form of in-kind transfers or restricted funding and there is some minimal "flypaper effect" such that capital stocks are "sticky" and cannot be divested immediately. This "restricted windfall" will force individuals to produce

assets would approach negative infinity as $t \rightarrow \infty$. In both of these cases, the transversality condition would be violated. While this condition $\delta(1+r)=1$ seems restrictive, we could argue that in reality, there will bounds for borrowing and savings. As long as there is lending and borrowing within some bounds at the rate $r$, our results would hold. We do not need $\delta(1+r)=1$ for our comparative analysis. 
above their efficient scale, $f_{k}^{E^{\prime}}(k, l, \theta)<r$. $c$ will increase as output increases in the enterprise. $l^{T}$ will decrease and $l^{E}$ could go either direction, depending on parameter values. Over time, if it is possible to shift capital to $a$, individuals will divest until the returns in enterprise drops back to $r$.

\section{C.2 Cash windfalls in imperfect financial markets}

\section{Credit constraint $a_{t} \geq 0$}

For simplicity, we consider an extreme credit constraint, $a_{t} \geq 0$. The intuition and comparative statics are similar for other less restrictive credit constraints. The credit constraint affects optimality conditions 1, which becomes:

$$
\frac{u_{c}^{\prime}\left(c_{t}, l_{t}\right)}{u_{c}^{\prime}\left(c_{t+1}, l_{t+1}\right)} \geq \delta(1+r) \quad \text { with equality if } a_{t+1}>0
$$

Initially wealthy entrepreneurs tend to operate at efficient scale, with marginal returns equal to $r$. The less wealthy, more impatient and higher ability do not have savings, will satisfy 7 with equality, and will invest below efficient scale with marginal returns are higher than $r$.

Credit constraints also change the steady state level of investments, returns to investments, and threshold $\theta^{*}$. Define $\rho=\frac{1-\delta}{\delta}$, where a high level of $\rho$ indicates impatience. Define $k^{* *}$ and $l^{E * *}$ such that $f_{k}^{\prime}\left(k^{* *}, l^{E * *}, \theta\right)=\rho$. For impatient individuals whose $\rho>r$, the steady state level of capital and hours in the enterprise would be $k^{* *}<k^{*}$ and $l^{E * *}$, and their returns to capital will be $\rho$. These individuals are investing below the efficient scale. For those whose $\rho<r$, the steady state level of returns will still be $r$ and investments will still be $k^{*}$ as before. To sum up, the steady state returns to capital will be $\max \{r, \rho\}$. For simplicity we will still refer to the threshold as $\theta^{*}$, while here $\theta^{*}=\theta^{*}(r, \underline{k}, \omega, \rho)$ and $\theta^{*}$ is increasing in $\rho$ whenever $\rho>r$. This means that with a credit constraint, more impatient individuals will find enterprise undesirable than in the benchmark case.

Not surprisingly, with a credit constraint, not all whose $\theta>\theta^{*}$ will immediately engage in enterprise. Specifically, if there is a credit constraint, $a_{t} \geq 0$, then compared to the benchmark case with no constraints at all then occupational choice and investment will vary by type and initial wealth in the following manner:

1. Low ABILITy individuals, $\theta<\theta^{*}$. A credit constraint will not change occupational choice, consumption or labor supply as they would not invest in the enterprise even if they are allowed to borrow. 
2. High ability And High wealth, $\theta \geq \theta^{*}$ And $a_{0} \geq k^{* *}$. A credit constraint will not change occupational choice. However, investment levels and returns will depend on time preferences:

(a) Patient types $(\rho<r)$ will invest $k^{*}$, with marginal returns $r$.

(b) Impatient types $(\rho>r)$ will invest $k^{* *}<k^{*}$, with marginal returns $\rho$.

3. High ability and Below steady state wealth $\left(\theta \geq \theta^{*}\right.$ And $\left.\underline{k} \leq a_{0} \leq k^{* *}\right)$. A credit constraint will reduce initial investment in enterprise only. They will start with an enterprise below efficient scale and over time will accumulate enough capital to reach the steady state level of investment.

4. High ability and Below minimum scale wealth $\left(\theta \geq \theta^{*}\right.$ And $\left.a_{0} \leq \underline{k}\right)$. A credit constraint will change initial occupational choice, but whether this effect is long-term or not depends on $a_{0}, \delta$ and abilities in each sector:

(a) if $a_{0}$ is close to $\underline{k}$ or $\omega$ is very high, and $\delta$ is close to one, the individual would be able to save in the initial periods and eventually accumulate enough wealth to invest in enterprise. In this case, the credit constraint only temporarily alters the individual's occupational choice. Individuals will not invest in enterprise until $a_{t+1}$ is above $\underline{k}$, after which they start investing in enterprise and reach the steady state level of investment over time.

(b) if $a_{0}$ is far below $\underline{k}$ or $\omega$ is very low, and $\delta$ is close to zero, the individual would remain in traditional labor forever. In this case, the credit constraint has a permanent effect on the individual's occupational choice.

Impact of a windfall. We first consider an unrestricted cash windfall. In cases 1 and 2(a), individuals are in their optimal steady state, and the windfall will increase consumption and savings and slightly reduce labor supplied, but will not affect entry into enterprise or earnings. In case 2(b), individuals will increase investments in enterprise temporarily above $k^{* *}$ and increase total earnings but reduce marginal returns to capital to a level below $\rho$, but not lower than $r$; over time they will reduce capital in the enterprise until capital returns in the enterprise rise up to $\rho$ again. Consumption will rise in the long run, but savings will be zero in the long run. In case 3 , the windfall will immediately increase their investments in enterprise and earnings, and they will continue to increase capital and earnings over time until they reach $k^{*}$. Likewise, in case 4 , individuals will start and sustain an enterprise if the windfall is enough to cover the capital requirement $\underline{k}$. For those with extremely low level 
of initial wealth $a_{0}<\underline{k}-M$, the windfall will not immediately affect their involvement in enterprises, but it does increase the chances of their engaging in enterprise in the long run. Whether they will eventually engage in the enterprise will again depend on their patience and productivity in traditional labor.

Next we consider a restricted windfall with some flypaper effect. In cases 1 and 2, individuals are in their optimal steady state and the results are the same as in the case of perfect financial markets: they will be forced to invest above efficient scale in the short run, earnings will increase, but returns will be low. In the long-run, they will divest and go back to the their steady state level of production, merely saving and consuming divested funds. In cases 3 and 4 , individuals are below steady state and the impact will be similar to the case of the unrestricted windfall.

\section{Savings constraint $a_{t} \leq 0$}

Now we consider the case of a savings constraint where individuals do not have any alternative means to invest other than enterprise. They are, however, still allowed to borrow at rate $r$. Condition 1 now becomes

$$
\frac{u_{c}^{\prime}\left(c_{t}, l_{t}\right)}{u_{c}^{\prime}\left(c_{t+1}, l_{t+1}\right)} \leq \delta(1+r) \quad \text { with equality if } a_{t+1}<0
$$

Savings constraints can lead to investment above the efficient scale. For those with debts $a_{t+1}<0$ (the impatient and poor ones), the first order conditions require their returns to capital to be the same as $r$; however, for those without debts $a_{t+1}=0$ (the patient and savings constrained ones), these conditions mean marginal returns are lower than $r$.

Among those who do invest in the enterprise, for the patient individuals whose $\rho<r$, the steady state level of capital and hours are $k^{* *}$ and $l^{E * *}$, and their returns will be $\rho$. Notice $k^{* *} / l^{E * *}>k^{*} / l^{E *}$. For those impatient ones whose $\rho>r$, steady state returns are still $r$ and investments are still $k^{*}$ as before. Thus the steady state returns to capital are $\min \{r, \rho\}$. Because individuals are still allowed to borrow, any individual with $\theta \geq \theta^{*}$ would invest in enterprise, though this $\theta^{*}$ is lower than in the benchmark and credit constraint cases for patient individuals whose $\rho<r .^{7}$ Thus, under a savings constraint, more people run an

\footnotetext{
${ }^{7}$ Savings constraints will lower the threshold level of $\theta^{*}$ for those whose $\rho<r$. This is because now we would need to define $\theta^{*}$ based on the new level of returns to capital $\min \{r, \rho\}$ instead of $r$. For simplicity of discussion, we will still refer to the threshold as $\theta^{*}$, while here $\theta^{*}=\theta^{*}(r, \underline{k}, \omega, \rho)$ and $\theta^{*}$ is increasing in $\rho$ whenever $\rho<r$. This means that with a credit constraint, more individuals will be engaging in enterprise than in the benchmark case.
} 
enterprise at any $t>0$, before and after everyone reaches their steady state. However, the average rate of returns among entrepreneurs will be lower than $r$.

Impact of a windfall. An unrestricted windfall will not change any individual's decision to engage in enterprise, since all those with $\theta \geq \theta^{*}$ will be already engage in enterprise at the outset. However, in the short run, since individuals cannot save, the windfall will increase consumption and capital stocks, and thus further reduce the marginal returns to capital in the enterprise below $\min \{r, \rho\}$. In the long run, however, capital and consumption will drop back to the steady state level and rate of returns will rise back to $\min \{r, \rho\}$.

A restricted cash transfer with a flypaper effect will immediately increase capital stocks and lower the rate of return while having no immediate impact on consumption. Over time, the individual will consume these transfers until consumption and capital stock falls back to the steady state level. The average impact on earnings will not be as high as under a credit constraint.

\section{Savings and credit constraints $a_{t}=0$}

Finally we consider the effect of a savings constraint on top of a credit constraint. For those who do invest in the enterprise, their rate of return will be $f_{k}^{E^{\prime}}\left(k, l^{E}, \theta\right)=\frac{1-\delta}{\delta}=\rho$. This means the less patient will be investing below the efficient scale while the more patient will be investing above the efficient scale. This also changes the threshold level $\theta^{*}$ for all individuals. We would need to define $\theta^{*}$ using $f_{k}^{E^{\prime}}\left(k, l^{E}, \theta\right)=\rho$ instead of $r$. For impatient ones whose $\rho>r, \theta^{*}$ would be higher than in the benchmark case; while for patient ones whose $r>\rho$, $\theta^{*}$ would be lower than in the benchmark case. This means, compared to the benchmark case, there will be more patient individuals and less impatient ones investing in enterprise. Individuals with $\theta<\theta^{*}$ (case 1 above) will be engaging in traditional labor only, as are those with high ability and below minimum scale wealth (case 4(a) and (b)).

Cash windfalls, restricted or unrestricted, will be invested in all cases. ${ }^{8}$ Those at or near their optimal steady state level of capital (including no enterprise) will have an average return below $\min \{r, \rho\}$, and those below their steady state will have average returns higher than this level.

\footnotetext{
${ }^{8}$ The sole exception is the very poor with initial wealth $a_{0}<\underline{k}-M$. They will no longer pass a point where they have incentives to save in order to accumulate $\underline{k}$. This is a moot point if $M>\underline{k}$.
} 


\section{C.3 Introducing uncertainty and imperfect insurance}

Next we consider the case of risky enterprise and risky traditional labor but a riskless financial alternative. It is possible to model risk in several ways. To incorporate uncertainty, we illustrate the case where the productivity measures $\theta_{t}$ and $\omega_{t}$ are uncertain and vary over time.

Specifically, we assume that realizations of ability are normally distributed around expected productivities $\bar{\theta}$ and $\bar{\omega}, \theta_{t} \sim N\left(\bar{\theta}, \delta_{\theta}\right)$ and $\omega_{t} \sim N\left(\bar{\omega}, \delta_{\omega}\right)$. Hours in enterprise and traditional labor are determined after the realization of $\theta_{t}$ and $\omega_{t}$. Investment decisions $k_{t}$ and $a_{t}$, however, are made in time $t-1$, before the realization of productivity $\theta_{t}$ and $\omega_{t}$. We can view the individual as having a stochastic income stream delivered by the stochastic wage from traditional labor. At the same time, the individual has the option of investing his asset in either the risky enterprise with expected return $\mathbb{E}_{t}\left(1+f_{k}^{E^{\prime}}\left(k_{t+1}, l_{t+1}^{E}, \theta\right)\right)$ or the riskless asset with return $1+r$.

The solution to the problem is characterized as time-paths of quantities $\left\{c_{t}, l_{t}^{E}, l_{t}^{T}, k_{t+1}, a_{t+1}\right\}_{t=0}^{\infty}$ that satisfy the following set of conditions for all time periods $t$ and for all states of the world at time $t$ :

$$
\begin{aligned}
\mathbb{E}_{t}\left[\frac{\delta u_{c}^{\prime}\left(c_{t+1}, l_{t+1}\right)}{u_{c}^{\prime}\left(c_{t}, l_{t}\right)}(1+r)\right] & =1 \\
-\frac{u_{l}^{\prime}\left(c_{t}, l_{t}\right)}{u_{c}^{\prime}\left(c_{t}, l_{t}\right)} & =f_{l}^{E^{\prime}}\left(k_{t}, l_{t}^{E}, \theta_{t}\right) \quad \text { if } l_{t}^{E}>0 \\
-\frac{u_{l}^{\prime}\left(c_{t}, l_{t}\right)}{u_{c}^{\prime}\left(c_{t}, l_{t}\right)} & =f_{l}^{T^{\prime}}\left(l_{t}^{T}, \omega_{t}\right) \quad \text { if } l_{t}^{T}>0 \\
\mathbb{E}_{t}\left[\frac{\delta u_{c}^{\prime}\left(c_{t+1}, l_{t+1}\right)}{u_{c}^{\prime}\left(c_{t}, l_{t}\right)}\left(1+f_{k}^{E}\left(k_{t+1}, l_{t+1}^{E}, \theta_{t}\right)\right)\right] & =1 \quad \text { if } k_{t+1}>0 \\
(1+r) a_{t}+k_{t}+f^{E}\left(k_{t}, l_{t}^{E}, \theta_{t}\right)+f^{T}\left(l_{t}^{T}, \omega_{t}\right) & =c_{t}+a_{t+1}+k_{t+1} \\
\lim _{j \rightarrow \infty} \mathbb{E}_{t} \beta^{j} u_{c}^{\prime}\left(c_{t+j}, l_{t+j}\right) a_{t+j} & =0
\end{aligned}
$$

given $k_{0}=0$ and $a_{0}>0$.

Following the asset pricing literature, we define $M_{t}=\frac{\delta u_{c}^{\prime}\left(c_{t+1}, l_{t+1}\right)}{u_{c}^{\prime}\left(c_{t}, l_{t}\right)}$ as the stochastic discount factor. Condition 9 and 12 imply that investment in the enterprise, if positive, must satisfy the usual asset pricing equation:

$$
\mathbb{E}_{t} f_{k}^{E^{\prime}}\left(k_{t+1}, l_{t+1}^{E}, \theta_{t}\right)-r=-(1+r) \operatorname{Cov}_{t}\left(f_{k}^{E^{\prime}}\left(k_{t+1}, l_{t+1}^{E}, \theta_{t}\right), M_{t+1}\right)
$$

Risk neutral individuals will invest until $\mathbb{E} f_{k}^{E^{\prime}}\left(k, l^{E}, \theta\right)=r$. As in the case without risk, we refer to the level of investment that corresponds to $\mathbb{E} f_{k}^{E^{\prime}}\left(k, l^{E}, \theta\right)=r$ as the efficient scale of 
investment.

For any risk averse individual, if $\theta_{t+1}$ and $\omega_{t+1}$ are positively correlated or uncorrelated, then $\operatorname{Cov}_{t}\left(f_{k}^{E^{\prime}}\left(k_{t+1}, l_{t+1}^{E}, \theta_{t}\right), M_{t+1}\right)<0$ and $\mathbb{E}_{t} f_{k}^{E^{\prime}}\left(k_{t+1}, l_{t+1}^{E}, \theta_{t}\right)>r$. This is saying that if the returns to enterprise and traditional labor are positively correlated, then the riskless asset will deliver higher expected utility than the risky enterprise, and the individual will invest below the efficient scale in the enterprise as long as he is risk averse. In this case, the more risk averse the individual is, the less he invests in risky enterprise, and the higher the returns to the enterprise. Similarly, the higher the variability of $\theta$ or $w$, the less the individual invests in risky enterprise,

If instead, $\theta_{t+1}$ and $\omega_{t+1}$ are negatively correlated, i.e. the returns to enterprise and traditional labor are negatively correlated, then the enterprise and traditional labor are a good hedge against each other. The individual will invest more in the enterprise, or even invest above the efficient scale. The returns to enterprise $\mathbb{E}_{t} f_{k}^{E^{\prime}}\left(k_{t+1}, l_{t+1}^{s E}, \theta_{t}\right)$ will be close to $r$, or even lower than $r$ if the variability of $\omega$ is high.

Here the optimal level of investment is a function of interest rate $r$, the mean and variance of productivity $\bar{\theta}, \delta_{\theta}, \bar{\omega}, \delta_{\omega}$, the correlation between $\theta$ and $\omega$, patience $\delta$ and the degree of risk aversion. The optimal choice of whether to invest in enterprise or not then depends on all these parameters, as well as the minimum scale of production $\underline{k}$.

Impact of a windfall. We ask the same question as before: Under what conditions will the cash windfall have a sustained effect on individuals' investment in enterprise and/or returns to investment in enterprise?

Even absent a credit constraint a windfall may induce some individuals to enter into enterprise, and change investment levels for those who do invest in enterprise, simply through the wealth effect. If utility displays constant absolute risk aversion (CARA) wealth would not have any effect on the optimal level of investment, and no effect on entry into enterprise. If, however, utility displays constant relative risk aversion (CRRA) then a windfall increases the level of wealth, which then increases the optimal level of investment in the risky enterprise.

Note that there will be individuals with either very low initial wealth, or very high risk aversion, who would not invest in the risky enterprise (because of $\underline{k}$ ) but would do so after receiving the cash windfall. Unless the amount of the windfall is very large (relative of the minimum scale $\underline{k}$ ) or the individual is very risk averse, we would not expect the windfall to have a large long-run average effect on investment across many individuals.

So long as both sectors are risky, for a windfall to result in high levels of investment and high returns, there must be some other form of imperfection on top of an environment with risk. Again, a credit constraint is a likely candidate in the setting described. This 
conclusion rests on the assumption that there are roughly similar levels of uncertainty in the two sectors. We turn to that assumption next.

Relative uncertainty. Intuitively, the relative volatility of traditional trade and enterprise matter for investments in enterprise. More importantly, the impact of their relative volatility depends on initial wealth, the degree of risk aversion, as well as the correlation between enterprise and traditional labor.

In general terms, if either enterprise or traditional labor is relatively safe (i.e. either $\sigma_{\theta}$ or $\sigma_{\omega}$ is low), then investment in enterprise $k$ falls as $\sigma_{\theta} / \sigma_{\omega}$ increases; and the more risk averse the individual is, the steeper the slope of the fall is. If $\sigma_{\theta}$ is low while $\sigma_{\omega}$ is high, the individual will very likely engage in the enterprise, as long as she is not bounded by a credit constraint. If $\sigma_{\theta}$ is high while $\sigma_{\omega}$ is low, the individual will likely not engage in the enterprise. In both cases, a windfall will have little impact on investments and earnings.

If, however, productivity in traditional labor and enterprise are both very volatile $\left(\sigma_{\theta}\right.$ and $\sigma_{\omega}$ both high), then the relationship between $k$ and $\sigma_{\theta} / \sigma_{\omega}$ would also depend on initial wealth $a_{0}$, the degree of risk aversion, as well as the correlation between $\theta$ and $\omega$. First, consider the case where traditional labor and enterprise are uncorrelated or positively correlated. Holding everything else constant, if an individual has very low (or negative) initial wealth, then given a highly volatile income stream from traditional labor, the safety asset would be much more appealing to her than the enterprise even if the enterprise is less volatile than traditional labor. In this case, the individual may not enter into enterprise even if she faces no credit constraint - she might fear that she would never be able to repay the debt with her earnings. The same happens if the individual is very risk averse - she would not enter the enterprise and instead use the safety asset to smooth consumption over time. In both of these cases, a large windfall might pull the individual out of these situations and allow her to invest in the enterprise. However, if the returns from traditional labor and enterprise are negatively correlated, then again $k$ increases as $\sigma_{\theta} / \sigma_{\omega}$ falls, and the individual will likely invest in the enterprise as long as she is not bounded by a credit constraint. In this case, a windfall will have a long term effect on those with high levels of risk aversion and low levels of initial wealth . Again, this is because a windfall increases wealth and lead the risk averse to invest more in risky assets - the enterprise. 


\section{C.4 Introducing time-inconsistency}

We introduce quasi-hyperbolic $(\beta, \delta)$ preferences to see what predictions they hold for investment and earnings. The problem becomes:

$$
\begin{array}{rl}
\max _{c_{t}>0, l_{t} \geq 0, k_{t+1} \geq 0, a_{t+1}} & u\left(c_{t}, l_{t}\right)+\beta \sum_{s=t+1}^{\infty} \delta^{s} u\left(c_{s}, l_{s}\right) \\
\text { s.t. } \quad c_{t}+a_{t+1}+k_{t+1}= & W_{t} \\
l_{t}= & l_{t}^{E}+l_{t}^{T} \leq 1 \\
W_{t} & \equiv\left(1+r_{t}\right) a_{t}+k_{t}+f^{E}\left(k_{t}, l_{t}^{E}, \theta\right)+f^{T}\left(l_{t}^{T}, \omega\right)
\end{array}
$$

We consider the case of a "naive" type, or "naif", who makes investment decisions under the false belief that future selves will act in the interest of the current self, and a "sophisticate" who knows exactly what her future selves' preferences will be.

\section{Perfect financial markets}

Optimal conditions 1 and 4 will now change into the general Euler equation for hyperbolic preferences:

$$
\frac{u_{c}^{\prime}\left(c_{t}, l_{t}\right)}{u_{c}^{\prime}\left(c_{t+1}^{P}, l_{t+1}\right)}=\left[\frac{\partial c_{t+1}}{\partial W_{t+1}} \beta \delta+\left(1-\frac{\partial c_{t+1}}{\partial W_{t+1}}\right) \delta\right] \cdot(1+r)
$$

and

$$
\frac{u_{c}^{\prime}\left(c_{t}, l_{t}\right)}{u_{c}^{\prime}\left(c_{t+1}^{P}, l_{t+1}\right)}=\left[\frac{\partial c_{t+1}}{\partial W_{t+1}} \beta \delta+\left(1-\frac{\partial c_{t+1}}{\partial W_{t+1}}\right) \delta\right] \cdot\left(1+f_{k}^{E^{\prime}}\left(k_{t+1}, l_{t+1}^{E}, \theta\right)\right) \quad \text { if } k_{t+1}>0
$$

These resemble the Euler equations 1 and 4 under exponential discounting, except that the discount factor $\delta$ is replaced by the effective discount factor $\frac{\partial c_{t+1}}{\partial W_{t+1}} \beta \delta+\left(1-\frac{\partial c_{t+1}}{\partial W_{t+1}}\right) \delta$, a weighted average of the short-run and long-run discount factors $\beta \delta$ and $\delta$ where the weights are the next period marginal propensity to consume out of total wealth. Here $W_{t}$ denotes total wealth at time $t . c_{t+1}^{P}$ denotes the individual's predicted future decision about $c_{t+1}$ at time $t$.

The differences between the naif and the sophisticate lie in the predicted consumption $c_{t+1}^{P}$ and the marginal propensity to consume $\frac{\partial c_{t+1}}{\partial W_{t+1}}$. Sophisticates are aware of the timeinconsistency problem and will correctly anticipate future consumption. For them, $c_{t+1}^{P}=$ $c_{t+1}$. Naifs, however, mistakenly believe that future selves will act as if their discount factor remains unchanged at all future dates. For them $c_{t+1}^{P}<c_{t+1}$. Time-inconsistency will affect both consumption and savings. 
Time-inconsistency should not affect the optimal use of a cash windfall. For those with $\theta \geq \theta^{*}$, they will still invest until the returns to capital are equal between the enterprise and alternative financial options, or $f_{k}^{E^{\prime}}\left(k, l^{E}, \theta\right)=r$. Note that consumption, hours and savings will all be different under time-inconsistency compared to our benchmark case without time-inconsistency. Thus threshold value of $\theta^{*}$ is different than in the benchmark case. However, the effect of a windfall will be similar to that in the benchmark case without time-inconsistency. This is because absent of any credit market imperfections, everyone will already be at their efficient scale.

\section{Time-inconsistency with credit constraints}

For a windfall to be invested and produce high average returns, some other constraint must be present. Similar to the case without time-inconsistency, credit constraints will suffice. To see this, we turn to the Euler equations again. Those who are credit constrained will put every additional dollar they get into consumption (not savings), because they are presentbiased. Therefore $\frac{\partial c_{t+1}}{\partial W_{t+1}}=1$ and the Euler equations become

$$
\frac{u_{c}^{\prime}\left(c_{t}, l_{t}\right)}{u_{c}^{\prime}\left(c_{t+1}^{P}, l_{t+1}\right)}=\beta \delta\left(1+f_{k}^{E^{\prime}}\left(k_{t+1}, l_{t+1}^{E}, \theta\right)\right) \quad \text { if } k_{t+1}>0
$$

for those who are bounded by the credit constraint, i.e. $a_{t+1}=0$.

With time inconsistency, all credit constrained individuals will invest less than if they were time-consistent. To see this, define $\tau$ such that $\frac{1}{1+\tau}=\beta \delta$, i.e. $\tau=\frac{1}{\beta \delta}-1$. Since the sophisticates can correctly anticipate their future consumptions, in their steady state $c_{t+1}^{P}=c_{t+1}=c_{t}$, and the marginal rate of return will be $f_{k}^{E^{\prime}}\left(k_{\text {sophisticate }}, l^{E}, \theta\right)=\tau$. Naifs will naively expect themselves to have more self-control tomorrow, and expect $c_{t+1}^{P}<c_{t}$. For them $\frac{u_{c}^{\prime}\left(c_{t}, l_{t}\right)}{u_{c}^{\prime}\left(c_{t+1}^{P}, l_{t+1}\right)}<1$ and $\rho<f_{k}^{E^{\prime}}\left(k_{\text {naive }}, l^{E}, \theta\right)<\tau$. Therefore, for those who are credit constrained $\left(a_{t+1}=0\right)$, their steady state level of investment satisfies $\rho<f_{k}^{E^{\prime}}\left(k_{n a i v e}, l^{E}, \theta\right)<\tau=$ $f_{k}^{E^{\prime}}\left(k_{\text {sophisticate }}, l^{E}, \theta\right)$. They also work less and consume a larger portion of their income.

Somewhat counter-intuitively, given the levels of $\beta$ and $\delta$, the sophisticates invest even less than the naifs. This is because the naifs believe (incorrectly) that they will consume less tomorrow and eventually grow to $k=k^{* *}$ just like a time-consistent type. Thus they think their average future marginal utility of consumption is low (i.e. high consumption) and therefore are willing to consume less than the sophisticates. In practice, however, we might expect $\beta$ and $\delta$ to be positively correlated, or sophisticates to have both higher $\beta$ and $\delta$ than naifs. In this case, sophisticates would invest more than naifs. 
Impact of a windfall. The impact of a cash windfall is similar to the case with timeconsistent preferences. Credit constraints (but not savings constraints) are needed in this simple model to expect investment and high returns. High investment and returns, moreover, will only be seen where people start below their steady state. The steady state levels of capital to which the time-inconsistent will move, however, are lower than the case without time inconsistency. Thus the average returns will be lower than the benchmark case, but still greater than $r$.

Recall, however, that in the time consistent case the average impact was expected to increase in patience (at least amongst those below their optimal steady state capital). With time inconsistency, holding patience constant, we expect the impacts to be larger among the more time-inconsistent. In practice, however, this comparative static will be difficult to identify, partly because $\beta$ and $\delta$ may be correlated and partly because they may be difficult to measure separately.

More importantly, restricted windfalls with a flypaper effect have the potential to increase investment levels to $k^{*}$, at least temporarily. Eventually as long as they can divert, both types will return to their steady state level of investment. However, if there is a commitment device, for example an in-kind transfer that cannot be diverted over time, then the sophisticates will more likely be the ones who apply for and use this in-kind transfer. Such a transfer will not only help some constrained individuals to enter into enterprise or get closer to their steady state level of investment, it will also change the steady state level of investment for the sophisticates from $k_{\text {sophisticate }}$ to $k^{* *}$. A naive type, on the other hand, would not want to tie their hands to such a transfer; they would prefer a transfer that can be diverted over time. Intuitively, time inconsistency makes the sophisticates act like a person with very low discount rate $\beta \delta$ every period, when in fact their real discount rate for the far future is $\delta$. So a windfall that also act as a commitment device could push them into a new equilibrium that it wouldn't do for someone who was time-consistent but merely impatient.

\section{Additional treatment effects analysis}

\section{D.1 Accounting for spillovers}

Here we provide more detail on the distance measures used to estimate the ITT via the OLS regression in equation ??. For each town, we calculate the exposure to spillovers from all treatment towns within $k$ kilometers of the town, via the following equation:

$$
D_{j}^{T}=\sum_{j: \delta_{j, j^{*}} \leq k, j \neq j^{*}, T_{j}=1} 1-\beta \frac{\delta_{j, j^{*}}}{k}
$$


where $\delta_{j, j^{*}}$ is the road distance between town $j$ and town $j^{*}$, and $T_{j}$ is an indicator equal to 1 if town $j$ is assigned to treatment. $\beta$ can take values in $[0,1]$. When $\beta=0, D_{j}^{T}$ is simply a count of treatment villages within a $k$ kilometer radius. This is the approach taken by Miguel and Kremer (2004). When $\beta=1, D_{j}^{T}$ is a sum of one minus the distance to each village, normalized by $k$, so that $1-\frac{\delta_{j, j^{*}}}{k}$ is close to 0 for far away villages and close to 1 for nearby villages. We choose $\beta=0.5$ and $k=4$, but our results are generally the same for any $\beta$ and $2<k<8$.

Equation ?? also controls for a weighted distance to all evaluation villages. We use a simulated rather than actual measure. Specifically, we simulate 100 random assignments of treatment to villages, and construct a $D_{j}^{\hat{T}}$ for each random assignment, $l$. We take an average over all 100 random assignments to obtain an estimate of the expected exposure to treatment spillovers for town $j$. More specifically,

$$
D_{j}^{A}=\frac{1}{100} \sum_{l=1}^{100}\left(D_{i}^{\hat{T}^{l}}=\sum_{j: \delta_{j, j^{*}} \leq k, j \neq j^{*}, \hat{T}_{j}^{l}=1} 1-\beta \frac{\delta_{j, j^{*}}}{k}\right)
$$

where $\hat{T}_{j}^{l}$ is equal to 1 if town $j$ is assigned to treatment in simulated assignment $l$. Using an actual distance measure provides broadly similar results, since it and $D_{j}^{A}$ are nearly collinear.

Note that the majority of tertiary roads in Uganda have not been mapped. Therefore, we used high-resolution satellite imagery in the OpenStreetMap platform to trace all tertiary roads and footpaths connecting villages. We then exported this road network to ArcGIS 10.0 and used the Origin-Destination Matrix tool in the Network Analyst extension to calculate road network distances.

\section{D.2 Robustness and sensitivity analysis}

Two concerns are potential bias arising from baseline imbalance and systematic attrition from unfound migrants. Table 7 tests the sensitivity of our Phase 1 impacts. Column 1 reports the ITT from Table 3 for major outcomes. Results are robust to exclusions of the distance measures that account for spillovers (Column 2), for removing baseline covariates (Column 3), and (where we have comparable baseline data) to a differences-in-differences ITT estimate controlling for other baseline covariates (Column 4). In general, the impacts are similar.

We also bound treatment effects for attrition bias. We consider an extreme bound, one that imputes the 10th percentile of treatment group outcomes for unfound treatment members and the 90th percentile for unfound controls (Column 6). Results are robust to 


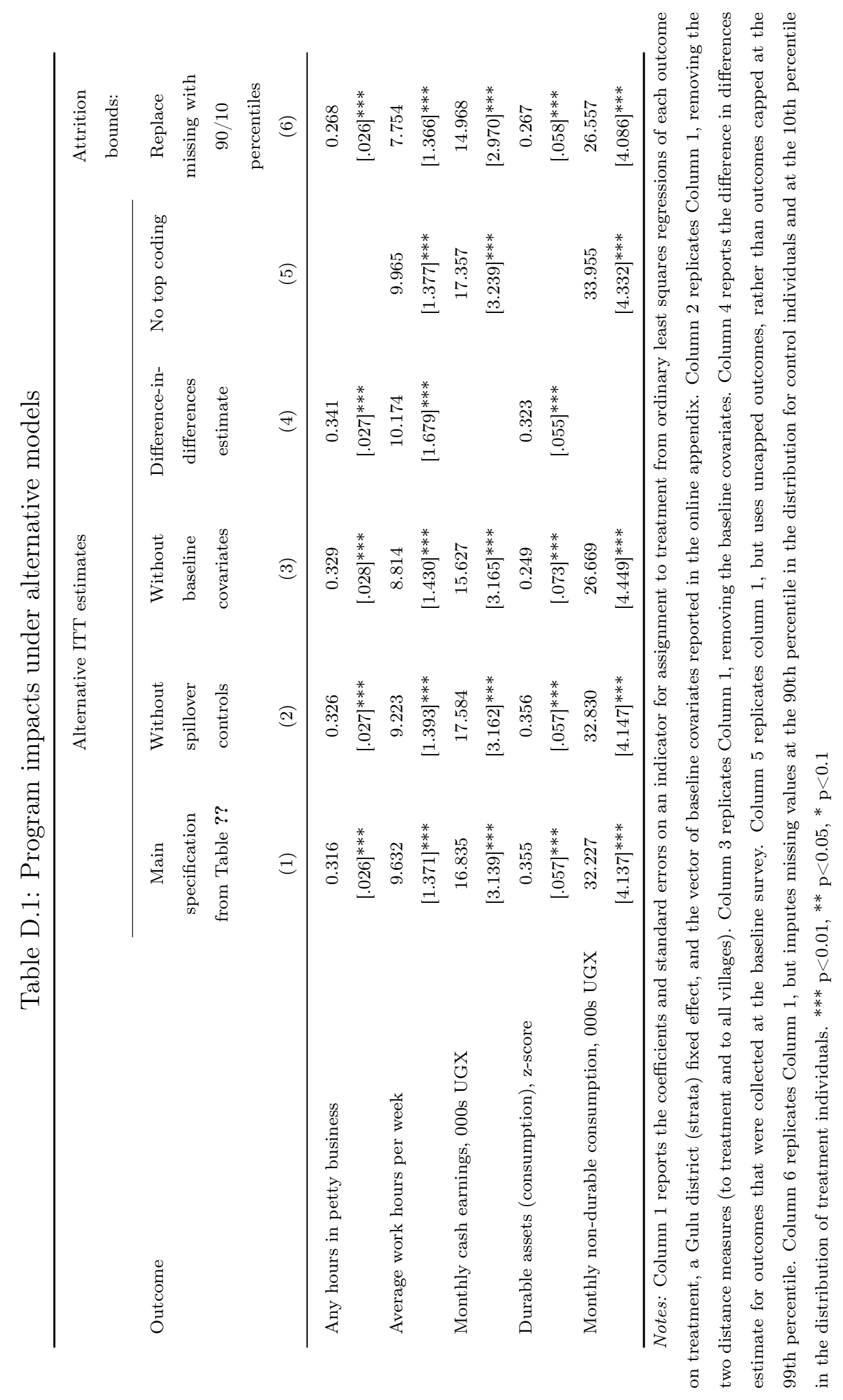

xxvii 
this bounding scenario.

\section{D.3 Other economic impacts of WINGS program}

Table D.2 reports treatment effects for additional economic outcomes. 
Table D.2: Economic impacts of WINGS program and group formation

\begin{tabular}{|c|c|c|c|c|}
\hline \multirow[b]{2}{*}{ Outcome } & \multirow[b]{2}{*}{$\begin{array}{c}\text { Control } \\
\text { mean } \\
(1)\end{array}$} & \multicolumn{3}{|c|}{ ITT estimates, 16 mo. after grants $(\mathrm{n}=1,734)$} \\
\hline & & $\begin{array}{l}\text { No group } \\
\text { training } \\
\quad(2)\end{array}$ & $\begin{array}{c}\text { Group } \\
\text { training } \\
(3)\end{array}$ & $\begin{array}{c}\text { Difference } \\
\qquad(4)\end{array}$ \\
\hline Non-durable consumption, 000s of UGX & 32.63 & $\begin{array}{c}10.62 \\
{[1.681]^{* * *}}\end{array}$ & $\begin{array}{c}10.57 \\
{[1.637]^{* * *}}\end{array}$ & $\begin{array}{c}-0.04 \\
{[1.934]}\end{array}$ \\
\hline \multicolumn{5}{|l|}{ Business practices: } \\
\hline \# of businesses tried to start since baseline & 0.64 & $\begin{array}{c}1.193 \\
{[.067]^{* * *}}\end{array}$ & $\begin{array}{c}1.300 \\
{[.066]^{* * *}}\end{array}$ & $\begin{array}{l}0.106 \\
{[.077]}\end{array}$ \\
\hline \# of these businesses still operating & 0.36 & $\begin{array}{c}0.578 \\
{[.054]^{* * *}}\end{array}$ & $\begin{array}{c}0.622 \\
{[.054]^{* * *}}\end{array}$ & $\begin{array}{l}0.044 \\
{[.064]}\end{array}$ \\
\hline Maintains business records & 0.105 & $\begin{array}{c}0.395 \\
{[.035]^{* * *}}\end{array}$ & $\begin{array}{c}0.449 \\
{[.034]^{* * *}}\end{array}$ & $\begin{array}{l}0.054 \\
{[.043]}\end{array}$ \\
\hline \multicolumn{5}{|l|}{ Access to credit: } \\
\hline Could get a loan of 15,000 UGX in next month & 0.63 & $\begin{array}{c}0.093 \\
{[.043]^{* *}}\end{array}$ & $\begin{array}{c}0.102 \\
{[.046]^{* *}}\end{array}$ & $\begin{array}{l}0.009 \\
{[.053]}\end{array}$ \\
\hline \# villagers can get 50,000 UGX loan from & 1.08 & $\begin{array}{c}0.293 \\
{[.165]^{*}}\end{array}$ & $\begin{array}{c}0.364 \\
{[.126]^{* * *}}\end{array}$ & $\begin{array}{l}0.071 \\
{[.170]}\end{array}$ \\
\hline \# of people outside village for 50,000 UGX loan & 0.64 & $\begin{array}{c}0.157 \\
{[.084]^{*}}\end{array}$ & $\begin{array}{c}0.270 \\
{[.105]^{* *}}\end{array}$ & $\begin{array}{l}0.113 \\
{[.117]}\end{array}$ \\
\hline \multicolumn{5}{|l|}{ Livestock: } \\
\hline Number of cattle and oxen & 0.167 & $\begin{array}{c}0.275 \\
{[.068]^{* * *}}\end{array}$ & $\begin{array}{c}0.241 \\
{[.059]^{* * *}}\end{array}$ & $\begin{array}{l}-0.034 \\
{[.079]}\end{array}$ \\
\hline Number of fowl & 6.007 & $\begin{array}{c}1.988 \\
{[.515]^{* * *}}\end{array}$ & $\begin{array}{c}3.370 \\
{[.626]^{* * *}}\end{array}$ & $\begin{array}{c}1.382 \\
{[.677]^{* *}}\end{array}$ \\
\hline Number of donkeys, goats, sheep and pigs & 1.239 & $\begin{array}{c}1.792 \\
{[.182]^{* * *}}\end{array}$ & $\begin{array}{c}1.398 \\
{[.216]^{* * *}}\end{array}$ & $\begin{array}{c}-0.394 \\
{[.245]}\end{array}$ \\
\hline \multicolumn{5}{|l|}{ Income risk: } \\
\hline \multirow[t]{2}{*}{$\begin{array}{l}\text { Highest-lowest projected income next year, 000s } \\
\text { UGX }\end{array}$} & 132.286 & 85.547 & 99.912 & 14.365 \\
\hline & & {$[17.612]^{* * *}$} & {$[17.308]^{* * *}$} & {$[22.563]$} \\
\hline Highest projected income & 243.634 & $\begin{array}{c}172.992 \\
{[24.157]^{* * *}}\end{array}$ & $\begin{array}{c}183.140 \\
{[27.672]^{* * *}}\end{array}$ & $\begin{array}{c}10.148 \\
{[33.473]}\end{array}$ \\
\hline Lowest projected income & 111.349 & $\begin{array}{c}87.445 \\
{[11.775]^{* * *}}\end{array}$ & $\begin{array}{c}83.228 \\
{[14.446]^{* * *}}\end{array}$ & $\begin{array}{c}-4.217 \\
{[16.606]}\end{array}$ \\
\hline \multicolumn{5}{|l|}{ Leisure: } \\
\hline Daily sleep time & 9.602 & $\begin{array}{l}-0.067 \\
{[.074]}\end{array}$ & $\begin{array}{l}-0.023 \\
{[.071]}\end{array}$ & $\begin{array}{l}0.044 \\
{[.086]}\end{array}$ \\
\hline Has less leisure time than last year & 0.394 & $\begin{array}{l}0.019 \\
{[.036]}\end{array}$ & $\begin{array}{l}0.019 \\
{[.038]}\end{array}$ & $\begin{array}{l}0.000 \\
{[.041]}\end{array}$ \\
\hline
\end{tabular}

Notes: All variables denominated in UGX and hours were top-censored at the 99th percentile to contain outliers. Columns 2 and 3 report the coefficients and standard errors on indicator for assignment to Phase 1 without and with the group dynamics component in an OLS regression of each outcome on treatment indicators, a Gulu district (strata) fixed effect, and baseline covariates. Column 4 reports the difference between the two treatment groups. Standard errors are robust and clustered at the village level. ${ }^{* * *} \mathrm{p}<0.01,{ }^{* *} \mathrm{p}<0.05,{ }^{*} \mathrm{p}<0.1$ 


\section{D.4 Expanded non-economic treatment effects}

Table D.3 reports the individual components of the outcome indexes listed in Table ??.

Table D.3: Expanded non-economic outcome indexes

\begin{tabular}{|c|c|c|c|c|}
\hline \multirow{3}{*}{ Covariate } & \multirow{3}{*}{$\begin{array}{c}\text { No } \\
\text { group } \\
\text { training }\end{array}$} & \multicolumn{3}{|c|}{ ITT estimates, 16 months after grants } \\
\hline & & $\underset{\text { training }}{\text { Group }}$ & Difference & $\begin{array}{l}\text { Assigned } \\
\text { to any } \\
\text { follow- } \\
\text { up } \\
(\mathrm{n}=904)\end{array}$ \\
\hline & & (2) & (3) & (4) \\
\hline \multirow[t]{2}{*}{ Health index, z-score } & 0.002 & 0.020 & -0.013 & -0.033 \\
\hline & & {$[.070]$} & {$[.069]$} & {$[.085]$} \\
\hline \multirow[t]{2}{*}{ Difficulty doing daily activities (0-9) } & 0.867 & -0.056 & 0.122 & 0.178 \\
\hline & & {$[.091]$} & [.117] & {$[.127]$} \\
\hline \multirow[t]{2}{*}{ Self-rating of health (1-10) } & 5.494 & 0.259 & 0.294 & 0.035 \\
\hline & & {$[.175]$} & {$[.141]^{* *}$} & {$[.180]$} \\
\hline \multirow[t]{2}{*}{ \# sick days last month } & 3.169 & 0.578 & 0.445 & -0.133 \\
\hline & & {$[.362]$} & {$[.386]$} & {$[.456]$} \\
\hline \multirow[t]{2}{*}{ Quality of family relationships, z-score } & 0.018 & 0.034 & 0.011 & -0.023 \\
\hline & & {$[.057]$} & {$[.052]$} & {$[.067]$} \\
\hline \multirow[t]{2}{*}{ Talk with $\mathrm{HH}$ about thoughts and troubles? $(0-3)$} & 2.195 & 0.078 & -0.006 & -0.084 \\
\hline & & {$[.058]$} & {$[.050]$} & {$[.067]$} \\
\hline \multirow[t]{2}{*}{ Receive practical help from $\mathrm{HH}$ ? (0-3) } & 2.384 & 0.091 & 0.045 & -0.046 \\
\hline & & {$[.048]^{*}$} & {$[.050]$} & {$[.057]$} \\
\hline \multirow[t]{2}{*}{ Have quarrels with $\mathrm{HH}$ members? $(0-3)$} & 2.591 & -0.101 & -0.020 & 0.081 \\
\hline & & {$[.049]^{* *}$} & {$[.047]$} & {$[.053]$} \\
\hline \multirow[t]{2}{*}{ Social support received, z-score } & -0.084 & 0.195 & 0.159 & -0.037 \\
\hline & & {$[.069]^{* * *}$} & {$[.063]^{* *}$} & {$[.081]$} \\
\hline \multirow[t]{2}{*}{ Someone who listened to your thoughts and feelings? $(0-3)$} & 1.062 & 0.112 & 0.051 & -0.062 \\
\hline & & {$[.062]^{*}$} & {$[.055]$} & {$[.068]$} \\
\hline \multirow[t]{2}{*}{ Someone who sat with you when you were sad or lonely? (0-3) } & 0.903 & 0.176 & 0.129 & -0.047 \\
\hline & & {$[.063]^{* * *}$} & {$[.065]^{* *}$} & {$[.074]$} \\
\hline \multirow[t]{2}{*}{ Someone who helped you get your mind off of things? $(0-3)$} & 0.403 & 0.109 & 0.083 & -0.025 \\
\hline & & {$[.057]^{*}$} & {$[.051]$} & {$[.063]$} \\
\hline \multirow[t]{2}{*}{ Someone who assisted you in making plans for the future? $(0-3)$} & 0.735 & 0.225 & 0.176 & -0.049 \\
\hline & & {$[.051]^{* * *}$} & {$[.061]^{* * *}$} & {$[.068]$} \\
\hline \multirow[t]{2}{*}{ You turn to friends or neighbors for advice? $(0-3)$} & 1.903 & 0.015 & -0.033 & -0.048 \\
\hline & & {$[.049]$} & [.051] & {$[.052]$} \\
\hline \multirow[t]{2}{*}{ Receive practical help from friends and neighbors? $(0-3)$} & 1.546 & 0.091 & 0.128 & 0.037 \\
\hline & & {$[.070]$} & {$[.059]^{* *}$} & {$[.069]$} \\
\hline \multirow[t]{2}{*}{ Receive material help from your friends or neighbors? (0-3) } & 0.701 & 0.057 & 0.108 & 0.051 \\
\hline & & {$[.063]$} & {$[.062]^{*}$} & {$[.074]$} \\
\hline
\end{tabular}




\begin{tabular}{|c|c|c|c|c|}
\hline \multirow{3}{*}{ Covariate } & \multirow{3}{*}{$\begin{array}{c}\underset{\text { No }}{\text { Noup }} \\
\text { training } \\
(1)\end{array}$} & \multicolumn{3}{|c|}{ ITT estimates, 16 months after grants } \\
\hline & & $\begin{array}{l}\text { Group } \\
\text { training }\end{array}$ & Difference & $\begin{array}{c}\text { Assigned } \\
\text { to any } \\
\text { follow- } \\
\text { up } \\
(\mathrm{n}=904)\end{array}$ \\
\hline & & $(2)$ & (3) & (4) \\
\hline \multirow[t]{2}{*}{ Community participation, z-score } & -0.086 & 0.159 & 0.345 & 0.187 \\
\hline & & {$[.055]^{* * *}$} & {$[.062]^{* * *}$} & {$[.070]^{* * *}$} \\
\hline \multirow[t]{2}{*}{ Community mobilizer } & 0.163 & 0.019 & 0.086 & 0.067 \\
\hline & & {$[.023]$} & {$[.027]^{* * *}$} & {$[.030]^{* *}$} \\
\hline \multirow[t]{2}{*}{ Participated in local election } & 0.542 & 0.060 & 0.050 & -0.010 \\
\hline & & {$[.039]$} & {$[.029]^{*}$} & {$[.038]$} \\
\hline \multirow[t]{2}{*}{ Given opinion at community meeting } & 0.279 & 0.079 & 0.185 & 0.106 \\
\hline & & {$[.026]^{* * *}$} & {$[.023]^{* * *}$} & {$[.029]^{* * *}$} \\
\hline \multirow[t]{2}{*}{ Is a community leader } & 0.157 & 0.003 & 0.092 & 0.089 \\
\hline & & {$[.023]$} & {$[.027]^{* * *}$} & {$[.030]^{* * *}$} \\
\hline \multirow[t]{2}{*}{ Would become leader if nominated } & 0.351 & 0.069 & 0.049 & -0.020 \\
\hline & & {$[.029]^{* *}$} & {$[.028]^{*}$} & {$[.033]$} \\
\hline \multirow[t]{2}{*}{ Community hostility index, z-score } & -0.070 & 0.164 & -0.018 & -0.182 \\
\hline & & {$[.073]^{* *}$} & {$[.050]$} & {$[.076]^{* *}$} \\
\hline \multirow[t]{2}{*}{ Conflict with neighbors } & 2.837 & -0.112 & -0.000 & 0.112 \\
\hline & & {$[.043]^{* *}$} & {$[.034]$} & {$[.045]^{* *}$} \\
\hline \multirow[t]{2}{*}{ Community member say hurtful things } & 2.794 & -0.103 & 0.001 & 0.104 \\
\hline & & {$[.042]^{* *}$} & {$[.029]$} & {$[.043]^{* *}$} \\
\hline \multirow[t]{2}{*}{ Community is physically aggressive } & 2.849 & -0.032 & -0.002 & 0.029 \\
\hline & & {$[.035]$} & {$[.027]$} & {$[.037]$} \\
\hline \multirow[t]{2}{*}{ Community insults your children } & 2.819 & -0.063 & 0.033 & 0.096 \\
\hline & & {$[.039]$} & {$[.030]$} & {$[.043]^{* *}$} \\
\hline \multirow[t]{2}{*}{ Autonomy/influence in purchases, z-score } & -0.026 & 0.082 & 0.089 & 0.007 \\
\hline & & {$[.059]$} & {$[.062]$} & {$[.075]$} \\
\hline \multirow[t]{2}{*}{ Can decide how to spend own pocket money $(0-3)$} & 2.028 & 0.069 & 0.066 & -0.003 \\
\hline & & {$[.080]$} & {$[.078]$} & {$[.096]$} \\
\hline \multirow[t]{2}{*}{ Can use earnings to buy clothes without permission (0-3) } & 1.346 & 0.007 & -0.091 & -0.099 \\
\hline & & {$[.071]$} & {$[.090]$} & {$[.095]$} \\
\hline \multirow[t]{2}{*}{ Have a say in purchase of large assets in household (0-3) } & 2.459 & 0.091 & 0.163 & 0.072 \\
\hline & & {$[.050]^{*}$} & {$[.047]^{* * *}$} & {$[.052]$} \\
\hline \multicolumn{5}{|l|}{ Women with partners at endline $(n=961)$ : } \\
\hline \multirow[t]{2}{*}{ Physical and emotional abuse, z-score } & -0.030 & 0.066 & -0.046 & -0.113 \\
\hline & & {$[.079]$} & {$[.078]$} & {$[.088]$} \\
\hline \multirow[t]{2}{*}{ Threatened Harm (0-3) } & 0.217 & 0.085 & -0.009 & -0.095 \\
\hline & & {$[.046]^{*}$} & {$[.050]$} & {$[.055]^{*}$} \\
\hline Humiliated in front of others $(0-3)$ & 0.096 & -0.049 & -0.039 & 0.010 \\
\hline
\end{tabular}




\begin{tabular}{|c|c|c|c|c|}
\hline \multirow{3}{*}{ Covariate } & \multirow{3}{*}{$\begin{array}{c}\text { No } \\
\text { training } \\
(1)\end{array}$} & \multicolumn{3}{|c|}{ ITT estimates, 16 months after grants } \\
\hline & & $\begin{array}{l}\text { Group } \\
\text { training }\end{array}$ & Difference & $\begin{array}{c}\text { Assigned } \\
\text { to any } \\
\text { follow- } \\
\text { up } \\
(\mathrm{n}=904)\end{array}$ \\
\hline & & $(2)$ & (3) & $(4)$ \\
\hline & & {$[.028]^{*}$} & {$[.025]$} & {$[.029]$} \\
\hline \multirow[t]{2}{*}{ Beaten (0-3) } & 0.112 & 0.046 & -0.027 & -0.073 \\
\hline & & {$[.034]$} & {$[.037]$} & {$[.037]^{* *}$} \\
\hline \multirow[t]{2}{*}{ Kicked or hit $(0-3)$} & 0.151 & 0.063 & -0.005 & -0.068 \\
\hline & & {$[.041]$} & {$[.043]$} & {$[.048]$} \\
\hline \multirow[t]{2}{*}{ Cannot refuse sex $(0-3)$} & 1.545 & -0.011 & 0.024 & 0.035 \\
\hline & & {$[.088]$} & {$[.099]$} & {$[.092]$} \\
\hline \multirow[t]{2}{*}{ Degree of partner control, z-score } & -0.110 & 0.170 & 0.129 & -0.041 \\
\hline & & {$[.082]^{* *}$} & {$[.079]$} & {$[.086]$} \\
\hline \multirow[t]{2}{*}{ Tries to limit your contact outside the home $(0-3)$} & 0.246 & 0.125 & 0.062 & -0.063 \\
\hline & & {$[.063]^{*}$} & {$[.055]$} & {$[.068]$} \\
\hline \multirow[t]{2}{*}{ Requires permission to transact in market $(0-3)$} & 2.328 & 0.042 & 0.081 & 0.038 \\
\hline & & {$[.091]$} & {$[.085]$} & {$[.103]$} \\
\hline \multirow[t]{2}{*}{ Refused you money for household needs $(0-3)$} & 0.591 & -0.087 & -0.036 & 0.051 \\
\hline & & {$[.076]$} & {$[.078]$} & {$[.094]$} \\
\hline \multirow[t]{2}{*}{ Must give you earnings to partner (0-3) } & 0.606 & 0.312 & 0.215 & -0.097 \\
\hline & & {$[.096]^{* * *}$} & {$[.094]^{* *}$} & {$[.108]$} \\
\hline \multirow[t]{2}{*}{ Partner takes your money against will $(0-3)$} & 0.121 & 0.040 & 0.075 & 0.035 \\
\hline & & {$[.038]$} & {$[.046]$} & {$[.053]$} \\
\hline \multirow[t]{2}{*}{ Partner accuses you of being unfaithful (0-3) } & 0.083 & -0.009 & -0.057 & -0.048 \\
\hline & & {$[.038]$} & {$[.031]^{*}$} & {$[.037]$} \\
\hline \multirow[t]{2}{*}{ Relationship quality, z-score } & -0.086 & 0.180 & 0.201 & 0.021 \\
\hline & & {$[.085]^{* *}$} & {$[.111]^{*}$} & {$[.119]$} \\
\hline \multirow[t]{2}{*}{ Self-rating of relationship health, z-score } & 0.063 & 0.139 & 0.114 & -0.025 \\
\hline & & {$[.077]^{*}$} & {$[.088]$} & {$[.094]$} \\
\hline \multirow[t]{2}{*}{ Feels partner treats you well, z-score } & -0.082 & 0.070 & 0.162 & 0.092 \\
\hline & & {$[.074]$} & {$[.096]^{*}$} & {$[.102]$} \\
\hline \multirow[t]{2}{*}{ You feel free to express your opinion, z-score } & -0.153 & 0.157 & 0.137 & -0.019 \\
\hline & & {$[.094]^{*}$} & {$[.106]$} & {$[.116]$} \\
\hline
\end{tabular}

\section{D.5 Spillovers}

\section{Within-village spillovers}

We analyze within-village spillovers to non-participants in Phase 1 treatment villages. To do so we estimate equation ?? for (a) community-level variables (such as prices), and (ii) 
outcomes for non-participant households in both treatment and control villages. The coefficient on the treatment indicator estimates within-village spillovers, which are reported in Table D.4. We examine impacts on households that were and were not traders at baseline.

Table D.4: Within-village spillovers of WINGS program

\begin{tabular}{|c|c|c|c|c|}
\hline \multirow[b]{2}{*}{ Outcome } & \multicolumn{2}{|c|}{ Traders $(\mathrm{n}=885)$} & \multicolumn{2}{|c|}{ Non-traders $(\mathrm{n}=1,933)$} \\
\hline & $\begin{array}{c}\text { Mean, control } \\
\text { villages } \\
(1)\end{array}$ & $\begin{array}{c}\text { Treatment } \\
\text { village } \\
(2)\end{array}$ & $\begin{array}{c}\text { Mean, control } \\
\text { villages } \\
\text { (3) }\end{array}$ & $\begin{array}{c}\text { Treatment } \\
\text { village } \\
(4)\end{array}$ \\
\hline \multicolumn{5}{|l|}{ Occupational choice: } \\
\hline Positive hours in petty trading & 0.280 & $\begin{array}{c}-.078 \\
{[.031]^{* *}}\end{array}$ & 0.065 & $\begin{array}{c}-.001 \\
{[.01]}\end{array}$ \\
\hline Average work hours per week & 31.836 & $\begin{array}{l}-2.305 \\
{[1.55]}\end{array}$ & 23.171 & $\begin{array}{c}.054 \\
{[.723]}\end{array}$ \\
\hline Agricultural & 21.376 & $\begin{array}{l}-1.911 \\
{[1.205]}\end{array}$ & 17.517 & $\begin{array}{c}.727 \\
{[.564]}\end{array}$ \\
\hline Non-agricultural & 10.461 & $\begin{array}{c}-.394 \\
{[1.041]}\end{array}$ & 5.655 & $\begin{array}{l}-.673 \\
{[.424]}\end{array}$ \\
\hline \multicolumn{5}{|l|}{ Income: } \\
\hline Index of income measures, z-score & 0.560 & $\begin{array}{c}-.148 \\
{[.087]^{*}}\end{array}$ & -0.020 & $\begin{array}{c}-.02 \\
{[.037]}\end{array}$ \\
\hline Monthly cash earnings, 000s UGX & 21.984 & $\begin{array}{c}-4.435 \\
{[2.601]^{*}}\end{array}$ & 10.483 & $\begin{array}{l}.481 \\
{[.86]}\end{array}$ \\
\hline Durable assets (consumption), z-score & 0.599 & $\begin{array}{c}-.166 \\
{[.089]^{*}}\end{array}$ & 0.076 & $\begin{array}{l}-.031 \\
{[.041]}\end{array}$ \\
\hline Non-durable consumption, 000s UGX & 177.071 & $\begin{array}{l}-3.358 \\
{[8.442]}\end{array}$ & 138.526 & $\begin{array}{l}-2.094 \\
{[4.124]}\end{array}$ \\
\hline \multicolumn{5}{|l|}{ Prices (village-level, $n=120$ ): } \\
\hline Imported goods & 0.036 & $\begin{array}{l}-.089 \\
{[.149]}\end{array}$ & & \\
\hline Exported (produced) goods & 0.048 & $\begin{array}{l}-.065 \\
{[.167]}\end{array}$ & & \\
\hline
\end{tabular}

Notes: See notes to Table ??. ${ }^{* * *} \mathrm{p}<0.01,{ }^{* *} \mathrm{p}<0.05,{ }^{*} \mathrm{p}<0.1$

In general, spillovers to non-participants were modest. We find no evidence of large or statistically significant spillovers to non-trading households. The effect on incomes is roughly zero on average. Prices of imported and produced/exported goods both fell a slight amount (.09 and .07 standard deviations, not statistically significant), potentially because increased trade decreased the market power of existing traders and brought prices closer to the competitive equilibrium. Thus the effect on real incomes was somewhat ambiguous (we do not have individual production data). 
We do, however, see an occupational shift among pre-existing traders in the treatment villages. They were 8 percentage points less likely to be engaged in petty trading but only had one fewer work hour per week than before. Their non-agricultural hours of work were almost unchanged, as they switch to casual labor and other work. Yet preexisting traders saw no significant decrease in incomes as a result.

\section{Cross-village spillovers}

Columns (2) and (7) in Table D.5 capture spillover across villages. Overall, we find no evidence of large cross-village spillovers (for traders, there is a statistically significant increase in hours worked and income, but the left bound of the $95 \%$ confidence interval is always very close to zero).

\section{D.6 Heterogeneity in impacts of supervision}

Our theory and the program design suggests that follow-up should have the greatest impact on the most present-biased or least autonomous individuals. To test this, we generate a measure of pre-program future orientation using both incentivized games and self-reported survey questions and interact it with treatment in Table D.6. ${ }^{9}$ We also use a composite measure of three self-reported financial autonomy questions at baseline (described further below) and interact this with treatment as well.

The future orientation measure generally has the expected sign (i.e. more investment and earnings) though the autonomy measure does not. These are difficult traits to measure and so the size and significance may reflect measurement error, but nonetheless we do not see strong evidence of present bias impeding investment. Likewise, the interactions with treatment are in the expected direction, but they are not statistically significant. The coefficients on treatment-which represents the effect of treatment on the present-biased and less autonomous-are now larger and more statistically significant than before, in accordance with the prediction. Without significant interactions, however, this is no more than weak evidence for a heterogeneous effect.

\footnotetext{
${ }^{9}$ Our measure of future orientation is a weighted average of eight baseline survey questions on self-reported patience and impulsiveness and indicators for play within incentivized games, where respondents were offered choices between payment of small sums now versus in two weeks, and in two versus four weeks. The indicators include ones for choosing future versus present rewards, an indicator for future bias (less likely to choose the future in the two versus four weeks choice) and for present bias (more likely to choose the future in the two versus four weeks choice). To generate weights, we regress the endline income index on all time preference measures for the control group alone, and use the estimated coefficients to generate a predicted patience level for the full sample. We omit observations where we do not have a time preference measure.
} 


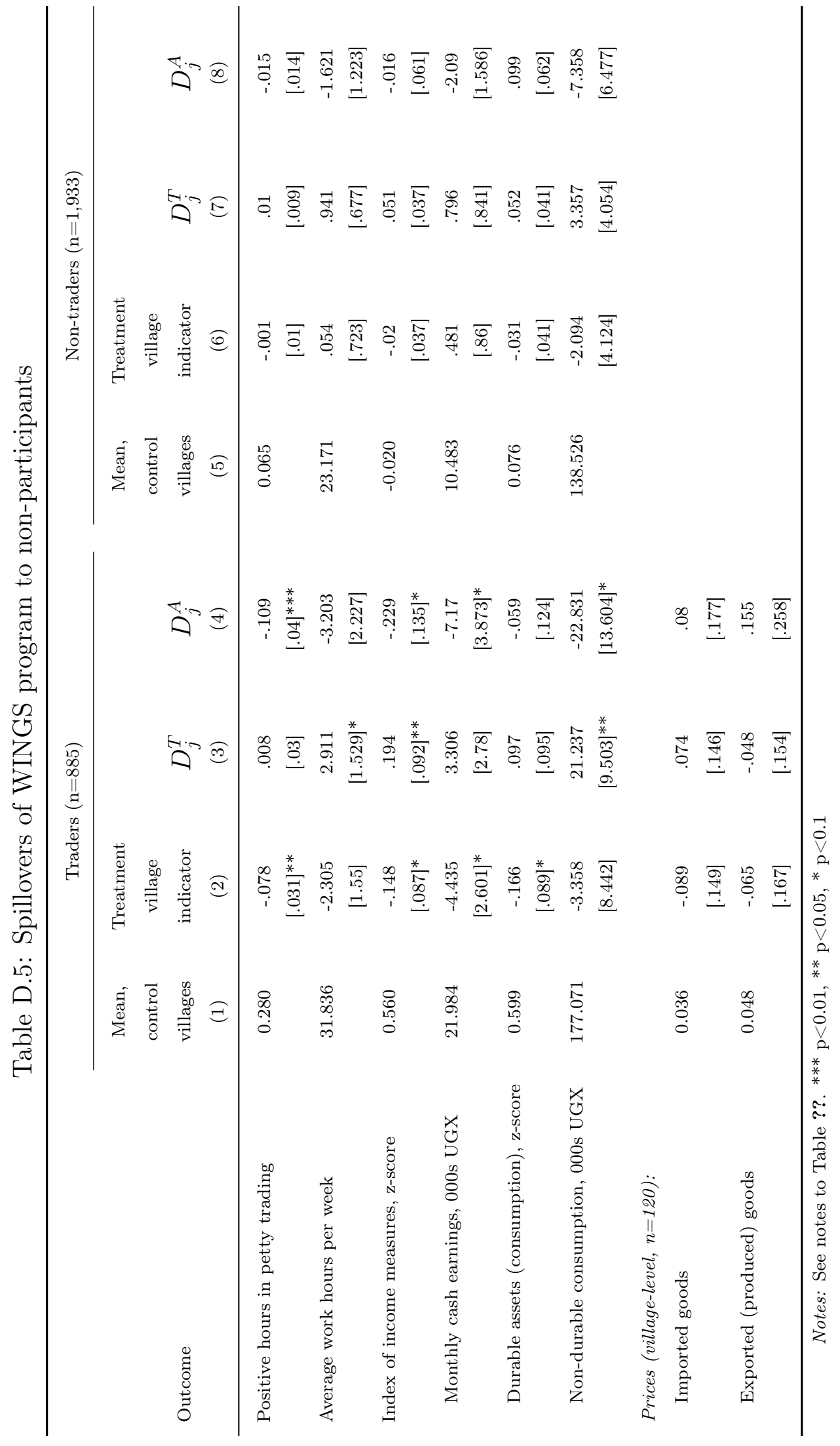


Table D.6: Impact heterogeneity from supervision by time preferences and autonomy

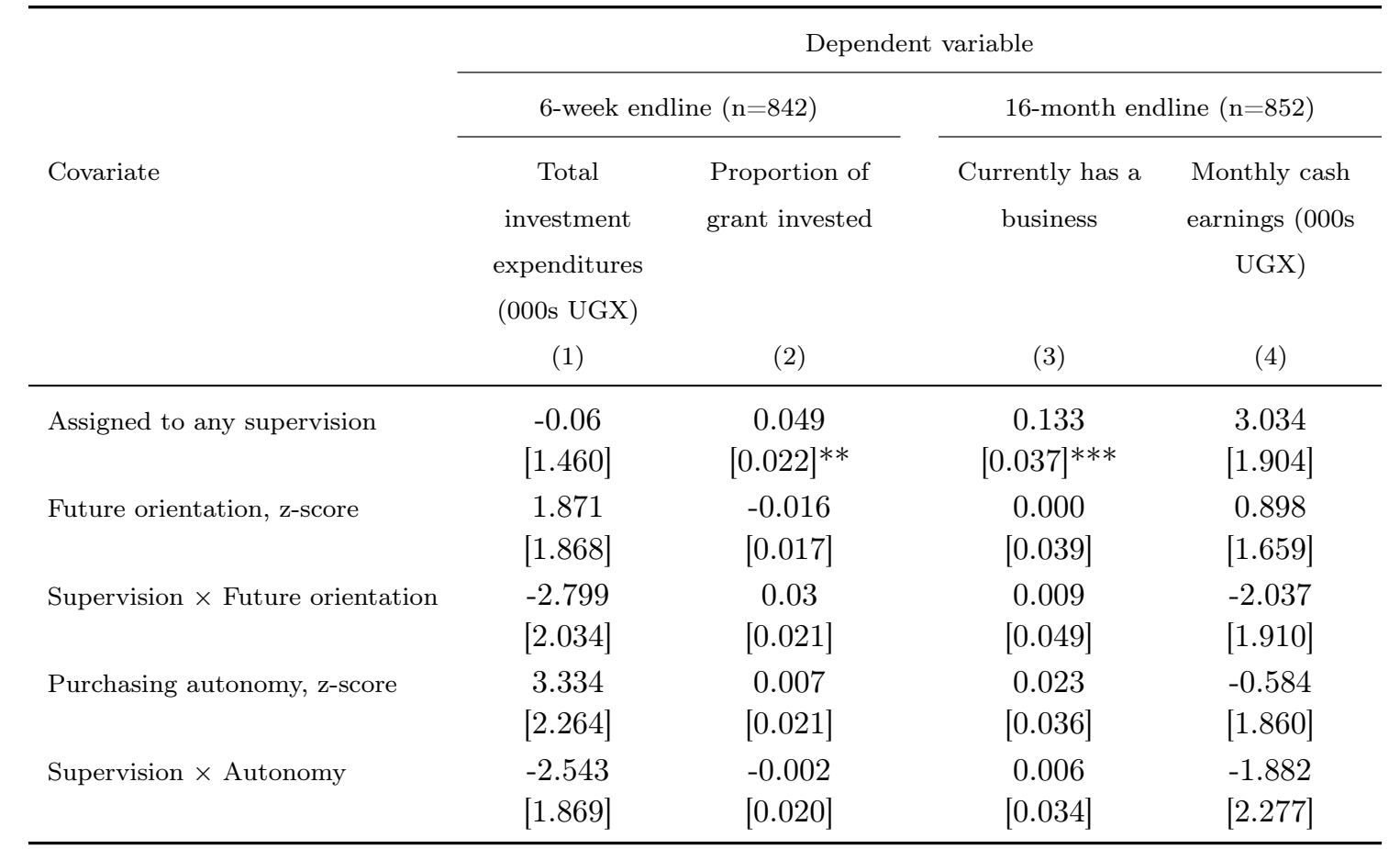

Notes: Coefficients and standard errors come from an OLS regression of each dependent variable on an indicator assignment to any follow-up treatment, an index measure of future orientation taken from baseline, and an interaction between these two indicators. Other baseline covariates and strata fixed effects were included in each regression and are omitted from this table. ${ }^{* * *} \mathrm{p}<0.01,{ }^{* *} \mathrm{p}<0.05,{ }^{*} \mathrm{p}<0.1$

\section{References}

Blattman, C., N. Fiala, and S. Martinez (2014). Generating skilled employment in developing countries: Experimental evidence from Uganda. Quarterly Journal of Economics 129(2), $697-752$.

Fafchamps, M., D. J. McKenzie, S. Quinn, and C. Woodruff (2014). When is capital enough to get female microenterprises growing? Evidence from a randomized experiment in Ghana. Journal of Development Economics 106(1), 211-226.

Kaboski, J. P. and R. M. Townsend (2011). A Structural Evaluation of a Large-Scale QuasiExperimental Microfinance Initiative. Econometrica 79(5), 1357-1406.

Miguel, E. and M. Kremer (2004). Worms: identifying impacts on education and health in the presence of treatment externalities. Econometrica 72(1), 159-217.

Udry, C. (2010). The Economics of Agriculture in Africa: Notes on a Research Program. African Journal of Agricultural and Resource Economics 5(1), 284-299. 